\title{
Axillary treatment and risk of regional recurrence in breast cancer patients
}

Citation for published version (APA):

Pepels, M. J. A. E. (2013). Axillary treatment and risk of regional recurrence in breast cancer patients.

[Doctoral Thesis, Maastricht University]. Maastricht University. https://doi.org/10.26481/dis.20130412mp

Document status and date:

Published: 01/01/2013

DOI:

10.26481/dis.20130412mp

Document Version:

Publisher's PDF, also known as Version of record

\section{Please check the document version of this publication:}

- A submitted manuscript is the version of the article upon submission and before peer-review. There can be important differences between the submitted version and the official published version of record.

People interested in the research are advised to contact the author for the final version of the publication, or visit the DOI to the publisher's website.

- The final author version and the galley proof are versions of the publication after peer review.

- The final published version features the final layout of the paper including the volume, issue and page numbers.

Link to publication

\footnotetext{
General rights rights.

- You may freely distribute the URL identifying the publication in the public portal. please follow below link for the End User Agreement:

www.umlib.nl/taverne-license

Take down policy

If you believe that this document breaches copyright please contact us at:

repository@maastrichtuniversity.nl

providing details and we will investigate your claim.
}

Copyright and moral rights for the publications made accessible in the public portal are retained by the authors and/or other copyright owners and it is a condition of accessing publications that users recognise and abide by the legal requirements associated with these

- Users may download and print one copy of any publication from the public portal for the purpose of private study or research.

- You may not further distribute the material or use it for any profit-making activity or commercial gain

If the publication is distributed under the terms of Article $25 \mathrm{fa}$ of the Dutch Copyright Act, indicated by the "Taverne" license above, 
Axillary treatment and risk of regional recurrence in breast cancer patients 
Copyright M.J.A.E. Pepels, Maastricht 2013

No part of this book may be reproduced or transmitted in any form or by any means, without prior permission in writing by the author, or when appropriate, by the publishers of the publications.

Cover design: Bas Werry

Lay-out: Tiny Wouters

Production: GVO drukkers en vormgevers B.V. | Ponsen en Looijen

ISBN: 978-90-6464-653-9

Printing of this thesis was financially supported by:

Amgen B.V., Bayer B.V., Janssen-Cilag B.V., Merck Sharp \& Dohme B.V., Novartis Pharma B.V., Roche B.V., Sanofi B.V. 


\title{
Axillary treatment and risk of regional recurrence in breast cancer patients
}

\author{
PROEFSCHRIFT
}

ter verkrijging van de graad van doctor aan de Universiteit Maastricht, op gezag van de Rector Magnificus, Prof. Dr. L.L.G. Soete

volgens het besluit van het College van Decanen, in het openbaar te verdedigen

op vrijdag 12 april 2013 om 10.00 uur

door

Maria Johanna Anna Elisabeth Pepels 


\section{Promotores}

Prof. dr. V.C.G. Tjan-Heijnen

Prof. dr. G.F. Borm (Universitair Medisch Centrum St Radboud, Nijmegen)

\section{Copromotor}

Dr. M. de Boer

\section{Beoordelingscommissie}

Prof. dr. M.F. von Meyenfeldt (voorzitter)

Dr. P.S.J.G. Hupperets

Prof. dr. H.C. Schouten 


\section{Contents}

$\begin{array}{lll}\text { Chapter } 1 & \text { Introduction and outline of the thesis } & 7\end{array}$

Chapter 2 Safety of avoiding routine use of axillary dissection in early stage breast cancer: a systematic review.

Breast Cancer Res Treat 2011;125:301-313

Chapter 3 Regional recurrence in breast cancer patients with sentinel node micrometastases and isolated tumor cells.

Ann Surg 2012;255:116-121

Chapter 4 Models predicting non-sentinel node involvement also

predict for regional recurrence in breast cancer patients without axillary treatment.

Eur J Surg Oncol 2013; in press

Chapter 5 Relevant impact of central pathology review on nodal classification in individual breast cancer patients. Ann Oncol 2012;23:2561-2566

Chapter 6 Is the sentinel lymph node pathology protocol in breast cancer patients associated with the risk of regional recurrence? Eur J Surg Oncol 2013; Epub ahead

Chapter 7 General conclusions and future perspectives

Summary

Nederlandse samenvatting

List of publications

Dankwoord 



\section{Chapter 1}

Introduction and outline of the thesis 
8 Chapter 1 


\section{Introduction and outline of the thesis}

In breast cancer patients, axillary lymph node status is still the most important prognostic factor ${ }^{1}$. Reasons to perform an axillary lymph node dissection are to stage the axilla, to improve local control ${ }^{2,3}$ and possibly overall survival ${ }^{4,5}$. In the nineties of the previous decade the sentinel node procedure was introduced in clinically nodenegative breast cancer patients to replace axillary lymph node dissection in staging the axilla ${ }^{6}$. Results of randomized studies confirmed the safety of omitting axillary lymph node dissection in patients with sentinel node-negative disease with respect to local control and overall survival ${ }^{7,8}$. Furthermore, the Axillary Lymphatic Mapping Against Nodal Axillary Clearance (ALMANAC) study showed that the sentinel node procedure was associated with less side effects such as lymph edema, pain and shoulder dysfunction as compared to axillary lymph node dissection ${ }^{9}$.

In the Netherlands, the sentinel node procedure was gradually implemented since 1996 in clinically node-negative breast cancer patients. In 2003 still 42\% of women with clinically negative axillary nodes were treated with axillary lymph node dissection. In 2006, 10 years after the introduction of the sentinel node biopsy, this number was reduced to $22 \%{ }^{10}$.

The sentinel node procedure is based on the premise that if the first node the breast tissue drains into contains no tumor cells, the remaining axillary lymph nodes are likely not involved, with no need for removal ${ }^{11}$. To identify sentinel nodes radioactive colloid is injected preoperatively into the breast around the tumor or around the nipple, generally followed by blue dye injection around the tumor before incision. Lymph nodes that are radioactive, blue, and/or clinically suspect are judged to be sentinel nodes, and subsequently removed. Sentinel nodes are postoperatively assessed by the pathologists using a step sectioning procedure, with routine haematoxylin-eosin stained sections at a maximum of about $2 \mathrm{~mm}$ intervals through the lymph node. Immunohistochemistry is in addition performed in cases to definitively diagnose an area that is suspicious for, but not diagnostic of, lymph node metastases on haematoxylin and eosin stains ${ }^{11}$. In the Netherlands, immunohistochemistry is always performed in case of negative haematoxyline-eosin stains.

Internationally, there has been no consensus regarding the optimal pathology protocol to assess the sentinel nodes. When more slices of the sentinel node are made, higher rates of positive sentinel nodes are found. To prevent under staging, pathologists intensified the nodal examination by using step sectioning and immunohistochemistry, resulting in a higher detection rate of small metastases ${ }^{12}$. However, the relevance of these small nodal metastases was unclear. For that reason the TNM classification was changed in 2002. Before 2002, metastases smaller than 
$2 \mathrm{~mm}$ were defined as micrometastases (pN1a). Since 2002, isolated tumor cells (pNo(i+), deposits $\leq 0.2 \mathrm{~mm}$ ), and micrometastases (pN1mi, deposits $>0.2-\leq 2.0 \mathrm{~mm}$ ) were defined as separate categories in the sixth American Joint Committee on Cancer (AJCC) Cancer Staging Manual ${ }^{13}$. Previously, our research group showed that introduction of the sentinel node procedure led to the detection of more positive lymph nodes because of the intensified workup of sentinel nodes by pathologists ${ }^{14}$. However, stage migration did not occur when tumor deposits of $0.2 \mathrm{~mm}$ or less were categorized as lymph node-negative disease, according to the 2002 TNM classification.

Until recent years, axillary lymph node dissection was always performed in patients with sentinel node isolated tumor cells or micrometastases ${ }^{15}$. Gradually, the attitude towards use of completion axillary lymph node dissection in patients with only a small risk of non-sentinel node involvement, e.g. those with small primary tumors and sentinel node isolated tumor cells or micrometastases, has changed. A survey among American Society of Oncology members revealed that in the USA axillary lymph node dissection for sentinel node micrometastases was routinely recommended by only $23 \%$ of surgeons, $23 \%$ of medical oncologists and $15 \%$ of radiation oncologists ${ }^{16}$. Radiation oncologists were more likely than medical oncologists or surgeons to consider axillary radiation instead of axillary lymph node dissection for sentinel node micrometastases.

Omission of axillary lymph node dissection increases the risk of a regional recurrence. In single centre and multi centre series, regional recurrence rates in sentinel node positive patients without axillary treatment seemed not worse as compared to results in sentinel node-negative patients not receiving additional axillary treatment ${ }^{17}$. However, these low recurrence rates in sentinel node positive patients may partly be explained by underreporting to cancer registries ${ }^{18}$, patient selection ${ }^{19}$, the classification of isolated tumor cells as "micrometastases"18,20-23, and use of axillary irradiation $^{24}$. Of note, the Memorial Sloan-Kettering Cancer Center (MSKCC) reported that in patients identified with a positive sentinel node by hematoxylin and eosin examination who did not undergo completion axillary lymph node dissection, the axillary recurrence rate was $5 \%$ at a median follow-up of only 23 months, even though these were highly selected patients ${ }^{19}$.

This thesis addresses several major topics with regard to the sentinel node procedure, based on the data of two studies, the MIRROR and the VAZ-01122 studies. First, whether patients can be identified that do not need completion axillary lymph node dissection in the presence of minimal sentinel node involvement. Secondly, whether models predicting non-sentinel node involvement can also be used to select patients for axillary lymph node dissection. Thirdly, the influence of the pathology protocol on decision making and quality of delivered axillary treatment. 
The MIRROR study, acronym for "Micrometastases or Isolated tumor cells, Relevant and Robust Or Rubbish?", was initially designed to assess the relationship between isolated tumor cells or micrometastases in regional lymph nodes and clinical outcome in patients who had undergone a sentinel node procedure and who did or did not receive systemic adjuvant therapy ${ }^{25}$. All Dutch hospitals and pathology laboratories participated. In the MIRROR study, patients with early-stage breast cancer who underwent a sentinel node biopsy between 1997 and 2006 were included, provided they had favorable primary tumor characteristics according to the Dutch guidelines version 2002, i.e., tumor size of $1 \mathrm{~cm}$ or smaller, irrespective of grade, or tumor size 1-3 cm and grade 1 or 2 . Of these, patients with isolated tumor cells or micrometastases as final nodal status after sentinel node biopsy and optionally additional axillary treatment were included. Further, a control group of patients with node-negative disease who underwent a sentinel node procedure in the year 2000 or 2001 was randomly selected. Nodal status was assessed after central pathology review and restaged according to the 6th AJCC classification. The MIRROR study demonstrated that sentinel node isolated tumor cells and micrometastases were associated with reduced 5-year disease-free survival compared with pN0 in patients not receiving adjuvant systemic therapy, and that prognosis was improved in patients who received adjuvant systemic therapy ${ }^{25}$.

The VAZ-01122 study was a regional study in the Eastern part of the Netherlands including 4 hospitals ${ }^{26}$. In this multi-institutional study, breast cancer patients who underwent a sentinel node biopsy were prospectively included $(n=556)$. Patients with a clinical tumor size of $5 \mathrm{~cm}$ or less were candidates for a sentinel node procedure provided there were no clinical signs of multifocality or axillary lymph nodes metastasis. Only patients who had detectable sentinel nodes were included in this study. Patients who had received prior radiotherapy to the breast or axilla or who had received neoadjuvant systemic therapy were not eligible. The primary aim of the study was to assess the risk of non-sentinel node involvement. It was shown that patients with small sentinel node metastases had a lower risk of non-sentinel node involvement than those with larger sentinel node metastases: $14 \%$ non-sentinel node involvement with sentinel node isolated tumor cells, $28 \%$ with sentinel node micrometastases and $38 \%$ with sentinel node macrometastases. Apart from sentinel node metastasize size, also primary tumor size and presence of vessel invasion were related to the risk of non-sentinel node involvement ${ }^{26}$.

In Chapter 2, we systematically describe the results of all published studies on axillary recurrence rates in patients with clinically node-negative breast cancer, who did or did not undergo axillary lymph node dissection ${ }^{17}$. Papers were eligible if published between January 1985 and September 2009. Pubmed and Cochrane library were searched for, leading to the inclusion of 68 studies. Primary endpoint was the pooled axillary recurrence rate of each category. 
Axillary dissection was until recently recommended to all patients with tumor-positive sentinel nodes. But, in recent studies regional recurrence rates seemed low if dissection was omitted ${ }^{18-24}$. In Chapter 3 we investigated, therefore, the impact of axillary treatment (axillary lymph node dissection or irradiation) on regional recurrence rate in Dutch breast cancer patients with invasive cancer and favorable primary tumor characteristics, and isolated tumor cells or micrometastases in the sentinel node. Patients were identified from the MIRROR database. In total 857 patients with node-negative disease, 795 patients with isolated tumor cells and 1028 patients with micrometastases in the sentinel node were included. The primary endpoint was 5-year regional recurrence rate. To investigate differences in recurrence rates between patients with and without axillary treatment, a proportional hazard regression was carried out correcting for potential confounders ${ }^{27}$.

In Chapter $\mathbf{4}$ we describe the association between predicted risk of non-sentinel node involvement by four models and the actual observed regional recurrence rate in patients with favorable early breast cancer and sentinel node isolated tumor cells or micrometastases who did not undergo axillary lymph node dissection who were included in the MIRROR study ${ }^{28}$.

In the MIRROR study, nodal status was assessed after central pathology review and restaged according to the 6th AJCC Cancer Staging Manual. In Chapter 5 we assessed the impact of pathology review on nodal status $(n=2842)$, and the impact of pathology review on 5-year disease free survival related to nodal status for those who did not receive adjuvant systemic therapy $(n=1712)^{29}$.

Next, data of patients included in the VAZ-01122 study were used to assess whether part of the advantages associated with the introduction of sentinel node biopsy in breast cancer patients might be lost due to an intensified pathology protocol with increased detection of isolated tumor cells and micro-metastases. Of relevance, internationally, there is no consensus on the pathology protocol to be used to examine the sentinel node. At present, therefore, various hospitals use different sentinel node pathology protocols, leading to different sentinel node findings and subsequent surgical treatment strategies ${ }^{30}$. In Chapter 6 we focus on the follow-up data of the patients who had a negative sentinel node, and did not undergo an additional axillary lymph node dissection. The question was, whether ultra-staging and thus more patients undergoing an additional axillary lymph node dissection, was effective in reducing the risk of relapse. In all cases a follow-up period of at least 5 years was guaranteed. Primary endpoint was 5 -year regional recurrence rate ${ }^{31}$.

In Chapter 7, the most important findings are summarized and discussed within the context of recent literature. Limitations of the thesis are mentioned, and recommendations for future research are given. 


\section{References}

1. Fisher $\mathrm{B}, \mathrm{Bauer} \mathrm{M}$, Wickerham $\mathrm{DL}$, et al. Relation of number of positive axillary nodes to the prognosis of patients with primary breast cancer. An NSABP update. Cancer 1983;52:1551-1557.

2. Fisher B, Wolmark N, Bauer M, Redmond C, Gebhardt M. The accuracy of clinical nodal staging and of limited axillary dissection as a determinant of histologic nodal status in carcinoma of the breast. Surg Gynecol Obstet 1981;152:765-772.

3. Graversen HP, Blichert-Toft M, Andersen JA, Zedeler K. Breast cancer: risk of axillary recurrence in node-negative patients following partial dissection of the axilla. Eur J Surg Oncol 1988;14:407-412.

4. Fisher B, Jeong JH, Anderson S, Bryant J, Fisher ER, Wolmark N. Twenty-five-year follow-up of a randomized trial comparing radical mastectomy, total mastectomy, and total mastectomy followed by irradiation. N Engl J Med 2002;347:567-575.

5. Orr RK. The impact of prophylactic axillary node dissection on breast cancer survival-a Bayesian meta-analysis. Ann Surg Oncol 1999;6:109-116.

6. Giuliano AE, Kirgan DM, Guenther JM, Morton DL. Lymphatic mapping and sentinel lymphadenectomy for breast cancer. Ann Surg 1994;220:391-398.

7. Giuliano AE, Chung AP. Long-term follow-up confirms the oncologic safety of sentinel node biopsy without axillary dissection in node-negative breast cancer patients. Ann Surg 2010;251:601-603.

8. Veronesi U, Viale G, Paganelli G, et al. Sentinel lymph node biopsy in breast cancer: ten-year results of a randomized controlled study. Ann Surg 2010;251:595-600.

9. Mansel RE, Fallowfield L, Kissin M, et al. Randomized multicenter trial of sentinel node biopsy versus standard axillary treatment in operable breast cancer: the ALMANAC Trial. J Natl Cancer Inst. 98:599609. Erratum in: J Natl Cancer Inst. 2006;98:876.

10. van Steenbergen LN, van de Poll-Franse LV, Wouters MW, Jansen-Landheer ML, Coebergh JW, Struikmans H, Tjan-Heijnen VC, van de Velde CJ.Variation in management of early breast cancer in the Netherlands, 2003-2006. Eur J Surg Oncol. 2010;36 Suppl 1:S36-43.

11. Lyman $G H$, Giuliano $A E$, Somerfield $M R$ et al. American Society of Clinical Oncology guideline recommendations for sentinel lymph node biopsy in early-stage breast cancer. J Clin Oncol 2005;23:7703-7720.

12. Cserni G, Amendoeira I, Apostolikas $\mathrm{N}$ et al. Pathological work-up of sentinel lymph nodes in breast cancer. Review of current data to be considered for the formulation of guidelines. Eur J Cancer 2003;39:1654-1667.

13. Green FL, Page DL, Fleming ID. American Joint Committee on Cancer Staging Manual. 6th ed. Philadelphia: Springer; 2002.

14. Bolster MJ, Bult P, Wauters CA, Strobbe L, Peer PG, Wobbes T, Tjan-Heijnen VC. More tumor-affected lymph nodes because of the sentinel lymph node procedure but no stage migration, because the 2002 TNM classifies small tumor deposits as pathologic NO breast cancer. Cancer. 2009;115:5589-5595.

15. Lyman $\mathrm{GH}$, Giuliano $A E$, Somerfield $M R$, et al. American Society of Clinical Oncology guideline recommendations for sentinel lymph node biopsy in early-stage breast cancer. J Clin Oncol . 2005;23:7703-7720.

16. Wasif $\mathrm{N}, \mathrm{Ye} X$, Giuliano AE. Survey of ASCO members on management of sentinel node micrometastases in breast cancer: variation in treatment recommendations according to specialty. Ann Surg Oncol.2009;16:2442-2449.

17. Pepels MJ, Vestjens JH, de Boer M, Smidt M, van Diest PJ, Borm GF, Tjan-Heijnen VC. Safety of avoiding routine use of axillary dissection in early stage breast cancer: a systematic review. Breast Cancer Res Treat 2011;125:301-313.

18. Bilimoria KY, Bentrem DJ, Hansen NM, et al. Comparison of sentinel lymph node biopsy alone and completion axillary lymph node dissection for node-positive breast cancer. J Clin Oncol 2009;27:29462953

19. Park J, Fey JV, Naik AM, et al. A declining rate of completion axillary dissection in sentinel lymph nodepositive breast cancer patients is associated with the use of a multivariate nomogram. Ann Surg 2007;245:462-468

20. Bulte CS, van der Heiden-van der Loo M, Hennipman A. Axillary recurrence rate after tumour negative and micrometastatic positive sentinel node procedures in breast cancer patients, a population based multicenter study. Eur J Surg Oncol 2009;35:25-31. 
21. Jeruss JS, Winchester DJ, Sener SF, et al. Axillary recurrence after sentinel node biopsy. Ann Surg Oncol 2005;12:34-40.

22. Fant JS, Grant MD, Knox SM, et al. Preliminary outcome analysis in patients with breast cancer and a positive sentinel lymph node who declined axillary dissection. Ann Surg Oncol 2003;10:126-130.

23. Guenther JM, Hansen NM, DiFronzo LA, et al. Axillary dissection is not required for all patients with breast cancer and positive sentinel nodes. Arch Surg 2003;138:52-56.

24. Hwang RF, Gonzalez-Angulo AM, Yi M, et al. Low locoregional failure rates in selected breast cancer patients with tumor-positive sentinel lymph nodes who do not undergo completion axillary dissection. Cancer 2007;110:723-730.

25. de Boer M, van Deurzen CH, van Dijck JA, Borm GF, van Diest PJ, Adang EM, Nortier JW, Rutgers EJ, Seynaeve C, Menke-Pluymers MB, Bult P, Tjan-Heijnen VC. Micrometastases or isolated tumor cells and the outcome of breast cancer. N Engl J Med 2009;13;361:653-63.

26. Bolster MJ, Peer PG, Bult P, Thunnissen FB, Schapers RF, Meijer JW, Strobbe LJ, van Berlo CL, Klinkenbijl JH, Beex LV, Wobbes T, Tjan-Heijnen VC. Risk factors for non-sentinel lymph node metastases in patients with breast cancer. The outcome of a multi-institutional study. Ann Surg Oncol 2007;14:181-189

27. Pepels MJ, de Boer M, Bult P, van Dijck JA, van Deurzen $\mathrm{CH}$, Menke-Pluymers MB, van Diest PJ, Borm GF, Tjan-Heijnen VC.Regional recurrence in breast cancer patients with sentinel node micrometastases and isolated tumor cells. Ann Surg 2012;255:116-121.

28. Pepels MJ, Vestjens JH, de Boer M, Bult P, van Dijck JA, Menke-Pluijmers M, van Diest PJ, Borm G, Tjan-Heijnen VC. Submitted. Presented in part at San Antonio Breast Cancer Congress December 2011. Models predicting non-sentinel node involvement also predict for regional recurrence in breast cancer patients without axillary treatment. Presented in part at San Antonio Breast Cancer Congress December 2011. Abstract PD02-07.

29. Vestjens JH, Pepels MJ, de Boer M, Borm GF, van Deurzen CH, van Diest PJ, van Dijck JA, Adang EM, Nortier JW, Rutgers EJ, Seynaeve C, Menke-Pluymers MB, Bult P, Tjan-Heijnen VC. Relevant impact of central pathology review on nodal classification in individual breast cancer patients. Ann Oncol. 2012 Apr 11. [Epub ahead of print].

30. Bolster MJ, Bult P, Schapers RF, Meijer JW, Strobbe LJ, van Berlo CL, Klinkenbij JH, Peer PG, Wobbes T, Tjan-Heijnen VC. Differences in sentinel lymph node pathology protocols lead to differences in surgical strategy in breast cancer patients. Ann Surg Oncol 2006;13:1466-1473.

31. Bolster MJ, Pepels MJ, Wauters CA, Schapers RF, Meijer JW, Strobbe LJ, van Berlo CL, Klinkenbijl JH, Wobbes $T$, Voogd AC, Bult P, Tjan-Heijnen VCG. Regional recurrence rate in sentinel lymph nodenegative breast cancer patients is associated with sentinel lymph node pathology protocol. Submitted. 


\section{Chapter 2}

\section{Safety of avoiding routine use of axillary dissection in early stage breast cancer:}

a systematic review

M.J.A.E. Pepels,·J.H.M.J. Vestjens,·M. de Boer,·M. Smidt, P.J. van Diest,.G.F. Borm,

V.C.G. Tjan-Heijnen

Breast Cancer Res Treat 2011;125:301-313 


\section{Abstract}

Physicians are moving away from routine axillary lymph node dissection in clinically node-negative breast cancer. We conducted a systemic review on the safety of this policy. Pubmed and Cochrane library were searched for. Sixty-eight studies were included: studies of clinically node-negative patients in the pre-sentinel lymph node era; observational studies of sentinel lymph node-negative patients, without axillary lymph node dissection; comparative studies of sentinel lymph node-negative patients, with a non-axillary lymph node dissection and an axillary lymph node dissection group; sentinel lymph node-positive studies, of patients without axillary lymph node dissection. Primary endpoint was the pooled axillary recurrence rate of each category; secondary endpoint was overall survival rate. In pre-sentinel lymph node studies, with larger tumors and less systemic therapy, axillary recurrence rate without axillary lymph node dissection after 5-10 years follow-up was $12-18 \%$, with $5 \%$ reduced overall survival. In the observational sentinel lymph node-negative studies, with median follow-up of 36 months, the pooled axillary recurrence rate was $0.6 \%(95 \% \mathrm{Cl}$ 0.6-0.8). In the comparative sentinel lymph node-negative studies, pooled axillary recurrence rate was $0.4 \%(95 \% \mathrm{Cl} 0.2-0.6)$ without axillary lymph node dissection versus $0.3 \%(95 \% \mathrm{Cl} 0.1-0.6)$ with axillary lymph node dissection at 31 and 47 months, respectively, and no survival disadvantage. In sentinel lymph node-positive studies, axillary recurrence rate was up to $1.7 \%(95 \% \mathrm{Cl} 1.0-2.7)$ at 30 months. For patients with an haematoxylin and eosin positive sentinel lymph node the axillary recurrence rate without axillary lymph node dissection was $5 \%$ after 23 months, which may imply rates as high as 13 and $18 \%$ after 5 and 8 years. In conclusion, this systematic review confirms the safety of omitting axillary lymph node dissection in sentinel lymph nodenegative patients. There is a potential role for avoiding axillary lymph node dissection in selected sentinel lymph node-positive patients, but eligibility criteria and the role of systemic therapy need further to be elucidated. 


\section{Introduction}

Axillary lymph node dissection has long been considered the golden standard in the work-up of early stage breast cancer patients. It offered as such the best opportunity for staging and prognostication to select patients requiring additional treatment. Whether axillary lymph node dissection also offers a therapeutic advantage is questioned $^{1}$.

Nowadays, approximately $60-70 \%$ of breast cancer patients have node-negative disease, due to an earlier diagnosis of breast cancer ${ }^{2}$. Obviously, if the axillary lymph nodes are truly negative, there can be no possible benefit from performing an axillary lymph node dissection. In the late 1990s, the sentinel lymph node procedure was introduced $^{3,4}$. The intrinsic hypothesis is that sentinel lymph node biopsy will identify patients with a negative axilla on pathology. The false negative rate of the sentinel lymph node procedure is on average $8.4 \%$, ranging from 0 to $29 \%{ }^{5}$. Based on the low false-negative rate, the sentinel lymph node procedure was rapidly implemented in routine daily practice, even before the first randomized trial on the safety of the sentinel lymph node procedure was finalized ${ }^{6,7}$.

In the Netherlands at least $70 \%$ of breast cancer patients undergo a sentinel lymph node procedure. Of these patients, in $65 \%$ a sentinel lymph node only is carried out, implying, that in daily practice in nearly $50 \%$ of newly diagnosed breast cancer patients axillary lymph node dissection is avoided ${ }^{7}$. (Completion) axillary lymph node dissection is still the standard of care for patients with axillary metastases being identified by sentinel lymph node biopsy, including micrometastases ${ }^{5}$.

To this end, many series have reported on axillary recurrence rates. A few randomized trials evaluated the safety of the sentinel lymph node procedure. Recently, attention was drawn to the fact that there is a trend towards omitting axillary lymph node dissection in patients with micrometastatic involvement of the sentinel lymph node, in contrast to the ASCO recommendations and despite lack of data on the safety of this strategy 8 .

The aim of our study was to provide a systematic review on the safety of withholding axillary lymph node dissection to clinically node negative breast cancer patients. For this purpose, we reviewed axillary recurrence rates in the pre-sentinel lymph node era of patients who did or did not undergo an axillary lymph node dissection, and we reviewed axillary recurrence rates of patients with a negative or positive sentinel lymph node in observational series and randomized trials that did or did not undergo a completion axillary lymph node dissection. As secondary endpoint we reviewed survival rates in relation to axillary surgery type. 


\section{Methods}

\section{Literature search strategy}

We performed a systematic review of the literature. Pubmed and the Cochrane Library were searched for (1st of January 1985 through 30th September 2009) with the use of the Medical Subject Heading terms "breast neoplasm", "sentinel node", "axillary lymph node dissection", "recurrence", and "survival". We only included studies which were published in English language. Studies were included irrespective of number of patients included, except for case reports.

\section{Study inclusion criteria}

The following criteria were applied to the papers that were identified by the literature search. Studies were included when they studied axillary lymph node dissection and/or axillary staging by the sentinel lymph node procedure if follow-up information was provided. Endpoints had to be available in terms of axillary recurrence rate and/or overall survival rates. Studies that reported on detection methods using molecular biology approaches like reverse transcriptase polymerase chain reaction, and studies in which neoadjuvant chemotherapy was administered were excluded. If duplicate or updated studies were identified, only the most recent study was included. Only full papers published in peer-reviewed journals and based on original data were included. Retrospective large database studies analyzing overall survival were only included if more than 1,000 patients were included. To prevent overlap of data from studies that described subpopulations besides a total population, only the total population was taken into account, and the most recent paper. For cohort studies and series based on overlapping selections, only the largest study was taken into account.

\section{Data extraction}

Two independent investigators (MP and JV) extracted data to rule out potential bias or errors. Discrepancies were resolved by consensus, if necessary through arbitrage by a third investigator (VTH). The following data were extracted from the included papers: number of patients studied, tumor size or stage, follow-up time, falsenegative rate, axillary recurrence rate, overall survival, type of surgery, number of nodes excised, use of adjuvant systemic therapy, and use of axillary radiotherapy. Complete data were not always obtainable for every characteristic evaluated in each study. For some studies the range for time of follow-up had to be estimated based on date of inclusion versus date of analysis and/or date of manuscript submission. If not provided in the text or tables in the original paper, data with respect to axillary recurrence rates were extracted from the recurrence-free survival curves. In some 
series, patients with in situ carcinoma were included; these patients were omitted in our tables, with recalculation of the axillary recurrence rate for invasive cancers only.

\section{Definitions}

The false-negative rate was obtained by dividing the number of patients who were sentinel lymph node-negative but non-sentinel lymph node positive by the number of patients who had a positive sentinel lymph node or a positive non-sentinel lymph node. This shows the reliability of the sentinel lymph node procedure, i.e., the sensitivity of the sentinel lymph node procedure is 1 minus the false-negative rate. This is essentially different from the percentage of patients with a negative sentinel lymph node, having a positive non- sentinel lymph node (1 minus negative predictive value). This percentage was collected or calculated and shown in the table regarding the validation and randomized studies. If a different definition was used in a paper, or if in situ carcinoma was included in the denominator, the rate was recalculated. Of note, if in a study axillary recurrence was reported as either isolated or in combination with local or distant relapse, the total number of axillary recurrences was counted. In most papers median (or mean) tumor size and T-stage were only described for the total population, both with a negative sentinel lymph node and positive sentinel lymph node. This overall number was then used in the tables.

\section{Statistical analyses}

Most studies were very small and only reported summary statistics for the exposure and the recurrence, such as median exposure time and number of recurrences. As no estimates of efficacy were reported, for example a 5 or 10 years recurrence rate, a routine meta-analysis was impossible. Hence, we used a more informal approach and calculated the overall recurrence by dividing the total number of recurrences by the total number of patients in all studies. In addition, we estimated the median exposure by the weighted median of the median exposure times in the studies, with study size as weight.

For the single group studies, we were able to calculate Kaplan-Meier estimates of the pooled 5 and 8 years axillary recurrence rates. As we did not have the individual patient data, we had to estimate the follow-up duration for each patient. For patients who did not have a recurrence, we used three different scenarios. Middle scenario: almost all studies reported minimal, median and maximal duration of follow-up. In this scenario, we assumed that the follow-up durations were uniformly distributed, with half of the durations between the minimum and median follow-up and half of the durations between the median and maximum follow-up. For three studies ${ }^{9-11}$, no minimal follow-up was reported, and we assumed it to be 0 . When no maximal followup was reported (one study) ${ }^{12}$, we assumed it to be twice the upper quartile. Worst case scenario: we assumed that $40 \%$ of the follow-up durations were equal to the minimum follow-up. The others were uniformly distributed, as in the middle scenario. 
In the worst case scenario, the follow-up duration is low, so the estimate of the recurrence rate will be high. Best case scenario: we assumed that $40 \%$ of the exposures were equal to the maximum follow-up duration. The others were uniformly distributed, as in the middle scenario.

In most studies, for patients that had a recurrence, the time of the recurrence was reported, so no assumptions about the follow-up duration were required. For the four studies, that only reported median, minimal and maximal duration till recurrence, we followed a similar approach as described above, using a middle, a worst and a best case scenario. For two studies with one event, the duration till recurrence was not reported and we set it to the median follow-up ${ }^{13}$.

The worst and best case scenarios are extremely conservative, because they assume worst and best case scenarios in every individual study. In practice, different studies probably had different follow-up patterns that more or less cancelled each other out. We therefore think that the middle scenario is the most realistic.

In addition to the approach above we investigated the results when the exposure data were not uniformly distributed, but followed a Weibull distribution.

Further, we calculated pooled survival rates for the three randomized sentinel lymph node studies. For the large database pre-sentinel lymph node studies we were not able to calculate pooled survival rates, because of large heterogeneity between studies.

All reported $\mathrm{P}$ values are two-sided, and confidence intervals $(\mathrm{Cl})$ are at $95 \%$ level. All analyses were performed in SAS (version 8.2).

\section{Results}

This search strategy resulted in 61 abstracts. The reference lists of selected papers were searched for additional papers, leading to the identification of in total 68 eligible studies which included follow-up of different axillary treatment strategies.

We decided to categorize the included studies according to type of axillary surgical approach. In this way, we aimed to show more clearly the differences and similarities between studies on the issue of axillary recurrence rate and overall survival. The first category consisted of studies of patients with clinically node-negative disease who did or did not undergo a conventional axillary lymph node dissection, in the pre-sentinel lymph node era, with a long-term follow-up. The second category consisted of observational studies of patients who had a negative sentinel lymph node and who did not undergo a completion axillary lymph node dissection. The third category consisted of comparative studies with a non-axillary lymph node dissection and an axillary lymph node dissection group. All Patients had a negative sentinel lymph node: the patients in the sentinel lymph node learning phase underwent a sentinel lymph node and axillary lymph node dissection, whereas the more recent patients did not undergo a completion axillary lymph node dissection anymore (i.e., validation and application phase studies). We also included randomized studies assessing the safety 
of the sentinel lymph node procedure in this category. The fourth category included observational studies that reported follow-up data on patients with a positive sentinel lymph node who did not undergo a completion axillary lymph node dissection. The last category concerned studies that reported on at least 5-years follow-up data on survival rates in either pre-sentinel lymph node or sentinel lymph node era.

Axillary recurrence rates with versus without conventional axillary lymph node dissection:

pre-sentinel lymph node studies

In order to evaluate the role of axillary lymph node dissection in patients with clinically node-negative disease in the pre-sentinel lymph node era, we included three randomized trials comparing axillary lymph node dissection versus no-axillary treatment $^{14,15}$ (Table 2.1).

In the NSABP B-04 trial, after a follow-up of 10 years the axillary recurrence rate was $18.4 \%$ in the total mastectomy group as compared to $1.4 \%$ in the radical mastectomy group, including axillary lymph node dissection, even though it was noted that a small number of lymph nodes was excised in one-third of the patients in the "no-axillary treatment $\mathrm{arm}^{\prime \prime}{ }^{15}$. Site of recurrence was only reported for the first event, which may have resulted in an underreported axillary recurrence rate.

Axillary lymph node dissection was compared to axillary radiotherapy in five randomized studies ${ }^{14,16-18}$. In two of these, the Guy I and Guy II trials, the radiotherapy dosage in the no-axillary lymph node dissection arms was considered inadequate to modern standards for axillary radiotherapy ${ }^{14}$, and for that reason these two latter studies were considered of interest for our systematic review. The axillary recurrence rates were 18.8 and $12.5 \%$ without axillary lymph node dissection compared to 0.9 and $1.4 \%$ with axillary lymph node dissection, in the Guy I and Guy II trials, respectively, after 5-10 years of follow-up, in agreement with findings in the B-04 trial. The difference in outcome between the Guy I and Guy II trial could be explained by the fact that there were significantly more patients with T1 tumors in the Guy II trial.

Table 2.1 Axillary recurrence rates with versus without axillary lymph node dissection (ALND) in patients with clinically node-negative breast cancer.

\begin{tabular}{lcccccc}
\hline Study & $\begin{array}{c}\text { No. } \\
\text { Patients }\end{array}$ & $\begin{array}{c}\text { pT1 } \\
\%\end{array}$ & $\begin{array}{c}\text { Node positive with } \\
\text { ALND } \\
\%\end{array}$ & $\begin{array}{c}\text { Follow-up, } \\
\text { months }\end{array}$ & $\begin{array}{c}\text { Axillary recurrence } \\
\text { with ALND } \\
\%\end{array}$ & $\begin{array}{c}\text { Axillary recurrence } \\
\text { no ALND } \\
\%\end{array}$ \\
\hline Guy I $^{14}$ & 232 & 17 & 24 & $60-120$ & 0.9 & 18.8 \\
Guy II $^{14}$ & 258 & 38 & - & $60-120$ & 1.4 & 12.5 \\
NSABP-B04 $^{15}$ & 727 & - & 39 & 120 & 1.4 & 18.4 \\
\hline
\end{tabular}


Axillary recurrence rates for a negative sentinel lymph node, without axillary lymph node dissection:

observational studies

Of 50 observational sentinel lymph node studies $^{9-13,19-63}$, information on axillary recurrence rates was available of patients who had a negative sentinel lymph node and who had not undergone a completion axillary lymph node dissection (Table 2.2; Figure 2.1). There was a large difference in tumor size and administered systemic therapy between studies.

Overall, follow-up of more than 26,000 patients was reported. The median and maximum follow-up duration of all studies pooled was 36 and 144 months, respectively. With a median follow-up duration of 36 months, the axillary recurrence rate was $0.6 \%$ (95\% $\mathrm{Cl} 0.6-0.8)$.

Figure 2.1 shows the Kaplan-Meier curves for the middle, best and worst case scenarios. According to the middle scenario, the 5- and 8-years axillary recurrence rates were $1 \%(95 \% \mathrm{Cl} 0.8-1.1)$ and $1.4 \%(95 \% \mathrm{Cl} 1.1-1.6)$, respectively. In the worst case scenario, the recurrence rates were approximately $0.1 \%$ worse.

Axillary recurrence rates for a negative sentinel lymph node, with and without axillary lymph node dissection:

comparative studies

The third category consisted of studies in which patients with a negative sentinel lymph node were randomized between a completion axillary lymph node dissection or not, and of studies in which patients with a negative sentinel lymph node in the learning/validation phase routinely underwent a completion axillary lymph node dissection, whereas the next patients with a negative sentinel lymph node did not undergo a completion axillary lymph node dissection anymore (sentinel lymph node application phase) (Table 2.3). 
Table 2.2 Axillary recurrence after sentinel (SN)-only in SN-negative breast cancer patients in relation to tumor size and type of AST: Single group studies.

\begin{tabular}{|c|c|c|c|c|c|c|}
\hline Source & $\begin{array}{c}\text { No. } \\
\text { patients }\end{array}$ & $\begin{array}{l}\% \text { T1 or } \\
\text { median T } \\
\text { (range) }\end{array}$ & $\begin{array}{l}\text { \% Chemo- } \\
\text { therapy / } \\
\text { hormonal } \\
\text { therapy }\end{array}$ & $\begin{array}{l}\text { Follow-up, } \\
\text { months } \\
\text { median } \\
\text { (range) }\end{array}$ & $\begin{array}{l}\text { Timing of } \\
\text { recurrence, } \\
\text { months } \\
\text { (range) }\end{array}$ & $\begin{array}{c}\text { Axillary } \\
\text { recurrence } \\
\%\end{array}$ \\
\hline 2009 Canavese $(R)^{10}$ & 77 & $87 \%^{a}$ & NR & $68(+/-17)$ & - & 0 \\
\hline 2009 Veronesi $^{11}$ & 3548 & $84 \%$ & 19 / 81 & $48(-132)$ & 29 (range $2-86$ ) & 0.9 \\
\hline 2009 Kiluk $^{19}$ & 1530 & $14 \mathrm{~mm}$ & $26 / 53$ & $60(0-144)$ & $23,46,102,110$ & 0.3 \\
\hline 2009 Gauthier ${ }^{20}$ & 194 & 15 mm (1-31) & $27 / 77$ & $40(7-72)$ & - & 0 \\
\hline 2009 Groetelaers $^{21}$ & 254 & $71 \%^{\mathrm{a}}$ & NR & $73(60-100)$ & 40 & 0.4 \\
\hline 2009 Sanli $^{22}$ & 121 & $81 \%$ & 37 (total) & $44(15-76)$ & $24,31,32$ & 2.5 \\
\hline 2009 Bulte $^{23}$ & 503 & $71 \%{ }^{a}$ & $21 / 23^{a}$ & $46(11-64)$ & $3,30,51$ & 0.6 \\
\hline $2009 \mathrm{Kim}^{24}$ & 293 & $82 \%^{a}$ & NR & $40(24-49)$ & $8,12,16$ & 1.0 \\
\hline 2008 Zavagno $(\mathrm{R})^{13}$ & 218 & $81 \%^{a}$ & 'to most' & 56 (IQ 42-63) & NR & 0.5 \\
\hline 2008 Ploeg $^{25}$ & 748 & $75 \%{ }^{a}$ & $21 / 23$ & $46(0-98)$ & 10,44 & 0.3 \\
\hline 2008 Christiansen $^{26}$ & 3717 & $68 \%^{a}$ & NR & $20(0-62)$ & range $0-50$ & 0.5 \\
\hline 2008 Poletti $^{27}$ & 804 & $79 \%$ & $18 / 82$ & 39 (4-97) & $4,11,18,19,22,72$ & 0.7 \\
\hline 2008 Bergkvist $^{28}$ & 2246 & 14 mm (5-30) & NR & $37(0-75)$ & $21(4-51)$ & 1.2 \\
\hline 2008 Kuijt $^{29}$ & 100 & $15 \mathrm{~mm}(3-31)$ & $13 / 39$ & $78(4-103)$ & $14,20,33,79,90$ & 5.0 \\
\hline 2008 Wely $^{30}$ & 392 & NR & NR & $65(33-123)$ & $27(4-63)$ & 2.8 \\
\hline 2008 Heuts $^{31}$ & 344 & $63 \%$ & NR & $43(1-96)$ & $17,21,26$ & 0.9 \\
\hline 2007 Domenech $^{32}$ & 91 & $85 \%$ & NR & $49(26-63)$ & - & 0 \\
\hline 2007 Konstantiniuk $^{33}$ & 1394 & $70 \%{ }^{a}$ & $24 / 79^{a}$ & $34(0-102)$ & $0-48$ & 0.4 \\
\hline 2007 Susini $^{34}$ & 165 & $95 \%$ & $40 / 67$ & $46(12-72)$ & - & 0 \\
\hline 2007 Takei $^{35}$ & 822 & $39 \%^{a}$ & 75 (total) & $34(2-83)$ & $9,18,21,29$ & 0.5 \\
\hline 2006 Rosing $^{9}$ & 89 & $19 \mathrm{~mm}(+/-14)$ & NR & $26(-48)$ & NR & 1.1 \\
\hline 2006 Schulze $e^{12}$ & 25 & $100 \%^{a}$ & $3 / 68^{a}$ & $47(+/-15)$ & - & 0 \\
\hline 2006 de Kanter ${ }^{36}$ & 149 & $56 \% \mathrm{~T} 1 \mathrm{c}$ & 13 (total) & $65(50-79)$ & $10,12,14,56$ & 2.7 \\
\hline 2006 Leikola $^{37}$ & 205 & $81 \%$ & $45 / 55$ & $36(0-36)$ & 24,36 & 1.0 \\
\hline 2006 Nagashima $^{38}$ & 241 & $8 \mathrm{~mm}(+/-9)$ & $16 / 76$ & $27(6-66)$ & - & 0 \\
\hline 2006 Paajanen $^{39}$ & 107 & $63 \%^{\mathrm{a}}$ & $44 / 57^{a}$ & $31(13-49)$ & - & 0 \\
\hline 2006 Palesty $^{40}$ & 335 & $83 \%$ & $32 / 76$ & $33(2-76)$ & 5,14 & 0.6 \\
\hline 2006 Veronesi $(R)^{7,41}$ & 167 & $100 \%$ & $47 / 90^{a}$ & 79 (15-97) & 86 & 0.6 \\
\hline 2005 Fan $^{42}$ & 237 & 13 mm (1-60) & NR & $31(0-70)$ & 5,18 & 0.8 \\
\hline 2005 Jeruss $^{43}$ & 592 & $74 \%^{\mathrm{a}}$ & $42 / 70^{a}$ & $27(1-98)$ & 22 & 0.2 \\
\hline 2005 Khakpour $^{44}$ & 202 & NR & 44 / 86 & $26(6-80)$ & - & 0 \\
\hline 2005 Kokke $^{45}$ & 113 & 14 mm (2-35) & $19 / 18$ & $38(24-54)$ & 29 & 0.9 \\
\hline 2005 Langer $^{46}$ & 122 & $72 \%^{a}$ & $20 / 76$ & $42(12-64)$ & 14 & 0.8 \\
\hline 2005 Sanjuan $^{47}$ & 158 & 17 mm (0-36) & NR & $21(4-45)$ & 17 & 0.6 \\
\hline 2005 Soni $^{48}$ & 101 & $75^{\mathrm{a}}$ & $21 / 71$ & $22(6-42)$ & 35 & 1.0 \\
\hline 2005 Snoj $^{49}$ & 50 & 13 mm (5-25) & NR & $32(10-50)$ & 26 & 2.0 \\
\hline 2005 Swenson $^{50}$ & 580 & $85 \%^{\mathrm{a}}$ & $42 / 58$ & $33(2-73)$ & $11,24,36$ & 0.5 \\
\hline 2005 Zavagno $^{51}$ & 479 & $90 \%$ & $53 / 47$ & $36(12-68)$ & - & 0 \\
\hline 2004 Imoto $^{52}$ & 112 & $56 \%$ & $32 / 17$ & $44(36-53)$ & $3-22$ & 4.5 \\
\hline 2004 Torrenga $^{53}$ & 104 & $15 \mathrm{~mm}(4-50)$ & 19 (total) & $57(48-83)$ & 24 & 1.0 \\
\hline 2004 Naik $^{54}$ & 2340 & $89 \%$ & NR & $31(1-75)$ & $19,29,38$ & 0.1 \\
\hline 2004 van der Vegt ${ }^{55}$ & 106 & $71 \%^{a}$ & 24 (total) & 35 (17-59) & 26 & 0.9 \\
\hline 2004 Wessem $^{56}$ & 56 & $58 \%$ & NR & $28(16-39)$ & 24 & 1.8 \\
\hline 2003 Badgwell $^{57}$ & 159 & 71 & NR & $32(24-34)$ & - & 0 \\
\hline 2003 Blanchard $^{58}$ & 685 & 78 & $26 / N R$ & $29(7-46)$ & 41 & 0.1 \\
\hline 2003 Estourgie & 361 & NR & NR & $16(1-34)$ & 22 & 0.3 \\
\hline 2003 Ponzone 60 & 150 & 80 & NR & $15(3-35)$ & - & 0 \\
\hline 2002 Chung $^{61}$ & 206 & 81 & $27 / 47$ & $26(2-50)$ & $4,11,40$ & 1.5 \\
\hline 2002 Hansen $^{62}$ & 238 & 85 & $25 / 56$ & $39(6-69)$ & - & 0 \\
\hline 2002 Loza $^{61}$ & 168 & NR & NR & $21(1-48)$ & 30 & 0.6 \\
\hline
\end{tabular}

${ }^{a}$ characteristics including patients with a positive SN; DCIS excluded, whenever information was available; $R$ indicates part of a randomized trial, NR patients received systemic therapy, but exact percentage was not reported, AST adjuvant systemic therapy 


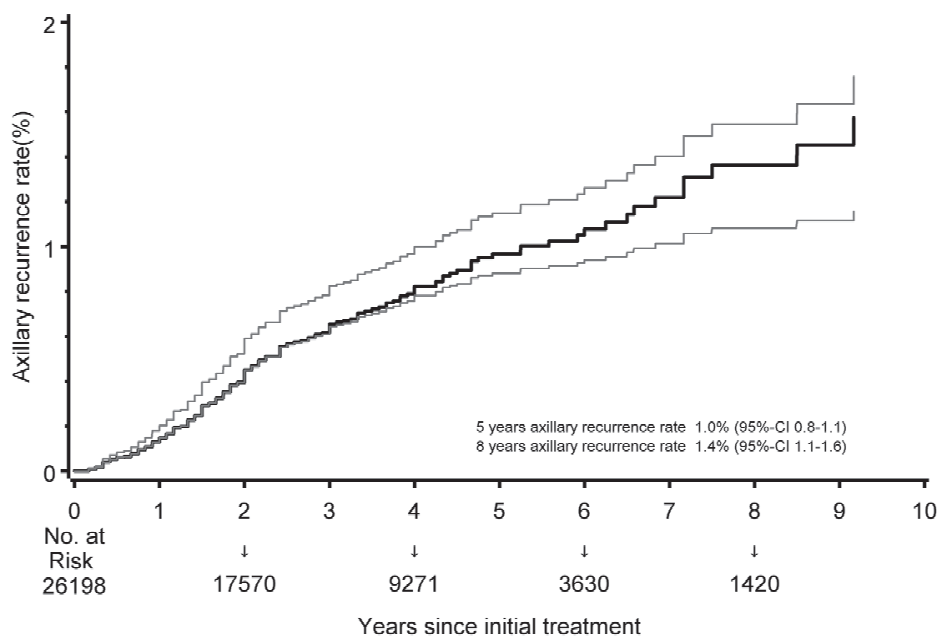

Figure 2.1 Kaplan Meier curves for the percentage axillary recurrence among patients with a negative SN who did not undergo a completion ALND, based on $\mathbf{5 0}$ observational series (Table 2.2). As the curves cannot be determined with certainty, the bold line shows the recurrence for the middle scenario, whereas the other lines indicate the recurrence for extreme best case and worst case scenarios, respectively. The numbers at risk correspond to the middle scenario.

In total, 12 studies ${ }^{10,12,13,24,33,35,41-43,52,54,64}$ were available with follow-up information, of which three ${ }^{10,13,41}$ were randomized. Overall, follow-up of 8,542 patients was reported. The axillary recurrence rate was $0 \%$ in all but three "sentinel lymph node and axillary lymph node dissection" study arms, leading to an overall recurrence rate of $0.3 \%$ (95\% $\mathrm{Cl} 0.1-0.6)$. As in one of these it was actually unclear whether the only patient with an axillary recurrence had a negative or positive sentinel lymph node, the recurrence rate may even be lower ${ }^{10}$. The median follow-up duration in these studies was 47 months, with a maximum of 102 months.

On the other hand, the pooled recurrence rate for sentinel lymph node-negative patients who did not undergo a completion axillary lymph node dissection was $0.4 \%$ (95\% Cl 0.2-0.6), which is still low but slightly higher compared with the sentinel lymph node-negative axillary lymph node dissection treated patients, especially when considering the shorter median follow-up duration of only 31 months, with a maximum of 98 months.

The false-negative rate ranged from 4.1 to $22.2 \%$. Conversely, the percentage of patients with a negative sentinel lymph node having a positive non-sentinel lymph node varied from 2.0 to $9.2 \%$. This latter rate reflects the potential long-term risk of axillary recurrence if no systemic treatment is offered. 
Table 2.3 Studies in which breast cancer patients with a negative SN were randomized between a completion axillary lymph node dissection (ALND) or not, and of studies in which patients with a negative $\mathrm{SN}$ in the learning / validation phase routinely underwent a completion ALND, whereas the next patients with a negative SN did not undergo a completion ALND anymore (SN application phase).

\begin{tabular}{|c|c|c|c|c|c|c|c|}
\hline Source $^{a}$ & $\begin{array}{l}\text { Only SN } \\
\text { negative } \\
\text { patients are } \\
\text { included }\end{array}$ & $\begin{array}{c}\text { No. } \\
\text { patients }\end{array}$ & $\begin{array}{c}\% \mathrm{~T} 1 \\
\text { or median } \\
\text { (range in } \\
\mathrm{mm} \text { ) }\end{array}$ & $\begin{array}{c}\text { Follow-up, } \\
\text { months } \\
\text { median (range) }\end{array}$ & $\begin{array}{c}\text { Axillary } \\
\text { recurrence } \\
\%\end{array}$ & $\begin{array}{l}\text { Positive } \\
\text { non- } \\
\text { SNs } \\
\%\end{array}$ & $\begin{array}{l}\text { False } \\
\text { negative } \\
\text { rate } \\
\%\end{array}$ \\
\hline \multicolumn{8}{|l|}{ Randomized trials } \\
\hline \multirow[t]{2}{*}{2009 Canavese $^{10}$} & SN and ALND & 88 & $74^{b}$ & mean $67(+/-16)$ & $1.1^{\mathrm{d} / \mathrm{NR}}$ & 9.2 & 22.2 \\
\hline & SN only & 79 & $87^{b}$ & mean $67(+/-16)$ & 0 & & \\
\hline \multirow[t]{2}{*}{2008 Zavagno $^{13}$} & SN and ALND & 233 & $82^{b}$ & 56 (IQ 42-63) & 0 & 7.7 & 16.7 \\
\hline & SN only & 218 & $81^{b}$ & 56 (IQ 42-63) & 0.5 & & \\
\hline \multirow[t]{2}{*}{2006 Veronesi $^{7,41}$} & SN and ALND & 174 & 100 & 79 (5-97) & 0 & 4.6 & 8.8 \\
\hline & SN only & 167 & 100 & 79 (5-97) & 0.6 & & \\
\hline \multicolumn{8}{|c|}{ Studies reporting on Validation and next Application phase } \\
\hline \multirow[t]{2}{*}{$2009 \mathrm{Kim}^{24}$} & SN and ALND & 174 & $73^{b}$ & $40(24-49)^{b}$ & 0 & & \\
\hline & SN only & 293 & $73^{b}$ & $40(24-49)^{b}$ & 1.0 & & \\
\hline \multirow[t]{2}{*}{2007 Konstantiniuk $^{33}$} & SN and ALND & 355 & $69^{b}$ & $47(0-102)$ & 0.8 & 3.7 & 6.5 \\
\hline & SN only & 1394 & $70^{\mathrm{b}}$ & $31(0-87)$ & 0.4 & & \\
\hline \multirow[t]{2}{*}{2007 Takei $^{35}$} & SN and ALND & 56 & 30 & $34(2-83)^{b}$ & 0 & & \\
\hline & SN only & 1062 & 34 & $34(2-83)^{b}$ & 0.4 & & \\
\hline \multirow[t]{2}{*}{2006 Schulze $e^{12}$} & SN and ALND & 56 & 100 & $66(+/-22)$ & 0 & 7.1 & 12.1 \\
\hline & SN only & 25 & 100 & $47(+/-15)$ & 0 & & \\
\hline \multirow[t]{2}{*}{$2005 \mathrm{Fan}^{42}$} & SN and ALND & 39 & $13(1-60)^{b}$ & $31(0.3-70)^{b}$ & 0 & 5.1 & \\
\hline & SN only & 237 & $13(1-60)^{b}$ & $31(0.3-70)^{b}$ & 0.8 & & \\
\hline \multirow[t]{2}{*}{2004 Jeruss $^{43}$} & SN and ALND & 30 & $71^{b}$ & $27(1-98)^{b}$ & 3.3 & 2.0 & \\
\hline & SN only & 557 & $71^{b}$ & $27(1-98)^{b}$ & 0.2 & & \\
\hline \multirow[t]{2}{*}{2004 Imoto $^{52}$} & SN and ALND & 97 & 31 & $62(53-71)$ & 0 & & \\
\hline & SN only & 112 & 56 & $44(36-52)$ & 4.5 & & \\
\hline \multirow[t]{2}{*}{2004 Naik $^{54}$} & SN and ALND & 326 & 66 & $32(1-74)$ & 0 & & \\
\hline & SN only & 2340 & 89 & $31(1-75)$ & 0.1 & & \\
\hline \multirow[t]{2}{*}{2002 Shivers $^{64}$} & SN and ALND & 250 & $96 \% \mathrm{~T} 1,2^{\mathrm{b}}$ & $16(12-42)^{b}$ & 0 & 2.0 & 4.1 \\
\hline & SN only & 180 & $96 \% \mathrm{~T} 1,2^{\mathrm{b}}$ & $16(12-42)^{b}$ & 0 & & \\
\hline
\end{tabular}

${ }^{a}$ Only studies that included consecutively all patients with a negative SN irrespective of non-SN status and with follow-up information with and without ALND were included (so, different from the main results of randomized trials, in which intent-to-treat analyses was performed irrespective of SN status). Only patients with negative SN are included in this table. ${ }^{\mathrm{b}} \mathrm{T}$ size also included of patients from other categories (e.g. positive SN). ${ }^{c}$ Follow-up time in validation studies: only median provided for total study population, whereas in reality follow-up of 'SN and ALND' group was somewhat longer than of the more recent 'SN only' group. In some studies, the range of follow-time was estimated from date of inclusion versus date of analysis. ${ }^{d}$ unclear whether this one patient with an axillary recurrence had a positive or a negative SN. Positive non-SN rate and false negative rate were calculated only for those studies that provided full information on the validation phase including patients with a positive SN. NR = not reported. IQ: interquartile range 
Axillary recurrence rates for a positive sentinel lymph node, without axillary lymph node dissection:

\section{observational studies}

One population-based study ${ }^{65}$ and 15 single centre studies $12,23,35,42,43,46,50,55,66-72$ reported on patients with a positive sentinel lymph node who did not undergo a completion axillary lymph node dissection (Table 2.4).

Table 2.4 Axillary recurrence rate in studies on selected SN-positive breast cancer patients who did not undergo completion axillary lymph node dissection (ALND).

\begin{tabular}{|c|c|c|c|c|c|c|c|}
\hline Source & $\begin{array}{c}\text { No. } \\
\text { patients }\end{array}$ & $\% \mathrm{~T} 1$ & $\begin{array}{c}\text { AST \% } \\
\text { chemo / } \\
\text { hormonal }\end{array}$ & $\begin{array}{c}\text { Radio- } \\
\text { therapy } \\
\text { Axilla } \\
\%\end{array}$ & SN status & $\begin{array}{c}\text { Median } \\
\text { follow up, } \\
\text { months } \\
\text { median } \\
\text { (range) }\end{array}$ & $\begin{array}{c}\text { Axillary } \\
\text { recurrence } \\
\%\end{array}$ \\
\hline 2009 Bulte $^{23}$ & 20 & $71^{a}$ & $21 / 23^{a}$ & NR & 20 "micro" & $46(11-64)$ & 0 \\
\hline 2009 Bilimoria $^{65}$ & 1,988 & 63 & $71 / 41$ & NR & 530“micro"; 1,458 macro & $64(60-72)$ & $0.6 / 1.2$ \\
\hline 2007 Takei $^{35}$ & 120 & 30 & 92 & 54 & Not specified & $34(2-83)^{a}$ & 0 \\
\hline 2007 Hwang ${ }^{66}$ & 196 & 72 & $56 / 27$ & 64 & 67itc; 90micro; 39macro & $30(1-62)$ & 0 \\
\hline 2007 Park $^{67}$ & 287 & 78 & NR & 15 & Not specified & $23(6-87)$ & $2.1(5.0)^{\mathrm{c}}$ \\
\hline 2006 Schulze ${ }^{12}$ & 6 & $100^{a}$ & $3 / 68^{a}$ & - & 1itc; 4micro; 1 macro & $49(+/-17)^{a}$ & 0 \\
\hline 2006 Pejavar $^{68}$ & 16 & $80^{a}$ & $30 / 34^{a}$ & 100 & Not specified & $24-60^{a}$ & 0 \\
\hline 2006 Haid $^{69}$ & 10 & $77^{a}$ & $32 / 93^{a}$ & - & 2itc; 6micro; 2macro & $47(7-90)$ & 0 \\
\hline $2005 \mathrm{Fan}^{42}$ & 38 & 71 & NR & 63 & 27 micro; 11 macro & $29(6-76)$ & 2.6 \\
\hline 2005 Jeruss $^{43}$ & 73 & $57^{a}$ & $85 / 70^{a}$ & - & 73 "micro" & $27(1-98)$ & 0 \\
\hline 2005 Langer $^{46}$ & 27 & $72^{a}$ & $20 / 76^{b}$ & - & 27 "micro" & $42(12-64)$ & 0 \\
\hline 2005 Swenson $^{50}$ & 67 & $82^{a}$ & $42 / 58^{a}$ & - & 32 itc; 31micro; 4 macro & $33(2-73)$ & 1.5 \\
\hline 2005 Chagpar $^{70}$ & 15 & $89^{a}$ & 33 & - & 2itc; 12 micro; 1 macro & $40(1-54)$ & 0 \\
\hline 2004 Vegt $^{55}$ & 10 & $85^{a}$ & NR & 100 & 4micro; 6macro & 35 (17-59) & 0 \\
\hline 2003 Fant $^{71}$ & 31 & 81 & 100 & 3 & 27"micro"; 4macro & $28(21-48)$ & 0 \\
\hline 2003 Guenther $^{72}$ & 46 & 67 & 100 & 2 & 23itc; 16"micro"; 7macro & $32(4-61)$ & 0 \\
\hline
\end{tabular}

a total group, not specified separately for SN-positive patients "micro": before 2002 there was no distinction between itc/micro, and these were, therefore, referred to as "micro". b for all SN only including both SN negatives as positives. " axillary relapse rate if positive $\mathrm{SN}$ was detected by haematoxylin and eosin. NR, patients received systemic therapy, but exact percentage was not reported

From the National Cancer Data Base of the United States of America, nearly 100,000 patients with clinically node-negative breast cancer who had a positive sentinel lymph node were identified $^{65}$. Of these, $21 \%$ underwent sentinel lymph node only ( $n=1,988$ patients). In this population-based study, $1 \%(95 \% \mathrm{Cl} 0.6-1.5)$ of the patients had a recurrence, while the median duration of follow-up was 64 months, with a maximum of 72 months. The authors themselves noted already that recurrences may have been underreported to cancer registries. Patients classified as "micrometastases" who did not undergo axillary lymph node dissection probably included patients with isolated tumor cells according to the 6th edition of AJCC classification ${ }^{73}$, implying that a substantial number of patients actually may have had "node-negative disease" according to current definition.

The pooled single centre studies resulted in $1.7 \%(95 \% \mathrm{Cl} 1.0-2.7)$ recurrences, with a median and maximum follow-up duration of 30 and 98 months, respectively. Overall, 
follow-up was reported from 962 patients.

In the largest single centre study from the Memorial Sloan-Kettering Cancer Center (MSKCC) ( $n=287)$, patients with sentinel lymph node positive/no axillary lymph node dissection had compared with the sentinel lymph node positive/ axillary lymph node dissection patients more favorable tumors with a lower median predicted risk of nonsentinel lymph node metastases ( 9 vs. $37 \%, P<0.001)^{67}$. The sentinel lymph node metastasis size was not reported, but sentinel lymph node positivity was detected by serial sectioning and/or immunohistochemistry in $39 \%$ of patients, indicating small volume disease in many patients.

Of note, in the "no axillary lymph node dissection" group, still a substantial number of nodes was excised, that is, 4 or more nodes (sentinel lymph node and non-sentinel lymph nodes) in $14 \%$ of patients. And, $15 \%$ of patients received radiotherapy to the axilla and/or supraclavicular nodes. In their series, axillary recurrences developed in $2.0 \%$ of sentinel lymph node positive/no axillary lymph node dissection patients at a median follow-up of 23 months versus in $0.4 \%$ of sentinel lymph node positive/ axillary lymph node dissection patients at 30 months $(P=0.004)$. Of importance, the highest axillary recurrence rate was seen in the subgroup of sentinel lymph node positive/no axillary lymph node dissection patients whom sentinel lymph nodes were positive on routine haematoxylin and eosin. In these patients the axillary recurrence rate was $5 \%$ after 23 months of follow-up.

In the second largest study, from the MD Anderson Cancer Center (MDACC), 196 patients with a positive sentinel lymph node did not undergo completion axillary lymph node dissection ${ }^{66}$. Twenty-three patients had non-sentinel lymph nodes removed, and relatively many sentinel lymph nodes (median 4, range 1-14) were excised. Radiotherapy covering part of the axilla was used in $64 \%$ of patients. The calculated risk of positive non-sentinel lymph nodes based on the MSKCC nomogram was $9.8 \%$, in line with the low risk profile according to the MDACC risk model. At a median follow-up of 30 months, no axillary recurrences were observed.

Overall survival in randomized and large database studies:

pre-sentinel lymph node and sentinel lymph node studies

Before the sentinel lymph node era, six randomized trials have assessed the role of axillary lymph node dissection with respect to survival in clinically node negative breast cancer patients (Table 2.5). Three of six studies, among others the NSABP B-04, did not show a statistically significant survival benefit, but likely due to lack of power. In a Bayesian meta-analysis, the combination of trials including almost 3,000 patients showed a $5.4 \%(95 \% \mathrm{Cl} 2.7-8.0)$ survival benefit in favor of axillary lymph node dissection ${ }^{74}$. Although three studies used axillary radiotherapy in patients who did not undergo an axillary lymph node dissection, these studies were yet included in the analysis $^{16-18}$. Of note, essentially none of the patients were treated with systemic therapy. 


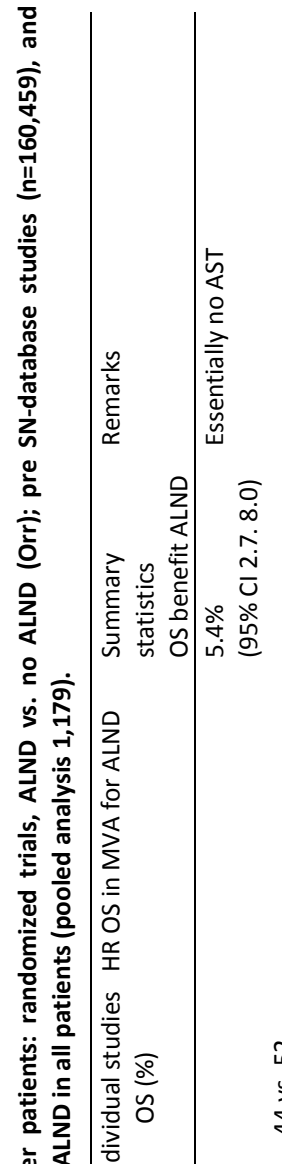

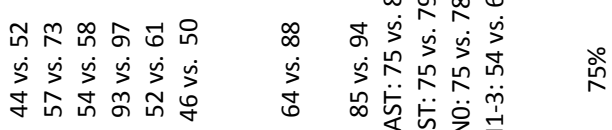
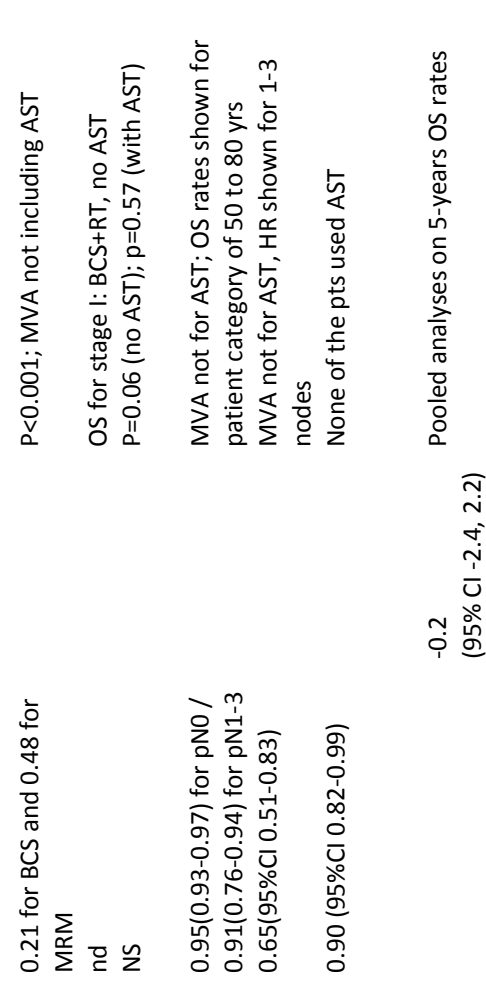

ஸू

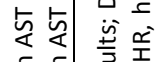

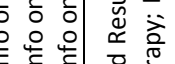

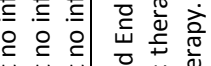

苛苛苛

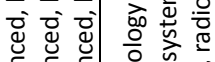

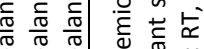

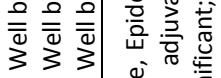

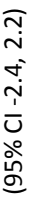

过珤

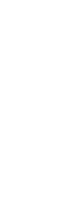

产市茄

ज该

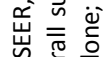

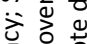

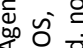

षे

당

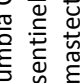

守

के

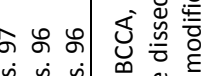

$\dot{s} \dot{>} \dot{s}$

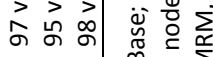

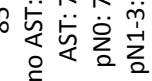

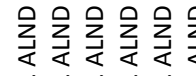

में

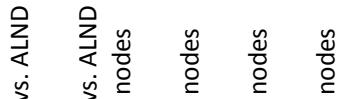

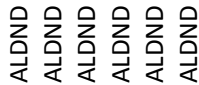

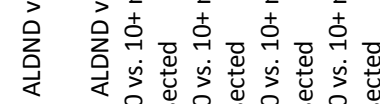

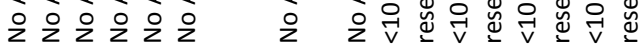

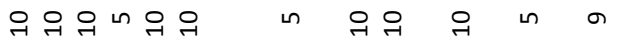

要

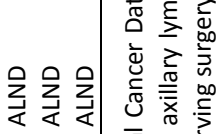

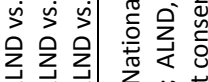

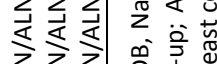

\&ั่

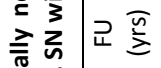

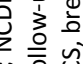

卷

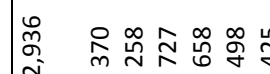

号

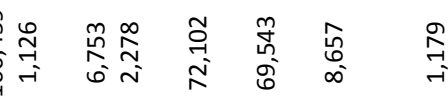

要

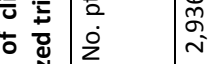

흘

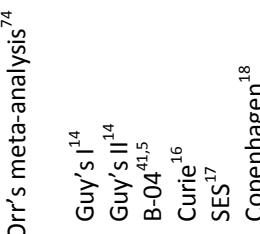

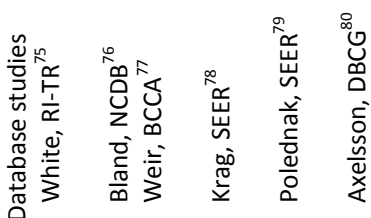

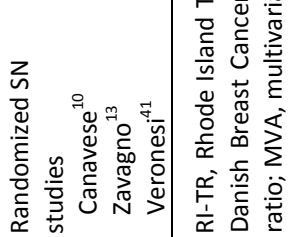


In addition, six large pre-sentinel lymph node database studies, including in total 160,459 patients, showed a survival benefit in direct proportion to the number of lymph nodes removed (Table 2.5$)^{75-80}$. Although it was noted that treatment choices may have been influenced by age, presence of comorbidity and likelihood of nodal involvement, these were not always taken into account in multivariate analyses.

Only one study corrected for use of systemic therapy and observed that the risk of death by omission of axillary lymph node dissection was diminished when systemic therapy was used ${ }^{77}$. Another interesting observation was that even when all regional lymph nodes were pathologically negative, the number of nodes removed was associated with survival ${ }^{78,79}$.

The three published studies randomizing patients to axillary lymph node dissection or to sentinel lymph node followed by axillary lymph node dissection only if the sentinel lymph node was involved did not show a survival benefit of axillary lymph node dissection, and concluded that completion axillary lymph node dissection can be avoided in patients with negative sentinel lymph nodes ${ }^{10,13,41}$. Pooled analysis of the three randomized trials also showed no significant differences in 5-year overall survival, with a hazard ratio of $-0.2(95 \% \mathrm{Cl}-2.4-2.2)$.

\section{Discussion}

In patients with clinically node-negative breast cancer the necessity of axillary surgery has been a matter of debate for many years. Leaving out axillary lymph node dissection in all clinically node-negative patients is potentially harmful ${ }^{74}$. With the introduction of the sentinel lymph node procedure a strategy to identify the patients who might not need axillary surgery became available. The aim of our study was to provide a systematic review to estimate axillary recurrence rates in patients with clinically node-negative breast cancer, who did or did not undergo axillary lymph node dissection. In this systematic review, we found that patients with a negative sentinel lymph node had a pooled axillary recurrence rate of only $0.6 \%$ at 36 months.

In contrast, in sentinel lymph node-positive studies the axillary recurrence rate was about 3 times higher, up to $1.7 \%(95 \% \mathrm{Cl} 1.0-2.7)$ at 30 months. For patients with a positive sentinel lymph node by haematoxylin and eosin examination these rates were even higher.

The sentinel lymph node procedure is based on the premise that it improves identification of patients with pathologically node-negative disease. Indeed, series including patients with a negative sentinel lymph node who did not undergo completion axillary lymph node dissection show low axillary recurrence rates of $1 \%$ after 5 years of follow-up (Figure 2.1). The results of the comparative studies, i.e. summary statistics of the follow-up duration and overall recurrence, are more difficult to interpret (Tables $2.2,2.3$ ). The observational study results may illustrate this. The overall recurrence rate in these studies was $0.6 \%$, the median follow-up was 
36 months and the maximal follow-up was 12 years. One may be tempted to assume that $0.6 \%$ is the recurrence rate at median follow-up, or at least for some time point between the median and the maximum follow-up duration. However, the KaplanMeier graph in Figure 2.1 shows that the recurrence rate at median follow-up is already $0.8 \%$ and it is steadily increasing to more than $1.5 \%$ after 9 years. So, in reported studies the axillary recurrence rate continued to increase over time, which was different from what we had expected. Based on the comparative studies, we conclude that omitting axillary lymph node dissection in sentinel lymph node-negative patients is associated with a small increase in risk of axillary recurrence. However, based on the single group studies, we conclude that this risk seems to be acceptable as long as techniques are validated and selection criteria do not change dramatically from the criteria in validated studies. New prospective randomized survival and regional recurrence data from the NSABP B-32 were very recently presented at $\mathrm{ASCO}^{81}$. In B-32, including 2,011 pathologically node-negative patients undergoing sentinel lymph node alone and 1,975 randomized to sentinel lymph node plus confirmatory axillary dissection, the sentinel lymph node biopsy false-negative rate was $9.8 \%$ with a sample size large enough to detect a $2 \%$ difference in survival between the control and experimental arms ${ }^{81,82}$. Median follow-up was 95 months. Axillary recurrence rates were 0.6 and $0.4 \%$, 5-year OS rates were 95.0 and $96.4 \%$, respectively, both statistically not different. This recent study supports the view that in sentinel lymph node-negative breast cancer patients with a T1 or (small) T2 tumor, omission of axillary lymph node dissection can be regarded as safe.

In daily practice there is a shift toward omitting completion axillary lymph node dissection in sentinel lymph node-positive patients ${ }^{8,65,83}$. At first glance, axillary recurrence rates in series and a population-based registry seem not worse as opposed to series in sentinel lymph node-negative patients (Table 2.4 vs. Tables 2.2 and 2.3). However, these low recurrence rates in sentinel lymph node-positive patients may be explained by more favorable tumor characteristics, the presence of isolated tumor cells (even if they were classified as "micrometastases"), a considerable number of patients being treated by axillary radiotherapy, and finally, the number of nodes removed during the sentinel lymph node procedure being higher than normally expected. Of note, the MSKCC reported that in patients identified with a positive sentinel lymph node by haematoxylin and eosin examination, the axillary recurrence rate was $5 \%$ at a median follow-up of 23 months, even though these were highly selected patients ${ }^{67}$. In a cohort study from The Netherlands (the MIRROR study), patients with sentinel lymph node micrometastases $(0.2-2.0 \mathrm{~mm})$ who did not undergo a completion axillary lymph node dissection were also shown to have an increased risk of axillary recurrence of $5 \%$ at 5 years follow-up ${ }^{84}$.

The results of the observational sentinel lymph node-negative studies may help to interpret the results for sentinel lymph node-positive patients. On the one hand, the single group sentinel lymph node-negative studies had a median follow-up duration of 36 months and an overall recurrence of $0.6 \%$. The 5 and 8 year recurrence rates were 
1 and $1.4 \%$, respectively. For the studies in sentinel lymph node-positive patients, the overall recurrence was $1.7 \%$, i.e., $1.7 / 0.6=2.8$ times higher than for the single group studies. Therefore, the 5 and 8 year recurrence rates in sentinel lymph node-positive patients may be $(1.7 / 0.6) * 1=2.8 \%$ and $(1.7 / 0.6) * 1.4=4 \%$, respectively. If we also take the median follow-up of 30 months for the sentinel lymph node-positive studies into account, the rates will be $(36 / 30) * 2.8=3.4 \%$ and $(36 / 30) * 4=4.8 \%$, respectively. In a similar way, we find that for patients identified with a positive sentinel lymph node by haematoxylin and eosin examination in the MSKCC study, the axillary recurrence rate after 5 and 8 years may be as high as $(5 / 0.6) *(36 / 23) * 1=13 \%$ and $(5 / 0.6) *$ $(36 / 23) * 1.4=18 \%$. Although these calculations are rather speculative, they are not implausible. They suggest that in many patients with a positive sentinel lymph node withholding axillary lymph node dissection may not be safe. Concerns regarding safety of general omission of axillary lymph node dissection in clinically node-negative but sentinel lymph node-positive patients are based on the survival rates in conventional axillary lymph node dissection versus no-axillary lymph node dissection studies ${ }^{74}$. However, in these studies most of the patients did not receive adjuvant systemic therapy. Recently, we showed that isolated tumor cells and micrometastases were associated with a reduced 5-year rate of disease-free survival among women with favorable early-stage breast cancer who underwent a sentinel lymph node procedure and who did not receive adjuvant systemic therapy ${ }^{85}$. Among patients who received systemic therapy, the 5-year disease-free survival rate was significantly improved with an absolute benefit of nearly $10 \%$, including a reduction in locoregional recurrence rate. Therefore, with more patients undergoing systemic therapy, the need for axillary treatment may change. In the studies reported so far, the rate of systemic therapy was highly varying and, therefore, impossible to analyse. This is a limitation of a systematic review on published data instead of a meta-analysis on individual data. Considering the number of trials and low number of patients included, an individually based analysis was considered not possible. Survival outcomes for the node-positive ACOSOG Z0011 trial were presented at $\mathrm{ASCO}^{82}$. Patients with one or two haematoxylin and eosin positive sentinel lymph nodes were randomized to observation or axillary lymph node dissection. The trial unfortunately failed to reach its targeted accrual. This otherwise would have been the most robust possible test of the null hypothesis that regional lymph node dissection does not improve breast cancer outcomes. That noted, among the 856 patients randomized and analyzed in an intent-to-treat analysis, at a median follow-up of 6.2 years there were no statistically significant differences in ipsilateral breast tumor or axillary recurrence. Five-year regional recurrence rate was $0.9 \%$ for sentinel lymph node only compared to $0.5 \%$ for axillary lymph node dissection $(P=0.11)$, with 5 -year OS rates of 92.5 and $91.9 \%$, respectively $(P=0.24)$. Of note, $82 \%$ of patients had received adjuvant systemic therapy. In $50 \%$ of patients the sentinel lymph node contained micrometastatic disease.

How should we now interpret these new findings together with existing data? On the one hand, conventional pre-sentinel lymph node studies showed reduced survival 
rates from omission of axillary lymph node dissection in clinically node-negative breast cancer patients. In sentinel lymph node-positive series, the overall axillary recurrence rate was 2.8 times higher than for the single group studies in sentinel lymph node-negative patients, with estimated axillary recurrence rate after 5 and 8 years as high as 13 and $18 \%$. On the other hand, in the one randomized phase III study omission of axillary lymph node dissection did not result in high axillary recurrence rates or reduced survival. One explanation could be the increasing use of systemic therapy over the last decade that also reduces the risk of locoregional recurrences. Another explanation could be the increased use of preoperative screening of the axilla by ultrasound, causing stage migration of clinically nodenegative disease. Apparently, the challenge will be to better define the patients that still need to undergo a completion axillary lymph node dissection versus those who do not. The risk of non-sentinel lymph node metastases, if the axilla is left untreated, is on average $8 \%$ for sentinel lymph node-negative disease, $12 \%$ for sentinel lymph node isolated tumor cells, $29 \%$ for micrometastases and $38 \%$ for macrometastases ${ }^{86,87}$. The risk of non-sentinel lymph node involvement is not only associated with sentinel lymph node status, but also with primary tumor size and presence or absence of lymph vessel invasion ${ }^{86}$. In the ACOSOG Z0011 study, $27 \%$ of patients in the axillary lymph node dissection group had positive non-sentinel lymph nodes. Further research on predictive nomograms and on impact of modern adjuvant systemic therapy is needed to improve selection of patients who will not benefit from further axillary surgery. In the decision process the risk of arm morbidity should be taken into account, because even though morbidity from axillary surgery in the NSABP B-32 was lower than expected, shoulder deficit, arm volume difference, arm numbness and tingling occurred at least twice as frequently in the axillary lymph node dissection arm as compared to the sentinel lymph node alone arm.

We conclude that the sentinel lymph node procedure can be regarded as nearly optimal to identify patients who do not need an axillary lymph node dissection, that is, patients who have a negative sentinel lymph node. However, additional eligibility criteria and the role of systemic therapy need further to be elucidated to determine a potential role for avoiding axillary lymph node dissection in selected sentinel lymph node-positive patients. 


\section{References}

1. Fisher B, Anderson S, Redmond CK et al. Reanalysis and results after 12 years of follow-up in a randomized clinical trial comparing total mastectomy with lumpectomy with or without irradiation in the treatment of breast cancer. N Engl J Med 1995;333:1456-1461.

2. Siesling S, van Dijck JA, Visser $O$ et al. Trends in incidence of and mortality from cancer in The Netherlands in the period 1989-1998. Eur J Cancer 2003;39:2521-2530.

3. Giuliano $A E$, Chung AP. Long-term follow-up confirms the oncologic safety of sentinel node biopsy without axillary dissection in node-negative breast cancer patients. Ann Surg 2010;251:601-603.

4. Ho VK, der Loo M, Rutgers EJ et al. Implementation of sentinel node biopsy in breast cancer patients in the Netherlands. Eur J Cancer 2008;44:683-691.

5. Lyman GH, Giuliano AE, Somerfield MR et al. American Society of Clinical Oncology guideline recommendations for sentinel lymph node biopsy in early-stage breast cancer. J Clin Oncol 2005;23:7703-7720.

6. Veronesi U, Paganelli G, Viale G et al. A randomized comparison of sentinel-node biopsy with routine axillary dissection in breast cancer. N Engl J Med 2003;349:546-553.

7. Veronesi U, Viale G, Paganelli G et al. Sentinel lymph node biopsy in breast cancer: ten-year results of a randomized controlled study. Ann Surg 2010;251:595-600.

8. Wasif $\mathrm{N}, \mathrm{Ye} \mathrm{X}$, Giuliano AE. Survey of ASCO members on management of sentinel node micrometastases in breast cancer: variation in treatment recommendations according to specialty. Ann Surg Oncol 2009;16:2442-2449.

9. Rosing DK, Dauphine CE, Vargas MP et al. Axillary regional recurrence after sentinel lymph node biopsy for breast cancer. Am Surg 2006;72:939-942.

10. Canavese G, Catturich A, Vecchio $C$ et al. Sentinel node biopsy compared with complete axillary dissection for staging early breast cancer with clinically negative lymph nodes: results of randomized trial. Ann Oncol 2009;20:1001-1007.

11. Veronesi U, Galimberti V, Paganelli G et al. Axillary metastases in breast cancer patients with negative sentinel nodes: a follow-up of 3548 cases. Eur J Cancer 2009;45:1381-1388.

12. Schulze T, Mucke J, Markwardt J et al. Long-term morbidity of patients with early breast cancer after sentinel lymph node biopsy compared to axillary lymph node dissection. J Surg Oncol 2006;93:109119.

13. Zavagno G, De Salvo GL, Scalco $G$ et al. A randomized clinical trial on sentinel lymph node biopsy versus axillary lymph node dissection in breast cancer: results of the Sentinella/GIVOM trial. Ann Surg 2008;247:207-213.

14. Hayward J, Caleffi M. The significance of local control in the primary treatment of breast cancer. Lucy Wortham James clinical research award. Arch Surg 1987;122:1244-1247.

15. Fisher $\mathrm{B}$, Jeong $\mathrm{JH}$, Anderson $\mathrm{S}$ et al. Twenty-five-year follow-up of a randomized trial comparing radical mastectomy, total mastectomy, and total mastectomy followed by irradiation. $\mathrm{N}$ Engl J Med 2002;347:567-575.

16. Louis-Silvestre C, Clough K, Asselain B et al. Axillary treatment in conservative management of operable breast cancer: dissection or radiotherapy? Results of a randomized study with 15 years of follow-up. J Clin Oncol 2004;22:97-101.

17. Hamilton $\mathrm{T}$, Langlands $\mathrm{O}$, Prescott RJ. The treatment of operable cancer of the breast: a clinical trial in the South-East region of Scotland. Br J Surg 1974;61:758-761.

18. Johansen $\mathrm{H}$, Kaae S, Schiodt T. Simple mastectomy with postoperative irradiation versus extended radical mastectomy in breast cancer. A twenty-five-year follow-up of a randomized trial. Acta Oncol 1990;29:709-715.

19. Kiluk JV, Ly QP, Meade T et al. Axillary recurrence rate following negative sentinel node biopsy for invasive breast cancer: long-term follow-up. Ann Surg Oncol 2010;17:552-557.

20. Gauthier T, Mollard J, Fermeaux V et al. Axillary recurrence after negative sentinel lymph node biopsy under local anesthesia in breast cancer. Eur J Surg Oncol 2009;35:464-468.

21. Groetelaers RP, van Berlo CL, Nijhuis PH et al. Axillary recurrences after negative sentinel lymph node biopsy under local anaesthesia for breast cancer: a follow-up study after 5 years. Eur J Surg Oncol 2009;35:159-163. 
22. Sanli I, Lemaire BM, Muller AJ et al. Axillary recurrence after negative sentinel lymph node biopsy: frequency and factors influencing recurrence on the long term. Breast J 2009;15:236-241.

23. Bulte CS, der Loo $M$, Hennipman A. Axillary recurrence rate after tumour negative and micrometastatic positive sentinel node procedures in breast cancer patients, a population based multicenter study. Eur J Surg Oncol 2009;35:25-31.

24. Kim HJ, Son BH, Park EW et al. Axillary recurrence after negative sentinel lymph node biopsy. Breast Cancer Res Treat 2009;114:301-305.

25. van der Ploeg IM, Kroon BB, Antonini $\mathrm{N}$ et al. Axillary and extra-axillary lymph node recurrences after a tumor-negative sentinel node biopsy for breast cancer using intralesional tracer administration. Ann Surg Oncol 2008;15:1025-1031.

26. Christiansen P, Friis E, Balslev E et al. Sentinel node biopsy in breast cancer: five years experience from Denmark. Acta Oncol 2008;47:561-568.

27. Poletti $P$, Fenaroli $P$, Milesi $A$ et al. Axillary recurrence in sentinel lymph node-negative breast cancer patients. Ann Oncol 2008;19:1842-1846.

28. Bergkvist L, de Boniface J, Jonsson PE et al. Axillary recurrence rate after negative sentinel node biopsy in breast cancer: three-year follow-up of the Swedish Multicenter Cohort Study. Ann Surg 2008;247:150-156.

29. Kuijt GP, Roumen RM. Second thoughts on sentinel lymph node biopsy in node-negative breast cancer. Br J Surg 2008;95:310-311.

30. van Wely BJ, Smidt ML, de Kievit IM et al. False-negative sentinel lymph node biopsy. Br J Surg 2008;95:1352-1355.

31. Heuts EM, van der Ent FW, Hulsewe KW et al. Incidence of axillary recurrence in 344 sentinel node negative breast cancer patients after intermediate follow-up. A prospective study into the accuracy of sentinel node biopsy in breast cancer patients. Acta Chir Belg 2008;108:203-207.

32. Domenech A, Benitez A, Bajen MT et al. Patients with breast cancer and negative sentinel lymph node biopsy without additional axillary lymph node dissection: a follow-up study of up to 5 years. Oncology 2007;72:27-32.

33. Konstantiniuk $P$, Schrenk $P$, Reitsamer $R$ et al. A nonrandomized follow-up comparison between standard axillary node dissection and sentinel node biopsy in breast cancer. Breast 2007;16:520-526.

34. Susini T, Nori J, Vanzi E et al. Axillary ultrasound scanning in the follow-up of breast cancer patients undergoing sentinel node biopsy. Breast 2007;16:190-196.

35. Takei H, Suemasu K, Kurosumi M et al. Recurrence after sentinel lymph node biopsy with or without axillary lymph node dissection in patients with breast cancer. Breast Cancer 2007;14:16-24.

36. de Kanter AY, Menke-Pluymers MM, Wouters MW et al. 5-Year follow-up of sentinel node negative breast cancer patients. Eur J Surg Oncol 2006;32:282-286.

37. Leikola J, Saarto T, Joensuu H et al. Ultrasonography of the axilla in the follow-up of breast cancer patients who have a negative sentinel node biopsy and who avoid axillary clearance. Acta Oncol 2006;45:571-575.

38. Nagashima T, Sakakibara M, Nakano $S$ et al. Sentinel node micrometastasis and distant failure in breast cancer patients. Breast Cancer 2006;13:186-191.

39. Paajanen $\mathrm{H}$, Kilponen VM, Heikkinen J et al. Feasibility of axillary ultrasound in the quality assessment of sentinel node biopsy in breast cancer surgery. Scand J Surg 2006;95:195-198.

40. Palesty JA, Foster JM, Hurd TC et al. Axillary recurrence in women with a negative sentinel lymph node and no axillary dissection in breast cancer. J Surg Oncol 2006;93:129-132.

41. Veronesi U, Paganelli G, Viale G et al. Sentinel-lymphnode biopsy as a staging procedure in breast cancer: update of a randomised controlled study. Lancet Oncol 2006;7:983-990.

42. Fan YG, Tan YY, Wu CT et al. The effect of sentinel node tumor burden on non-sentinel node status and recurrence rates in breast cancer. Ann Surg Oncol 2005;12:705-711.

43. Jeruss JS, Winchester DJ, Sener SF et al. Axillary recurrence after sentinel node biopsy. Ann Surg Oncol 2005;12:34-40.

44. Khakpour N, Hunt KK, Kuerer HM et al. Sentinel lymph node dissection provides axillary control equal to complete axillary node dissection in breast cancer patients with lobular histology and a negative sentinel node. Am J Surg 2005;190:598-601.

45. Kokke MC, Jannink I, Barneveld PC et al. Incidence of axillary recurrence in 113 sentinel node negative breast cancer patients: a 3-year follow-up study. Eur J Surg Oncol 2005;31:221-225. 
46. Langer I, Marti WR, Guller $U$ et al. Axillary recurrence rate in breast cancer patients with negative sentinel lymph node (SLN) or SLN micrometastases: prospective analysis of 150 patients after SLN biopsy. Ann Surg 2005;241:152-158.

47. Sanjuan A, Vidal-Sicart S, Zanon $\mathrm{G}$ et al. Clinical axillary recurrence after sentinel node biopsy in breast cancer: a follow-up study of 220 patients. Eur J Nucl Med Mol Imaging 2005;32:932-936.

48. Soni NK, Spillane AJ. Experience of sentinel node biopsy alone in early breast cancer without further axillary dissection in patients with negative sentinel node. ANZ J Surg 2005;75:292-299.

49. Snoj M, Bracko M, Zagar I. Axillary recurrence rate in breast cancer patients with negative sentinel lymph node. Croat Med J 2005;46:377-381.

50. Swenson KK, Mahipal A, Nissen MJ et al. Axillary disease recurrence after sentinel lymph node dissection for breast carcinoma. Cancer 2005;104:1834-1839.

51. Zavagno G, Carcoforo P, Franchini $Z$ et al. Axillary recurrence after negative sentinel lymph node biopsy without axillary dissection: a study on 479 breast cancer patients. Eur J Surg Oncol 2005;31:715-720.

52. Imoto S, Wada N, Murakami K et al. Prognosis of breast cancer patients treated with sentinel node biopsy in Japan. Jpn J Clin Oncol 2004;34:452-456.

53. Torrenga $\mathrm{H}$, Fabry $\mathrm{H}$, van der Sijp JR et al. Omitting axillary lymph node dissection in sentinel node negative breast cancer patients is safe: a long term follow-up analysis. J Surg Oncol 2004;88:4-7.

54. Naik AM, Fey J, Gemignani $M$ et al. The risk of axillary relapse after sentinel lymph node biopsy for breast cancer is comparable with that of axillary lymph node dissection: a follow-up study of 4008 procedures. Ann Surg 2004;240:462-468.

55. van der Vegt $B$, Doting $\mathrm{MH}$, Jager PL et al. Axillary recurrence after sentinel lymph node biopsy. Eur J Surg Oncol 2004;30:715-720.

56. van Wessem KJ, Meijer WS. Sentinel lymph node biopsy in breast cancer: results of intradermal periareolar tracer injection and follow-up of sentinel lymph node-negative patients. Breast 2004;13:290-296.

57. Badgwell BD, Povoski SP, Abdessalam SF et al. Patterns of recurrence after sentinel lymph node biopsy for breast cancer. Ann Surg Oncol 2003;10:376-380.

58. Blanchard DK, Donohue JH, Reynolds C et al. Relapse and morbidity in patients undergoing sentinel lymph node biopsy alone or with axillary dissection for breast cancer. Arch Surg 2003;138:482-487.

59. Estourgie SH, Nieweg OE, Valdes Olmos RA et al. Eight false negative sentinel node procedures in breast cancer: what went wrong? Eur J Surg Oncol 2003;29:336-340.

60. Ponzone R, Biglia N, Maggiorotto F et al. Sentinel node dissection as definitive treatment for node negative breast cancer patients. Eur J Surg Oncol 2003;29:703-706.

61. Chung MA, Steinhoff MM, Cady B. Clinical axillary recurrence in breast cancer patients after a negative sentinel node biopsy. Am J Surg 2002;184:310-314.

62. Hansen NM, Grube BJ, Giuliano AE. The time has come to change the algorithm for the surgical management of early breast cancer. Arch Surg 2002;137:1131-1135.

63. Loza J, Colo F, Nadal J et al. Axillary recurrence after sentinel node biopsy for operable breast cancer. Eur J Surg Oncol 2002;28:897-898.

64. Shivers S, Cox C, Leight $G$ et al. Final results of the Department of Defense multicenter breast lymphatic mapping trial. Ann Surg Oncol 2002;9:248-255.

65. Bilimoria KY, Bentrem DJ, Hansen NM et al. Comparison of sentinel lymph node biopsy alone and completion axillary lymph node dissection for node-positive breast cancer. J Clin Oncol 2009;27:2946-2953.

66. Hwang RF, Gonzalez-Angulo AM, Yi M et al. Low locoregional failure rates in selected breast cancer patients with tumor-positive sentinel lymph nodes who do not undergo completion axillary dissection. Cancer 2007;110:723-730.

67. Park J, Fey JV, Naik AM et al. A declining rate of completion axillary dissection in sentinel lymph nodepositive breast cancer patients is associated with the use of a multivariate nomogram. Ann Surg 2007; 245:462-468.

68. Pejavar S, Wilson LD, Haffty BG. Regional nodal recurrence in breast cancer patients treated with conservative surgery and radiation therapy (BCS + RT). Int J Radiat Oncol Biol Phys 2006;66:13201327. 
69. Haid A, Knauer M, Koberle-Wuhrer $R$ et al. Medium-term follow-up data after sentinel node biopsy alone for breast cancer. Eur J Surg Oncol 2006;32:1180-5118.

70. Chagpar A, Middleton LP, Sahin AA et al. Clinical outcome of patients with lymph node-negative breast carcinoma who have sentinel lymph node micrometastases detected by immunohistochemistry. Cancer 2005;103:1581-1586.

71. Fant JS, Grant MD, Knox SM et al. Preliminary outcome analysis in patients with breast cancer and a positive sentinel lymph node who declined axillary dissection. Ann Surg Oncol 2003;10:126-130.

72. Guenther JM, Hansen NM, Di Fronzo LA et al. Axillary dissection is not required for all patients with breast cancer and positive sentinel nodes. Arch Surg 2003;138:52-56.

73. Green FL, Page DL, Fleming ID et al. American Joint Committee on Cancer Staging Manual, 6th edition. Springer, Philadelphia, PA. 2002.

74. Orr RK. The impact of prophylactic axillary node dissection on breast cancer survival-a Bayesian meta-analysis. Ann Surg Oncol 1999;6:109-116.

75. White RE, Vezeridis MP, Konstadoulakis M et al. Therapeutic options and results for the management of minimally invasive carcinoma of the breast: influence of axillary dissection for treatment of T1a and T1b lesions. J Am Coll Surg 1996;183:575-582.

76. Bland $\mathrm{KI}$, Scott-Conner $\mathrm{CEH}$, Menck $\mathrm{H}$ et al. Axillary dissection in breast-conserving surgery for stage I and II breast cancer: a National Cancer Data Base study of patterns of omission and implications for survival. J Am Coll Surg 1999;188:586-596.

77. Weir L, Speers C, D' yachkova $Y$ et al. Prognostic significance of the number of axillary lymph nodes removed in patients with node-negative breast cancer. J Clin Oncol 2002;20:1793-1799.

78. Krag DN, Single RM. Breast cancer survival according to number of nodes removed. Ann Surg Oncol 2003;10:1152-1159.

79. Polednak AP. Survival of lymph node-negative breast cancer patients in relation to number of lymph nodes examined. Ann Surg 2003;237:163-167.

80. Axelsson CK, During M, Christiansen PM et al. Impact on regional recurrence and survival of axillary surgery in women with node-negative primary breast cancer. Br J Surg 2009;96:40-46.

81. Krag DN. Primary outcome results of NSABP B-32, a randomized phase III clinical trial to compare sentinel node resection (SNR) to conventional axillary dissection (AD) in clinically node-negative breast cancer patients. 2010 ASCO annual meeting. Chicago, 2010, \#CRA505 Nodes Removed. Ann Surg Oncol 2010;10:1152-1159.

82. Giuliano AE. ACOSOG Z0011: a randomized trial of axillary node dissection in women with clinical T1-2 NO MO breast cancer who have a positive sentinel node, 2010 ASCO annual meeting. Chicago, 2010, \#CRA506.

83. Rescigno J, Zampell JC, Axelrod D. Patterns of axillary surgical care for breast cancer in the era of sentinel lymph node biopsy. Ann Surg Oncol 2009;16:687-696.

84. Tjan-Heijnen VC, Pepels MJ, de Boer M, et al. Impact of omission of completion axillary lymph node dissection (cALND) or axillary radiotherapy (ax RT) in breast cancer patients with micrometastases (pN1mi) or isolated tumor cells (pNO[i ?]) in the sentinel lymph node (SN): results from the MIRROR study, American Society of Clinical Oncology 2009. Orlando, FL, 2009, CRA506.

85. de Boer $\mathrm{M}$, van Deurzen $\mathrm{CH}$, van Dijck JA et al. Micrometastases or isolated tumor cells and the outcome of breast cancer. N Engl J Med 2009;361:653-663.

86. Bolster MJ, Peer PG, Bult $P$ et al. Risk factors for non-sentinel lymph node metastases in patients with breast cancer. The outcome of a multi-institutional study. Ann Surg Oncol 2007;14:181-189.

87. van Deurzen $\mathrm{CH}$, de Boer M, Monninkhof EM et al. Non-sentinel lymph node metastases associated with isolated breast cancer cells in the sentinel node. J Natl Cancer Inst 2008;22:1574-1580. 


\section{Chapter}

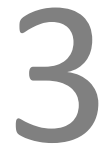

\section{Regional recurrence in breast cancer patients with sentinel node micrometastases and isolated} tumor cells

M.J.A.E. Pepels, M. de Boer, P. Bult, J.A.A.M. van Dijck, C.H.M. van Deurzen, M.B.E. Menke-Pluymers, P.J. van Diest, G.F. Borm, V.C.G. Tjan-Heijnen Ann Surg 2012;255:116-121 


\section{Abstract}

\section{Objective}

The impact of axillary treatment in daily practice on 5-year regional recurrence rate in breast cancer patients with isolated tumor cells or micrometastases in the sentinel node.

\section{Background}

Axillary dissection is recommended in patients with tumor-positive sentinel nodes. But, in recent studies regional recurrence rates seemed low if dissection was omitted.

\section{Methods}

We identified all patients in the Netherlands with invasive breast cancer who had a sentinel node biopsy before 2006, favorable primary tumor characteristics, and nodenegative disease, isolated tumor cells or micrometastases as final nodal status. The primary endpoint was regional recurrence rate. To investigate differences in recurrence rates between patients with and without axillary treatment, a proportional hazard regression was carried out correcting for potential confounders.

\section{Results}

In total, 857 patients with node-negative disease, 795 patients with isolated tumor cells and 1028 patients with micrometastases in the sentinel node were included. Without axillary treatment, the 5-year regional recurrence rates were $2.3 \%, 2.0 \%$ and $5.6 \%$, respectively. Compared with patients who underwent axillary treatment, the adjusted hazard ratio for regional recurrence in patients who underwent a sentinel node procedure only was $1.08(95 \% \mathrm{Cl} 0.23-4.98)$ for node-negative disease, 2.39 $(95 \% \mathrm{Cl}$ 0.67-8.48) for isolated tumor cells, and $4.39(95 \% \mathrm{Cl} 1.46-13.24)$ for micrometastases. Doubling of tumor size, grade 3 and negative hormone receptor status were also significantly associated with recurrence.

\section{Conclusion}

Not performing axillary treatment in patients with sentinel node micrometastases is associated with an increased 5-year regional recurrence rate. Axillary treatment is recommended in patients with sentinel node micrometastases and unfavorable tumor characteristics. 


\section{Introduction}

The axillary lymph node status is the most important prognostic factor in patients with breast cancer ${ }^{1}$. Since the late 1990s, the sentinel lymph node procedure was introduced in clinically node negative early breast cancer. The sentinel node is the first lymph node or nodes draining the primary tumor site. If the sentinel node is negative, the probability of additional involved non-sentinel nodes is assumed to be $5-10 \%$, and the remaining axillary nodes do not need to be explored ${ }^{2}$. To prevent false-negative results, the sentinel node is intensively examined with the use of step sectioning and/or immunohistochemical staining, with an increased detection rate of small nodal metastases. Since 2002, isolated tumor cells ( $\mathrm{pNO}(\mathrm{i}+)$, deposits $\leq 0.2 \mathrm{~mm}$ ) and micrometastases (pN1mi, deposits $>0.2-\leq 2.0 \mathrm{~mm}$ ) are defined as separate categories in the American Joint Committee on Cancer (AJCC) Cancer Staging Manual ${ }^{3}$.

One pivotal question, to justify the intensified work-up of the sentinel node, is whether these small nodal metastases are of prognostic relevance. A recent systematic review on studies from the pre-sentinel node era showed that the presence of metastases $2 \mathrm{~mm}$ or less in diameter in axillary lymph nodes was associated with poorer overall survival ${ }^{4}$. In addition, we demonstrated in the Dutch MIRROR (Micrometastases and Isolated tumor cells: Relevant and Robust or Rubbish?) cohort study that isolated tumor cells and micrometastases detected after a sentinel node procedure were also of significant prognostic relevance in patients not receiving adjuvant systemic therapy ${ }^{5}$. Furthermore, we showed that prognosis was improved in patients who received adjuvant systemic therapy.

A second relevant question is whether the detection of sentinel node isolated tumor cells or micrometastases warrants further axillary treatment. All patients in the MIRROR study underwent a sentinel node biopsy, in some followed by a completion axillary lymph node dissection or axillary irradiation. Nearly $50 \%$ of patients with isolated tumor cells in the sentinel nodes and approximately $15 \%$ of patients with micrometastases had not received additional axillary treatment. In $8 \%$ of patients with isolated tumor cells or micrometastases, axillary treatment consisted of axillary irradiation only.

The primary goal of the current analysis of the MIRROR cohort study was to determine the impact of axillary treatment (axillary lymph node dissection or axillary irradiation) on 5-year regional recurrence rate in patients with isolated tumor cells or micrometastases in the sentinel node. Secondary aims were to determine the efficacy of axillary irradiation compared to axillary lymph node dissection, and to examine other factors predictive for regional recurrence. 


\section{Methods}

\section{Patients}

Patient characteristics were largely described previously ${ }^{5}$. In summary, we identified all female patients who underwent surgery for early-stage breast cancer, irrespective of type of histology, and who had undergone a sentinel node biopsy between 1997 and 2005 from the Netherlands Cancer Registry. We included patients with favorable primary tumor characteristics according to the Dutch guidelines, version 2002, that is, tumor size of $1 \mathrm{~cm}$ or smaller, irrespective of grade, or tumor size 1-3 cm and grade 1 or $2^{6}$. Of these, we selected patients with isolated tumor cells or micrometastases as final nodal status after sentinel node biopsy and optionally additional axillary treatment (dissection or irradiation). All patients with sentinel node or non-sentinel node macrometastases were excluded. Furthermore, we randomly selected a control group of patients with node-negative disease who underwent a sentinel node procedure in the year 2000 or 2001. All 113 Dutch hospitals and 60 pathology laboratories participated in the study (see Table 1 of the Supplementary Appendix). The Review Board of the Netherlands Cancer Registry approved this study.

\section{Data collection}

Registration clerks of all $(n=8)$ comprehensive cancer centers in the Netherlands collected data with respect to patient and tumor characteristics, breast surgery, sentinel node procedure, axillary lymph node dissection, axillary irradiation, adjuvant systemic therapy, and regional recurrences during follow-up.

\section{Pathology Review}

Three pathologists who are specialized in breast pathology (C. van Deurzen., P. van Diest, and P. Bult) reviewed all available original slides of the sentinel nodes and positive non-sentinel nodes. These slides included haematoxylin-eosin stained slides, slides stained for immunohistochemistry, and frozen sections. Neither additional sections nor new immunohistochemical stains were performed. Grade of the primary tumor was assessed, if not available from the original pathology report.

As previously reported, almost all participating pathology laboratories used a protocol in which the sentinel node was step-sectioned at least at every $150 \mu \mathrm{m}$ and a minimum of three levels, using keratin immunohistochemical staining if the haematoxylin-eosin stain was negative. In contrast, the non-sentinel nodes were macroscopically sectioned every $2-5 \mathrm{~mm}$, with one haematoxylin-eosin stained section per slice ${ }^{5}$. Tumor deposits were classified according to the 6th AJCC Cancer Staging Manual $^{3}$. 


\section{Cohorts}

For this present analysis, patients were categorized by their sentinel node status and by axillary treatment. We identified three cohorts. Cohort I consisted of patients with node-negative disease; cohort II consisted of patients with sentinel node isolated tumor cells; and cohort III consisted of patients with sentinel node micrometastases. All cohorts were divided into two subgroups consisting of patients with no axillary treatment, or axillary treatment consisting of axillary lymph node dissection or axillary irradiation. The choice of axillary treatment was at the discretion of the physician and the patient at that time.

\section{Endpoints}

To determine whether an association existed between lymph node status, axillary treatment, and regional recurrence, we compared the regional recurrence rate for each cohort in the subgroups with and without axillary treatment. The primary endpoint was the 5-year regional recurrence rate, involving axilla and infra- and supraclavicular sites. The time to regional recurrence was defined as the interval from the date of diagnosis to regional recurrence. If a patient had a local recurrence or a contralateral breast cancer (before a regional recurrence), the follow-up continued to assess the time of the first regional recurrence. That is, regional recurrence was not always a first event for the patient. If the patient had a combined local and regional recurrence, the primary endpoint was reached, as was also the case if a combined distant and regional recurrence was diagnosed. Also, if a regional recurrence was unexpectedly detected at surgery of a local recurrence, this was coded as a regional recurrence. Secondary aims were to determine the efficacy of axillary irradiation compared to completion axillary lymph node dissection with regard to regional recurrence rate and to examine other patient, tumor, and treatment-related factors predictive for regional recurrence.

\section{Statistical analysis}

To assess the primary and secondary goals, we used Cox proportional-hazards regression to evaluate the differences in occurrence of regional recurrences between axillary treated and untreated patients, adjusted for known prognostic clinical and pathological variables. These included age at diagnosis, histological grade, hormone receptor status, adjuvant systemic therapy, breast irradiation and $\log _{2}$ tumor size. We used a $\log _{2}$ transformation, because the corresponding coefficient in the Cox model will then correspond to the hazard ratio associated with a doubling of the tumor size, which makes the interpretation of the hazard ratio easier. In an additional analysis, we included date of biopsy in the model to investigate a possible change in recurrence rate over the 1997-2005 period. Two-sided 95\% confidence intervals (Cls) were calculated. 


\section{Results}

\section{Patients}

We identified 2707 women with early-stage breast cancer who were potentially eligible. For the present study, we excluded 27 patients $(0.08 \%)$ who received both axillary lymph node dissection and axillary irradiation, leaving 2680 women for analyses: 857 patients with node-negative disease, 795 patients with isolated tumor cells, and 1028 patients with micrometastases in the sentinel node. Of patients with a negative sentinel node, 732 patients (85\%) received no axillary therapy; the remaining 125 patients (15\%) underwent an axillary lymph node dissection during the sentinel node learning phase of a surgeon. Of patients with isolated tumor cells in the sentinel node, 345 patients (43\%) received no additional axillary therapy, 396 patients (50\%) underwent axillary lymph node dissection, and 54 patients (7\%) received axillary irradiation. Of patients with micrometastases in the sentinel node, 141 patients (14\%) received no further axillary therapy, 793 patients (77\%) underwent axillary lymph node dissection, and 94 patients $(9 \%)$ received axillary irradiation.

Table 3.1 shows the baseline characteristics of the three nodal status cohorts. In the node-negative cohort, compared to the patient group without additional axillary treatment, patients with axillary treatment had significantly larger primary tumor size, had more frequently undergone mastectomy instead of breast conserving therapy, and had less frequently undergone irradiation of the breast. In both the sentinel node isolated tumor cells cohort and the sentinel node micrometastases cohort, compared to the patients without additional axillary treatment, patients with axillary treatment more frequently received adjuvant systemic therapy.

The median duration of follow-up was 5.1 years (range, 0.04 to 9.3). Ninety-five (3.5\%) patients were lost to follow-up 0.04 to 5.6 years after diagnosis. At the last date of follow-up $97.5 \%$ were free of regional recurrence. Regional recurrence was in $91 \%$ of patients the first recurrence, and in $52 \%$ of patients the only presenting recurrence.

\section{No axillary treatment vs. axillary treatment in patients with negative sentinel nodes}

In patients with negative sentinel nodes, the 5-year regional recurrence rate was $2.3 \%$ in patients without axillary treatment, and $1.6 \%$ in patients with axillary treatment (Figure 3.1A). After adjustment for age, tumor size, histological grade, hormone receptor status, adjuvant systemic therapy and irradiation of the breast, there was no difference in risk of regional recurrence in the no axillary treatment group versus the axillary treatment group (hazard ratio 1.08 ; 95\% confidence interval $[\mathrm{Cl}] 0.23-4.98$ ) (Table 3.2). 
Table 3.1 Baseline characteristics of 2680 Patients with early stage breast cancer according to axillary lymph node status.

\begin{tabular}{|c|c|c|c|c|c|c|}
\hline \multirow[b]{2}{*}{ Characteristic } & \multicolumn{2}{|c|}{$\mathrm{NO}(\mathrm{i}-)(\mathrm{sn})$} & \multicolumn{2}{|c|}{$\mathrm{NO}(\mathrm{i}+)(\mathrm{sn})$} & \multicolumn{2}{|c|}{$\mathrm{N} 1(\mathrm{mi})(\mathrm{sn})$} \\
\hline & $\begin{array}{c}\text { No axillary } \\
\text { treatment } \\
(\mathrm{n}=732) \\
\end{array}$ & $\begin{array}{c}\text { Axillary } \\
\text { treatment } \\
(n=125)\end{array}$ & $\begin{array}{c}\text { No axillary } \\
\text { treatment } \\
(n=345)\end{array}$ & $\begin{array}{c}\text { Axillary } \\
\text { treatment } \\
(n=450)\end{array}$ & $\begin{array}{c}\text { No axillary } \\
\text { treatment } \\
(n=141)\end{array}$ & $\begin{array}{c}\text { Axillary } \\
\text { treatment } \\
(\mathrm{n}=887)\end{array}$ \\
\hline \multicolumn{7}{|c|}{$\begin{array}{l}\text { No. of sentinel lymph nodes } \\
\text { removed }\end{array}$} \\
\hline median & 2 & 1 & 2 & 2 & 2 & 2 \\
\hline interquartile range & 1,2 & 1,2 & 1,3 & 1,2 & 1,3 & 1,3 \\
\hline \multicolumn{7}{|l|}{ Age at diagnosis - year } \\
\hline median & 59 & 61 & 58 & 57 & 59 & 56 \\
\hline range & $30-89$ & $34-87$ & $34-93$ & $31-89$ & $36-88$ & $32-89$ \\
\hline \multicolumn{7}{|l|}{ Tumor size-no. (\%) } \\
\hline$\leq 1 \mathrm{~cm}$ & $310(42 \%)$ & 37 (30\%) & $91(27 \%)$ & $125(28 \%)$ & $34(24 \%)$ & $197(22 \%)$ \\
\hline$>1$ to $\leq 2 \mathrm{~cm}$ & $375(51 \%)$ & 73 (58\%) & 201 (58\%) & 239 (53\%) & $80(57 \%)$ & 539 (61\%) \\
\hline$>2$ to $\leq 3 \mathrm{~cm}$ & $47(7 \%)$ & $15(12 \%)$ & $53(15 \%)$ & $86(19 \%)$ & $27(19 \%)$ & $151(17 \%)$ \\
\hline \multicolumn{7}{|l|}{ Tumor grade-no. (\%) } \\
\hline 1 & $264(37 \%)$ & $54(44 \%)$ & 117 (35\%) & 137 (31\%) & 41 (30\%) & 287 (33\%) \\
\hline 2 & $408(57 \%)$ & 66 (53\%) & $211(62 \%)$ & $283(64 \%)$ & 93 (67\%) & $543(62 \%)$ \\
\hline 3 & $45(6 \%)$ & $4(3 \%)$ & $11(3 \%)$ & $22(5 \%)$ & $5(3 \%)$ & $45(5 \%)$ \\
\hline \multicolumn{7}{|c|}{$\begin{array}{l}\text { Hormone receptor status- } \\
\text { no. }(\%)\end{array}$} \\
\hline negative & $42(6 \%)$ & $9(8 \%)$ & $22(7 \%)$ & $33(7 \%)$ & $11(8 \%)$ & $41(5 \%)$ \\
\hline positive & 661 (94\%) & $100(92 \%)$ & 311 (93\%) & 407 (93\%) & 130 (92\%) & 834 (95\%) \\
\hline \multicolumn{7}{|l|}{$\begin{array}{l}\text { Type of breast surgery- } \\
\text { no. (\%) }\end{array}$} \\
\hline mastectomy & $167(23 \%)$ & 57 (46\%) & 109 (32\%) & 140 (31\%) & $40(28 \%)$ & 267 (30\%) \\
\hline breast conserving & $565(77 \%)$ & 68 (54\%) & $236(68 \%)$ & $310(69 \%)$ & 101 (72\%) & $620(70 \%)$ \\
\hline \multicolumn{7}{|l|}{$\begin{array}{l}\text { Radiation of the breast- } \\
\text { no. (\%) }\end{array}$} \\
\hline no & $185(25 \%)$ & 59 (47\%) & $118(34 \%)$ & 136 (30\%) & 48 (34\%) & $270(30 \%)$ \\
\hline yes & 547 (75\%) & 66 (53\%) & 227 (66\%) & 314 (70\%) & 93 (66\%) & 617 (70\%) \\
\hline \multicolumn{7}{|c|}{$\begin{array}{l}\text { Adjuvant systemic therapy- } \\
\text { no (\%) }\end{array}$} \\
\hline no systemic therapy & $732(100 \%)$ & $125(100 \%)$ & $260(75 \%)$ & 239 (53\%) & 73 (52\%) & $283(32 \%)$ \\
\hline chemotherapy & $0(0 \%)$ & $0(0 \%)$ & $4(1 \%)$ & $14(3 \%)$ & $3(2 \%)$ & $32(3 \%)$ \\
\hline hormonal therapy & $0(0 \%)$ & $0(0 \%)$ & $67(20 \%)$ & 143 (32\%) & $53(38 \%)$ & 349 (39\%) \\
\hline both & $0(0 \%)$ & $0(0 \%)$ & $14(4 \%)$ & $54(12 \%)$ & $12(8 \%)$ & $223(25 \%)$ \\
\hline
\end{tabular}

\section{No axillary treatment vs. axillary treatment for sentinel node isolated tumor cells}

In patients with isolated tumor cells in the sentinel node, the 5-year regional recurrence rate was $2.0 \%$ in patients without axillary treatment, and $0.9 \%$ in patients with axillary treatment (Figure 3.1B). The adjusted hazard ratio for regional recurrence among women who did not receive further axillary treatment was 2.39 (95\% Cl 0.678.48) (Table 3.2) as compared to women who did receive axillary treatment. 


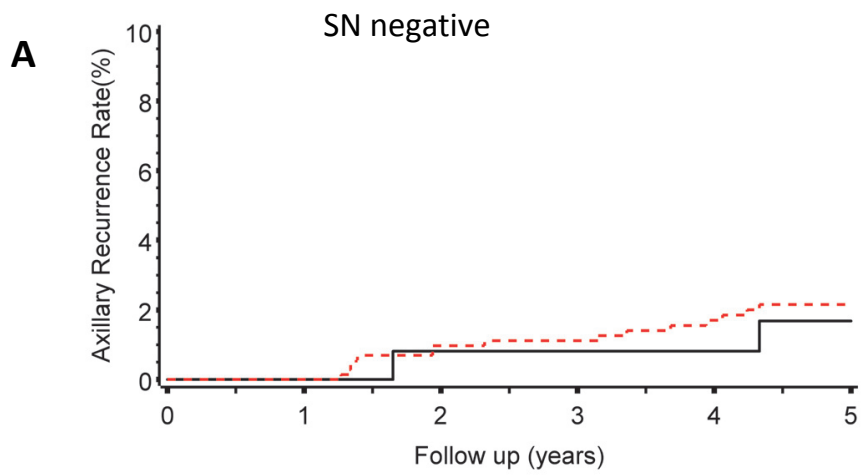

Treatment - Axillary treatment - No axillary treatment

$\mathrm{SN}$ isolated tumor cells

B

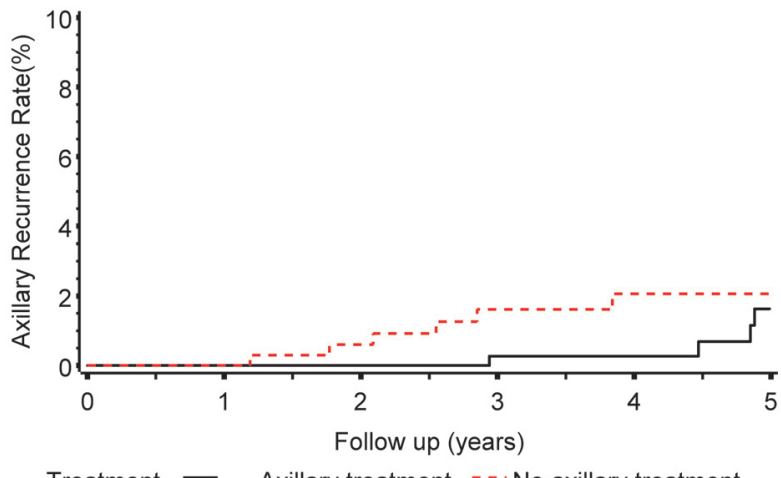

Treatment - Axillary treatment - No axillary treatment

SN micrometastases

C

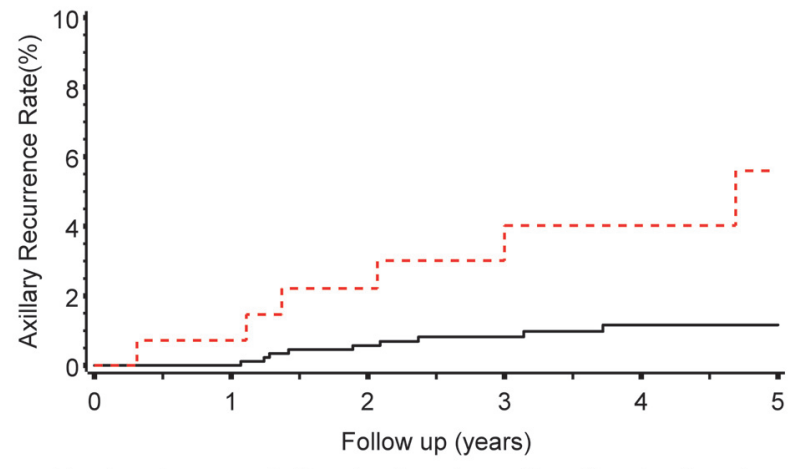

Treatment - Axillary treatment - No axillary treatment

Figure 3.1 Axillary recurrence rates among patients with early breast cancer with node-negative disease (Panel A), with sentinel node (SN) isolated tumor cells (Panel B), and with sentinel node micrometastases (Panel C), who did or did not receive axillary treatment. 


\section{No axillary treatment vs. axillary treatment for sentinel node micrometastases}

In patients with micrometastases in the sentinel node, the 5-year regional recurrence rate was $5.6 \%$ if no axillary treatment was carried out (Figure 1C), 1.0\% in case of completion axillary lymph node dissection, and $0 \%$ in case of axillary irradiation. In these patients, omission of axillary treatment resulted in a significantly increased hazard ratio for regional recurrence of 4.39 (95\% Cl 1.46-13.24) (Table 3.2), as compared to patients with axillary treatment, after adjustment for age, tumor size, histological grade, hormone receptor status, adjuvant systemic therapy and irradiation of the breast.

\section{Efficacy of axillary irradiation compared to axillary lymph node dissection}

None of the 54 patients with sentinel node isolated tumor cells and none of the 94 patients with sentinel node micrometastases treated with axillary irradiation had a regional recurrence at 5-year follow-up. In contrast, $1.0 \%$ of 396 patients with sentinel node isolated tumor cells and $1.1 \%$ of 793 patients with sentinel node micrometastases treated with axillary lymph node dissection had a regional recurrence. However, due to low numbers we were not able to assess hazard ratios for regional recurrence rates in case of axillary irradiation as compared to axillary lymph node dissection.

\section{Other risk factors associated with regional recurrence in patients with sentinel node micrometastases not receiving additional axillary treatment}

In patients with micrometastases in the sentinel node, doubling of tumor size (hazard ratio, 7.91; 95\% Cl 1.36-45.91), histological grade 3 (hazard ratio, 25.05; 95\% Cl 1.26497.18) and negative hormone receptor status (hazard ratio, 4.96; 95\% Cl 1.48-16.62) were significantly associated with regional recurrences. No adjuvant systemic therapy (hazard ratio 1.36; $95 \% \mathrm{Cl} 0.47-3.99$ ) and breast irradiation (hazard ratio $1.01 ; 95 \% \mathrm{Cl}$ 0.36-2.88) were not significantly associated with regional recurrences (Table 3.2). 
Table 3.2 Cox proportional-hazards model of the effect of variables on regional recurrences in patients with negative sentinel nodes, patients with sentinel node isolated tumor cells, and patients with sentinel node micrometastases.

\begin{tabular}{|c|c|c|c|c|c|c|}
\hline \multirow[b]{2}{*}{ Variable } & \multicolumn{2}{|c|}{$\mathrm{NO}(\mathrm{i}-)(\mathrm{sn})$} & \multicolumn{2}{|c|}{$\mathrm{NO}(\mathrm{i}+)(\mathrm{sn})$} & \multicolumn{2}{|c|}{$\mathrm{N} 1(\mathrm{mi})(\mathrm{sn})$} \\
\hline & $\begin{array}{l}\text { Hazard } \\
\text { ratio for } \\
\text { regional } \\
\text { recurrence }\end{array}$ & $95 \% \mathrm{Cl}$ & $\begin{array}{l}\text { Hazard } \\
\text { ratio for } \\
\text { regional } \\
\text { recurrence }\end{array}$ & $95 \% \mathrm{Cl}$ & $\begin{array}{l}\text { Hazard } \\
\text { ratio for } \\
\text { regional } \\
\text { recurrence }\end{array}$ & $95 \% \mathrm{Cl}$ \\
\hline No axillary treatment & 1.08 & $0.23-4.98$ & 2.39 & $0.67-8.48$ & 4.39 & $1.46-13.24$ \\
\hline Young age at diagnosis (per year) & 1.08 & $1.02-1.12$ & 1.06 & $1.00-1.12$ & 1.05 & $1.00-1.10$ \\
\hline Doubling of tumor diameter & 1.22 & $0.48-3.05$ & 3.80 & $0.74-19.42$ & 7.91 & $1.36-45.91$ \\
\hline Histological grade 2 vs 1 & NE & & 1.60 & $0.32-7.96$ & 4.90 & $0.63-38.33$ \\
\hline Histological grade 3 vs 1 & NE & & NE & & 25.05 & $1.26-497.18$ \\
\hline Negative hormone receptor status & 1.23 & $0.35-4.39$ & 5.92 & $1.52-23.00$ & 4.96 & $1.48-16.62$ \\
\hline No adjuvant systemic therapy & $\mathrm{NE}$ & & 1.03 & $0.28-3.85$ & 1.36 & 0.47-3.99 \\
\hline No breast irradiation & 1.96 & $0.73-5.29$ & 1.54 & $0.44-5.39$ & 1.01 & $0.36-2.88$ \\
\hline
\end{tabular}

$\mathrm{NE}=$ not estimable

\section{Discussion}

In the MIRROR study, we evaluated whether omitting axillary treatment in patients with early breast cancer having no tumor cells, isolated tumor cells or micrometastases in their sentinel nodes was associated with regional recurrence. This study was based on a nationwide Dutch cohort study, reflecting daily clinical practice, in 2680 patients in which central pathology review of all sentinel nodes was carried out. Compared with patients who underwent axillary treatment, the adjusted hazard ratio for regional recurrence in patients who underwent only a sentinel node procedure was 1.08 (95\% Cl 0.23-4.98) for node-negative disease, 2.39 (95\% Cl 0,67$8,48)$ for patients with isolated tumor cells in the sentinel node(s), and $4.39(95 \% \mathrm{Cl}$ 1,46-13.24) for patients with micrometastases in the sentinel node(s). The efficacy of axillary irradiation compared with axillary lymph node dissection could not be assessed due to low numbers. In patients with micrometastases in the sentinel node, doubling of tumor size, histological grade 3 , and negative hormone receptor status were significantly associated with regional recurrences.

To deal with confounders, we corrected for factors that might have influenced the decision to carry out additional axillary treatment, which was at the discretion of the physician and the patient at that time. These factors were age at diagnosis, tumor size, histological grade, hormone receptor status, irradiation of the breast and use of adjuvant systemic therapy. Previous investigators have highlighted the importance of the learning curve in the sentinel node procedure. For that reason, we also carried out an exploratory analysis with the year of diagnosis as additional covariate, but this did not change the results (data not further shown). Notably, omission of axillary treatment in the presence of sentinel node isolated tumor cells or micrometastases was increasingly the case in the more recent years of the cohort study. 
As can be expected, the risk of regional recurrence in our cohort was associated with risk factors known for non-sentinel node involvement ${ }^{7}$. Unfortunately, we were not able to develop a predictive model to identify patients who are more at risk to develop a recurrence, but, obviously by taking both sentinel node and primary tumor characteristics into account one can individualize treatment recommendations. Based on the results obtained in the Cox-proportional hazards model, one can consider omission of axillary treatment in patients with sentinel node micrometastases who have small, low grade, hormone receptor positive tumors. In remaining patients, the (small) increased risk of recurrence without axillary treatment should be offset against the increased risk of shoulder and arm morbidity if a level I-II axillary lymph node dissection is performed.

In sentinel node negative disease, we did not observe an increased risk of regional recurrence if axillary treatment was omitted, which is in agreement with results seen in randomized trials ${ }^{8-11}$. The relevance of isolated tumor cells with respect to the risk of regional recurrence is considered to be of uncertain significance, not supporting routine use of axillary treatment, in contrast to recommendations in sentinel node micrometastases, according to American Society of Clinical Oncology (ASCO) guidelines ${ }^{2}$. We have noticed differences in daily practice between hospitals within The Netherlands. We showed that half of the patients with isolated tumor cells in the sentinel node did not undergo additional axillary treatment, whereas $15 \%$ of patients with sentinel node micrometastases did not receive further axillary treatment. Recently, a survey among ASCO members revealed that in the USA axillary lymph node dissection for sentinel node micrometastases was routinely recommended by only $23 \%$ of surgeons, $23 \%$ of medical oncologists and $15 \%$ of radiation oncologists ${ }^{12}$. Radiation oncologists were more likely than medical oncologists or surgeons to consider axillary radiation instead of axillary lymph node dissection for sentinel node micrometastases.

In single centre and multi centre series, regional recurrence rates in sentinel node positive patients without axillary treatment seemed not worse as compared to results in sentinel node negative patients not receiving additional axillary treatment ${ }^{13}$. However, these low recurrence rates in sentinel node positive patients may partly be explained by underreporting to cancer registries ${ }^{14}$, patient selection ${ }^{15}$, the classification of isolated tumor cells as "micrometastases"14,16-20, and use of axillary irradiation $^{21}$. Of note, the Memorial Sloan-Kettering Cancer Center (MSKCC) reported that in patients identified with a positive sentinel node by haematoxylin-eosin examination who did not undergo completion axillary lymph node dissection, the axillary recurrence rate was $5 \%$ at a median follow-up of only 23 months, even though these were highly selected patients ${ }^{15}$.

Recently, the results from the ACOSOG trial 20011 were published ${ }^{22,23}$. In this study, patients with one or two haematoxylin-eosin positive sentinel nodes were randomized between axillary lymph node dissection (38\% micrometastases) or no further treatment of the axilla ( $45 \%$ micrometastases). In sharp contrast to our study 
and the observations in the MSKCC trial, only $0.9 \%$ regional recurrences with sentinel node alone as compared to $0.5 \%$ with axillary lymph node dissection were reported after a median follow up of 6.3 years. Important to note, in our study only $48 \%$ of patients with sentinel node micrometastases and none of the patients with nodenegative disease, who did not undergo axillary treatment, had received adjuvant systemic therapy whereas in the ACOSOG Z0011 study $97 \%$ of patients who had not undergone axillary treatment had received adjuvant systemic therapy. In our study, omission of systemic therapy resulted in a non-significant increase of number of regional recurrences, comparable with evidence from the literature ${ }^{24}$. This nonsignificant increase was seen, even though the majority of patients who had received systemic therapy had only received endocrine therapy. Therefore, if omission of axillary treatment is considered, the use of adjuvant systemic therapy should be considered. In particular, this is relevant in countries using conservative adjuvant systemic therapy guidelines.

Further, only patients who were treated with breast-conserving therapy were included in the Z0011 trial. Previously, it was shown that with opposing tangential field irradiation as part of breast-conserving therapy "only" $55 \%$ of level I and II nodes received an adequate irradiation dose $\mathrm{e}^{25}$. Yet, this inadequate dose may have a potential role on regional recurrence rate. The randomized NSABP B-06 study showed a regional recurrence rate of $4.5 \%$ after breast radiotherapy compared to $7.2 \%$ in the absence of breast radiotherapy ${ }^{26}$. In another trial, $4 \%$ of patients receiving whole breast radiotherapy had an axillary recurrence versus 14\% in patients in whom local fields were used ${ }^{27}$. These findings suggest that the nodes at greatest risk of involvement in early-stage breast cancer patients treated with breast-conserving treatment are often included in standard breast tangential fields. This may have had major implications for the outcome of the $Z 0011$ trial $^{22,23}$. So, for implementation in daily practice, it is important to stress that the excellent results of the Z0011 trial may only be applicable for women who have low-volume nodal disease, receiving adjuvant systemic therapy and breast conserving treatment with tangential irradiation fields. In the MIRROR study, a number of patients with isolated tumor cells or micrometastases in the sentinel node received axillary irradiation instead of axillary surgery. In none of the 54 patients with isolated tumor cells in the sentinel node and the 94 patients with sentinel node micrometastases who were treated with axillary irradiation, regional recurrences occurred. The absence of regional recurrences in patients treated with axillary irradiation is challenging with respect to the current recommendation of axillary lymph node dissection in node positive patients, including those with micrometastases ${ }^{2}$. Unfortunately, we were not able to perform any meaningful statistical analysis on the differential impact of type of axillary treatment, as the number of patients in our cohort study treated with axillary irradiation was quite small. An ongoing prospective study on this topic is the European After Mapping the Axilla: Radiotherapy Or Surgery?, trial $^{28}$. 
The most important issue is, of course, not the occurrence of a relapse, but whether this relapse is associated with poorer survival. In a meta-analysis before the sentinel node-era, it was shown that omission of axillary lymph node dissection in clinically node-negative patients was associated with reduction in overall survival of about $5 \%$ after 5 to 10 years of follow-up ${ }^{29}$. However, in these older studies relatively few patients had T1 tumors, the percentage of patients with pathologically tumor-positive lymph nodes was quite high, and essentially none of the patients were treated with systemic therapy, in contrast to current practice. The Early Breast Cancer Trialists' Collaborative Group found that variations in local treatment had a definite, although moderate effect on breast cancer mortality by 15 years ${ }^{24}$. Recently, it was reported that with increased use of adjuvant systemic therapy this ratio changed from $4: 1$ to $2: 1$, that is for every two locoregional recurrences avoided, about one breast cancer death over the next 15 years is prevented ${ }^{30}$. The 5 -year overall survival in the 20011 study was not different for patients who underwent nodal dissection or only a sentinel node procedure, as could be expected from the observed comparable regional recurrence rates in these selected patients ${ }^{22,23}$. However, we showed that uncontrolled omission of axillary treatment resulted in an increased recurrence rate. These different findings stress the importance of first identifying the patients in whom a new strategy can safely be used, before it is broadly implemented in routine daily practice.

In conclusion, we found that omitting axillary treatment in patients with sentinel node micrometastases resulted in a significantly increased 5-year regional recurrence rate of $5.6 \%$ with an adjusted hazard ratio of 4.39 (95\% Cl 1.46-13.24). However, regional recurrence was also strongly associated with tumor size, grade and hormone receptor status. Use of systemic therapy and breast irradiation as part of breast conserving therapy may reduce the risk of recurrence. For an individual patient, all these factors have to be taken into account to offer the most optimal, personalized, treatment strategy. 


\section{References}

1. Fisher B, Bauer M, Wickerham DL, et al. Relation of number of positive axillary nodes to the prognosis of patients with primary breast cancer. An NSABP update. Cancer 1983;52:1551-1557.

2. Lyman GH, Giuliano AE, Somerfield MR, et al; American Society of Clinical Oncology. American Society of Clinical Oncology guideline recommendations for sentinel lymph node biopsy in early-stage breast cancer. J Clin Oncol. 2005;23;7703-7720.

3. Green FL, Page DL, Fleming ID, et al. American Joint Committee on Cancer Staging Manual.6th ed. Philadelphia, PA: Springer; 2002.

4. de Boer M, van Dijck JA, Bult P, Borm GF, Tjan-Heijnen VC. Breast cancer prognosis and occult lymph node metastases, isolated tumor cells, and micrometastases. J Natl Cancer Inst 2010:102:410-425.

5. de Boer $\mathrm{M}$, van Deurzen $\mathrm{CH}$, van Dijck JA, et al. Micrometastases or isolated tumor cells and the outcome of breast cancer. N Engl J Med 2009;361:653-663.

6. Rutgers EJ, Nortier JW, Tuut MK, et al; Nationaal Borstkanker Overleg Nederland; Kwaliteitsinstituut voor de Gezondheidszorg. Dutch Institute for Healthcare Improvement guidelines, "Treatment of breast cancer". Ned Tijdschr Geneeskd 2002;146:2144-2151.

7. Van Zee KJ, Kattan MW. Validating a predictive model for presence of additional disease in the nonsentinel lymph nodes of a woman with sentinel node positive breast cancer. Ann Surg Oncol 2007;14:2177-2178.

8. Krag DN, Anderson SJ, Julian TB, et al. Sentinel-lymph-node resection compared with conventional axillary-lymph-node dissection in clinically node-negative patients with breast cancer: overall survival findings from the NSABP B-32 randomised phase 3 trial. Lancet Oncol 2010;11:927-933.

9. Veronesi U, Paganelli G, Viale G, et al. Sentinel-lymph-node biopsy as a staging procedure in breast cancer: update of a randomised controlled study. Lancet Oncol 2006;7:983-990.

10. Canavese G, Catturich A, Vecchio C, et al. Sentinel node biopsy compared with complete axillary dissection for staging early breast cancer with clinically negative lymph nodes: results of randomized trial. Ann Oncol 2009;20:1001-1007.

11. Zavagno G, De Salvo GL, Scalco G, et al; GIVOM Trialists. A Randomized clinical trial on sentinel lymph node biopsy versus axillary lymph node dissection in breast cancer: results of the Sentinella/GIVOM trial. Ann Surg 2008;247:207-213.

12. Wasif N, Ye X, Giuliano AE. Survey of ASCO members on management of sentinel node micrometastases in breast cancer: variation in treatment recommendations according to specialty. Ann Surg Oncol 2009;16:2442-2449.

13. Pepels MJ, Vestjens JH, de Boer M, et al. Safety of avoiding routine use of axillary dissection in early stage breast cancer: a systematic review. Breast Cancer Res Treat 2011;125:301-313

14. Bilimoria KY, Bentrem DJ, Hansen NM, et al. Comparison of sentinel lymph node biopsy alone and completion axillary lymph node dissection for node-positive breast cancer. J Clin Oncol 2009;27:29462953.

15. Park J, Fey JV, Naik AM, Borgen PI, Van Zee KJ, Cody HS 3rd. A declining rate of completion axillary dissection in sentinel lymph node-positive breast cancer patients is associated with the use of a multivariate nomogram. Ann Surg 2007;245:462-468.

16. Bulte CS, van der Heiden-van der Loo M, Hennipman A. Axillary recurrence rate after tumour negative and micrometastatic positive sentinel node procedures in breast cancer patients, a population based multicenter study. Eur J Surg Oncol 2009;35:25-31.

17. Langer I, Marti WR, Guller U, et al M. Axillary recurrence rate in breast cancer patients with negative sentinel lymph node (SLN) or SLN micrometastases: prospective analysis of 150 patients after SLN biopsy. Ann Surg 2005;241:152-158.

18. Jeruss JS, Winchester DJ, Sener SF, et al. Axillary recurrence after sentinel node biopsy. Ann Surg Oncol 2005;12:34-40.

19. Fant JS, Grant MD, Knox SM, et al. Preliminary outcome analysis in patients with breast cancer and a positive sentinel lymph node who declined axillary dissection. Ann Surg Oncol 2003;10:126-130.

20. Guenther JM, Hansen NM, DiFronzo LA, et al. Axillary dissection is not required for all patients with breast cancer and positive sentinel nodes. Arch Surg 2003;138:52-56. 
21. Hwang RF, Gonzalez-Angulo AM, Yi M, et al. Low locoregional failure rates in selected breast cancer patients with tumor-positive sentinel lymph nodes who do not undergo completion axillary dissection. Cancer 2007;110:723-730.

22. Giuliano $A E, M c C a l l ~ L$, Beitsch $P$, et al. Locoregional Recurrence after sentinel lymph node dissection with or without axillary dissection in patients with sentinel lymph node metastases. The ACOSOG Z0011 randomized trial. Ann Surg 2010;252:426-432.

23. Giuliano $A E, M c C a l l ~ L$, Beitsch $P$, et al. Locoregional recurrence after sentinel lymph node dissection with or without axillary dissection in patients with sentinel lymph node metastases: the American College of Surgeons Oncology Group Z0011 randomized trial. Ann Surg 2010;252:426-432.

24. Early Breast Cancer Trialists' Collaborative Group (EBCTCG).Effects of chemotherapy and hormonal therapy for early breast cancer on recurrence and 15-year survival: an overview of the randomised trials. Lancet 2005;365:1687-1717.

25. Reed DR, Lindsley SK, Mann GN, et al. Axillary lymph node dose with tangential breast irradiation. Int J Rad Oncology Biol. Phys 2005;61:358-364.

26. Fisher B, Redmond C, Poisson R, et al. Eight-year resuls of a randomized clinical trial comparing total mastectomy and lumpectomy with or without irradiation in the treatment of breast cancer. $\mathrm{N}$ Engl J Med 1989;320:822-828.

27. Ribeiro GG, Dunn G, Swindell R, Harris M, Banerjee SS. Conservation of the breast using two different radiotherapy techniques: interim report of a clinical trial. Clin Oncol 1990;2:27-34.

28. Straver ME, Meijnen $P$, van Tienhoven $G$, et al. Role of axillary clearance after a tumor-positive sentinel node in the administration of adjuvant therapy in early breast cancer. J Clin Oncol 2010;28:731-737.

29. Orr RK. The impact of prophylactic axillary node dissection on breast cancer survival-a Bayesian metaanalysis. Ann Surg Oncol 1999;6:109-116.

30. Harris JR, Morrow M. How the ' $4: 1$ ratio' will likely change with increasingly effective systemic therapy San Antonio Breast Cancer Symposium. San Antonio, TX, 2009, MS3-2. 
Table S1. Individuals and institutions participating in this study.

Comprehensive Cancer Centre East, Nijmegen -C. Lennards; Canisius Wilhelmina Hospital, Nijmegen -C. Wauters, L. Strobbe; Radboud University Medical Centre, Nijmegen -Th. Wobbes; Maas Hospital, Boxmeer -A. Meersman; Rijnstate Hospital, Arnhem -F. van de Molengraft, R. Keus, J. Klinkenbijl; Gelderse Vallei Hospital, Ede -E. Balk, J. Kroeze; Zevenaar Hospital, Zevenaar -J. van Wijk; Slingeland Hospital, Doetinchem -E. Muller; St. Jansdal Hospital, Harderwijk -R. Tobon Morales; Comprehensive Cancer Centre Amsterdam, Amsterdam -O. Visser, W. Heijbroek-de Clerq; Academic Medical Centre, Amsterdam -M. van de Vijver, A. Kluit; IJsselmeerziekenhuizen, Lelystad -E. Neefjes-Borst, G. Algie; Onze Lieve Vrouwe Gasthuis, Amsterdam -E. Nijhuis, P. Borgstein; Flevo Hospital, Almere -M. Regoort; Medical Centre Alkmaar, Alkmaar -H.J. van Slooten, B. Langenhorst; Gemini Hospital, Den Helder -H. Tjeenk Willink; Westfries Gasthuis, Hoorn -J.W. Jansen, M. Govaert; Zaans Medical Centre, Zaandam -M. Flens, J. Oomen; BovenIJ Hospital, Amsterdam -R. Klicks; Waterland Hospital, Purmerend -L. de Widt-Levert; Netherlands Cancer Institute/Antoni van Leeuwenhoek Hospital, Amsterdam -H. van Boven, J. Westerga; Slotervaart Hospital, Amsterdam -L. de Kock; Hospital Amstelland, Amstelveen -S. Veltkamp; Spaarne Hospital, Hoofddorp -J. Burggraaf, A. Tanka; Sint Lucas Andreas Hospital, Amsterdam -E. Barbé, E. Steller; Vrije Universiteit Medical Centre, Amsterdam -W. Mooi, S. Meijer; Kennemer Gasthuis, Haarlem -D. Willebrand, H. Rijna; Rode Kruis Hospital, Beverwijk - M. Hunfeld; Tergooi Hospitals, Blaricum -M. Prins, P. Bor, A. ten Tije; Tergooi Hospitals, Hilversum -J. Juttmann, S. Luykx-de Bakker; Comprehensive Cancer Centre West, Leiden -P. Krijnen, B. Jongejan; Bronovo Hospital, Den Haag -I. Koelma, J. van Esser, O. Guicherit; Diaconessenhuis, Leiden, -J. Graadt van Roggen, R. Vree, E. Planken; Rijnland Hospital, Leiderdorp - J. Calame, A. Zeilemaker, W. Molendijk; Medical Centre Haaglanden, Den Haag E. Ooms, A. Marinelli, R. Brouwer; Medical Centre Haaglanden, Leidschendam -I. Groot; 't Lange Land Hospital, Zoetermeer -B. Jas, A. Ogilvie; Groene Hart Hospital, Gouda -M. Giessen, R. Schmitz, A. van der Torren-Konze; Haga Hospital Leyenburg, Den Haag -P. Blok, W. Steup, H. Sleeboom; Haga Hospital Rode Kruis, Den Haag -J. Merkus; Leiden University Medical Centre, Leiden -V. Smit, B. Bonsing; Reinier de Graaf Groep, Delft -A. van Leeuwen, C. Marcoen, E. Maartense; Comprehensive Cancer Centre Eindhoven, Eindhoven -M. Janssen-Heijnen, A. van den Eijnden-van Rooijen; Laboratory for Pathology (PAMM), Eindhoven -M. van Beek; Catharina Hospital, Eindhoven -Y. van Riet, G. Creemers; Máxima Medical Centre, Eindhoven -O. Repelaer van Driel, M. Nijziel; Máxima Medical Centre, Veldhoven -R. Roumen, G. Vreugdenhil; Sint Anna Zorggroep, Geldrop -E. Luiten, A. Smals; Jeroen Bosch Hospital, `s Hertogenbosch -J. Broekman, W. Gelderman, J. Wissing, S. Bouwer, T. Smilde, Hospital Bernhoven, Veghel -B. Storck, N. van Diemen; Bernhoven Hospital, Oss -Y. Paquay, A. Vos; Amphia Hospital Molengracht, Breda -P. de Wit, J. Nuytinck, G. Ras; Amphia Hospital Pasteurlaan, Oosterhout -O. van West, J. van Wissen; Amphia Hospital Langendijk, Breda - A. van Gent; Sint Elizabeth Hospital, Tilburg -A. Croonen, J. Roukema, J. van Riel; Tweesteden Hospital, Tilburg -S. Brenninkmeijer, H. van Ojik; Elkerliek Hospital, Helmond -M. Tutein Nolthenius-Puylaert, B. Lemaire; VieCuri Medical Centre, Venlo -R. Schapers, P. Nijhuis, A. van der Wouw; Comprehensive Cancer Centre Rotterdam, Rotterdam -R. Damhuis, J. Paulides; Erasmus Medical Centre, Rotterdam -M. Kliffen; Medical Centre Rijnmond-Zuid Zuider, Rotterdam - S. Henzen-Logmans; Medical Centre Rijnmond-Zuid Clara, Rotterdam -H. van den Ingh, W. Meijer; Laboratory for Pathology (PATHAN), Rotterdam -J. Ruizeveld de Winter; Vlietland Hospital, Schiedam -I. Mares-Engelberts; Ruwaard van Putten Hospital, Spijkenisse -R. den Toom; IJsselland Hospital, Capelle aan de IJssel -G. Tetteroo; Sint Fransiscus Hospital, Rotterdam -H. Strijdhorst; Ikazia Hospital, Rotterdam -W. Vles; Haven Hospital, Rotterdam -J. van Dam; Albert Schweitzer Hospital, Dordrecht -P. Westenend, P. Plaisier; Laboratory for Pathology Zeeland -L. de Bruijckere; Hospital Walcheren, Vlissingen -J. ten Thije; Oosterschelde Hospitals, Goes - H. de Morree; Van WeelBethesda Hospital, Dirksland -R. van der Hul; Hospital Zeeuw-Vlaanderen, Terneuzen -W. Mostert, K. Ongena; Hospital Lievensberg, Bergen op Zoom -V. Potters, E. Slingenberg; Franciscus Hospital, Roosendaal -H. Kemperman; Comprehensive Cancer Centre Limburg, Maastricht -J. Bruijnen, S. Adema; Maastricht University Medical Hospital, Maastricht -M. von Meyenfeldt, P. Hupperets; Maasland Hospital, Sittard - W. Vos, F. van der Ent, F. Erdkamp; Atrium Medical Centre Parkstad, Heerlen -M. Nap, J. van der Bijl, M. Pannebakker; Laurentius Hospital, Roermond -A. Willig, C. Finaly-Marais, M. den Boer; Sint Jans Gasthuis, Weert -F. Limbeek, P. den Haan; Comprehensive Cancer Centre Midden-Nederland, Utrecht -M. van der Heiden-van der Loo, A. Koppejan-Rensenbrink; Sint Antonius Hospital, Nieuwegein -C. Seldenrijk, R. Koelemij, P. de Jong; Mesos Medical Centre, Utrecht -A. van Wieringen, R. Oltmans; Zuwe Hofpoort Hospital, Woerden -J. Vente, M. VerhaarLangereis; Diakonessenhuis, Utrecht -J. van Gorp, T. van Dalen, P. Thunnissen; Meander Medical Centre, Amersfoort -E. Ahsmann, A. van Overbeeke, C. Rodenburg; University Medical Centre Utrecht, Utrecht -R. van Hilligersberg, E. van der Wall; Hospital Rivierenland, Tiel -K. Ong, C. Henkens; Comprehensive Cancer Centre North East, Enschede, Groningen -S. Siesling, M. Schaapveld, R. Otter, A. Wit; Laboratory for Pathology Oost Nederland (LPON), Enschede -M. Brinkhuis; Medisch Spectrum Twente, Enschede -W. Mastboom, W. Smit; Ziekenhuisgroep Twente Twenteborg, Almelo -D. van der Velde, R. Hoekstra; Ziekenhuisgroep Twente SMT, Hengelo -H. Heijmans, H. Dankbaar; Streekziekenhuis Koningin Beatrix, Winterswijk -F. Slootmans, P. Schiphorst; Gelre Hospitals, Apeldoorn -E. Weltevreden, J. Roussel, S. Radema; Hospital Spittaal, Zutphen -J. Ketel, O. van Dobbenburgh; Deventer Hospital, Deventer -J. Arends, H. de Vries, A. Imholz; Laboratory for Pathology (LVF), Leeuwarden -H. Eggink; Antonius Hospital, Sneek -E. Mulder, G. Woolthuis; Medical Centre Leeuwarden, Leeuwarden -C. Hoff, H. de Graaf; Hospital Nij Smellinghe, Drachten -H. van der Mijle, H. van Kamp; Hospital Talma Sionsberg, Dokkum -J. Kaspers, J. de Graaf; Hospital de Tjongerschans, Heerenveen - P. Veldman, J. de Boer; Bethesda Hospital, Hoogeveen -G. Freling, R. Haasen, J. Haasjes; Röpke-Zweers Hospital, Hardenberg -M. Jagers, R. Blankenburgh; Diaconessenhuis, Meppel -L. Hanssen, H. de Korte; Isala Klinieken, Zwolle -A. Jonker, E. Pierik, J. de Graaf; Laboratory for Pathology, Winschoten -C. Schoots; Sint Lucas Hospital, Winschoten -M. Klöppner, H. Potthoff; Refaja Hospital, Stadskanaal -A. Kemper, J. Jansen; Delfzicht Hospital, Delfzijl -J. Ashruf, Z. Erjavec; Martini Hospital, Groningen -A. Groote, A. Olieman, R. de Jong; University Medical Centre Groningen, Groningen -A. Suurmeijer, J. de Vries, P. Willemse; Wilhelmina Hospital, Assen -R. Wijffels, F. Blok; Scheper Hospital, Emmen -M. van den Aardweg, E. Weernink -all in the Netherlands. 


\section{Chapter 4}

\section{Models predicting non-sentinel node involvement also predict for regional recurrence in breast cancer} patients without axillary treatment

M.J.A.E. Pepels, J.H.M.J. Vestjens, M. de Boer, P. Bult, J.A.A.M. van Dijck, M.B.E. Menke-Pluymers P.J. van Diest, G.F. Borm, V.C.G. Tjan-Heijnen Eur J Surg Oncol 2013; in press 


\section{Abstract}

\section{Objective}

Validation of non-sentinel node prediction models in predicting regional recurrences in patients without axillary treatment.

\section{Background}

Non-sentinel node prediction models are frequently used as decision aid to identify patients that may not need axillary treatment, but these models still need to be validated by follow-up data.

\section{Methods}

We followed a cohort of 486 women with favorable primary tumor characteristics and $\mathrm{pNO}(\mathrm{i}+)(\mathrm{sn})$ or $\mathrm{pN} 1 \mathrm{mi}(\mathrm{sn})$ for median 4.5 years. None of the patients underwent axillary treatment. Based on four published non-sentinel node prediction models, the threshold allowing separation into low versus high-risk on non-sentinel node involvement was set at $10 \%$.

\section{Results}

Overall 5-year regional recurrence rate was 3.0\% (SE, +/-0.1\%). Using the Tenon scoring system, 438 low-risk patients had a 5-year regional recurrence rate of $2.3 \%$ (+/-0.8\%), and 48 high-risk patients a recurrence rate of $10.1 \%(+/-0.4 \%)$. The MSKCC nomogram identified 300 low-risk patients with a recurrence rate of $2.8 \%(+/-1.1 \%)$, versus 166 high-risk patients with a rate of 3.4\% (+/-.5\%) (20 patients not assessable). The Stanford nomogram identified 21 high-risk patients without recurrence, and 465 low-risk patients with a $3.2 \%(+/-0.9 \%)$ recurrence rate. A Dutch model discriminated between 384 low-risk patients with a recurrence rate of $2.2 \%(+/-0.8 \%)$ and 102 highrisk patients with a rate of $6.3 \%(+/-2.9 \%)$.

\section{Conclusion}

The Tenon scoring system outperformed the other models as it identified the largest subgroup of patients with low recurrence rate. In patients resembling our cohort we would recommend axillary treatment if they had a Tenon score above 3.5. 


\section{Introduction}

Breast cancer patients with a clinically negative axilla and a primary breast tumor of less than $5 \mathrm{~cm}$ in diameter currently undergo axillary staging by sentinel node biopsy ${ }^{1}$. A negative sentinel node identifies the patients who are likely to have a pathologically negative axilla, and thus do not need completion axillary lymph node dissection, thereby reducing the risk of morbidity such as lymph edema, pain, and shoulder dysfunction. Generally accepted is the omission of axillary lymph node dissection if the sentinel node is entirely tumor-negative; most physicians currently also accept to withhold axillary lymph node dissection in patients with solely sentinel node isolated tumor cells ${ }^{1}$.

In recent years there is a trend towards omitting completion axillary lymph node dissection in sentinel node positive patients ${ }^{2,3,4}$, with low recurrence rates in series, although it was noted that the majority of the patients had sentinel node micrometastases, and only a minority sentinel node macrometastases ${ }^{2}$. Recently, the randomized Z0011 study showed the safety of withholding axillary lymph node dissection in patients with 1 or 2 positive sentinel nodes, provided they used systemic adjuvant therapy and whole breast irradiation (which includes part of the axilla) as part of breast conserving therapy ${ }^{5}$. In sharp contrast to the excellent results of Z0011, we observed in the Dutch MIRROR study, one of the largest sentinel node cohort studies on isolated tumor cells and micrometastases, that patients with sentinel node micrometastases without further axillary treatment had a 5-year regional recurrence rate of $5.6 \%{ }^{6}$. Part of this difference might be explained by the at the time quite conservative approach regarding systemic therapy in the Netherlands. However, inclusion of patients with mastectomy without radiotherapy and different patient selection may also have played a role.

Several studies showed that non-sentinel node involvement is not only associated with sentinel node status but also with primary tumor characteristics ${ }^{7,8}$. Van Zee et al. were the first to develop a model to predict non-sentinel node status in patients with sentinel node metastases ${ }^{8}$. Subsequently, other models have been designed ${ }^{8-13}$. In a study comparing the various published models, it was noted that three models were particularly accurate in predicting non-sentinel node status in patients with sentinel node isolated tumor cells or micrometastases ${ }^{14}$ : the Tenon scoring system, the Memorial Sloan-Kettering Cancer Center (MSKCC) nomogram, and the Stanford nomogram $^{8,7,11}$. However, non-sentinel node involvement not necessarily indicates future disease recurrence if left unresected. Due to adjuvant systemic therapy and breast irradiation recurrences may be prevented. Actually, in the NSABP B-04 study, in which patients were randomized between axillary dissection and observation, it was already reported that there was not a 1:1 relation between 'untreated' axillary involvement and recurrence ${ }^{15}$. After 25 years of follow-up, the patients with untreated axilla had a recurrence rate (as first event) that was half of the expected lymph node involvement rate. 
Therefore, we decided to determine the significance of the aforementioned three non-sentinel node prediction models and an additional Dutch logistic regression model described by Bolster ${ }^{16}$ with respect to 5 -year risk prediction of regional recurrence in the absence of axillary treatment. We tested the models in a subgroup of patients from the MIRROR study ${ }^{17}$. Our main aim was to identify, within a favorable group of patients, a subset of patients that yet might benefit from additional axillary treatment based on actually observed recurrence rates if classified by non-sentinel node prediction models. This study is the first to validate the accuracy of non-sentinel node prediction models in predicting regional recurrence.

\section{Methods}

\section{Patients}

The MIRROR cohort included patients with favorable primary tumor characteristics and $\mathrm{pNO}$, pNO(i+), or pN1mi as final nodal status. A detailed description of this study has been described elsewhere ${ }^{17}$. A selection of patients from the MIRROR study was included in the present study, i.e., those who had sentinel node isolated tumor cells or micrometastases, but had not received additional axillary treatment (axillary lymph node dissection or axillary irradiation). Patient and primary tumor characteristics were used for the non-sentinel node prediction models. Patients were followed for a median of 5 years with respect to recurrences.

\section{Non-sentinel node prediction models}

The Tenon non-sentinel node prediction was calculated by a scoring system based on attribution of points for informative variables ${ }^{8}$. The predicted non-sentinel node status by the MSKCC nomogram and the Stanford Online Calculator were obtained from dedicated Web Sites ${ }^{7,11}$. As a fourth model, we used a prognostic logistic regression model to predict non-sentinel node involvement from a Dutch series by Bolster et al. ${ }^{16}$.

The Tenon score is based on tumor size, sentinel node metastasis size, and number of positive sentinel nodes ${ }^{8}$. The most important determinators of the MSKCC nomogram are tumor size, number of positive and number of negative sentinel nodes, and sentinel node metastasis detection method (immunohistochemistry or serial hematoxylin and eosin), besides to a smaller degree histology with nuclear grade, lymphovascular invasion, multifocality, and ER status ${ }^{7}$. The Stanford nomogram and the Bolster model are both based on primary tumor size, sentinel node metastasis size, and presence or absence of lymphovascular invasion ${ }^{11,16}$.

The threshold allowing separation into low versus high-risk patients was set at $10 \%$ risk estimation of non-sentinel node involvement ${ }^{14}$. 


\section{Endpoints}

The primary aim of this present study was to determine whether the risk estimation of non-sentinel node involvement (low versus high risk) according to one of these four models was associated with the actually observed regional recurrence rate (low versus high). We aimed to assess the predictive quality of the four models. That is, being able to identify a large subgroup of patients with a low recurrence rate in the absence of axillary surgery and a small subgroup of patients with an increased recurrence rate. A secondary objective was to determine the optimal cut-off point per nomogram, distinguishing between a low- and high recurrence rate.

\section{Results}

\section{Patient characteristics}

Table 4.1 shows the baseline characteristics of the patients. In total, we included 486 patients with sentinel node isolated tumor cells or micrometastases who had not undergone additional axillary treatment.

Due to the selection criteria of the MIRROR study, the majority of patients had a tumor with a size of $2 \mathrm{~cm}$ or less (84\%), of low-grade (96\%) and a positive hormone receptor status (93\%). Overall, $66 \%$ of patients received irradiation as part of the breast conserving therapy, and $31 \%$ of patients received adjuvant systemic therapy, mostly hormone therapy alone.

\section{Observed recurrence rate}

The median follow-up was 4.6 years (range $0.2-7.5$ ). Regional recurrences occurred in 14 of 486 patients with an overall regional recurrence rate of 3.0\% (Standard Error, $\mathrm{SE}=0.1 \%)$.

\section{Predicted non-sentinel node involvement versus observed regional recurrence}

In Table 4.2 the outcome related to risk prediction is presented. Using a cut-off level of 3.5 or lower for the Tenon nomogram, 438 patients had a Tenon score of 3.5 or lower with a 5-year regional recurrence rate of $2.3 \%$ (SE +/- $0.8 \%$ ), compared to a recurrence rate of $10.1 \%$ (SE +/- $0.4 \%$ ) in 48 patients with a score above 3.5 (Figure 4.1). Varying the cut-off level did not improve the performance of this nomogram. For instance, using a cut-off level of 4 , a Tenon score of 4 or less was seen in 458 patients with a 5 -year regional recurrence rate of $2.7 \%$, compared to a recurrence rate of $8.3 \%$ in 28 patients. 
Table 4.1 Characteristics of patients from the MIRROR cohort who had SN isolated tumor cells or micrometastases, but had not received additional axillary treatment.

\begin{tabular}{|c|c|c|c|c|c|c|}
\hline Characteristic & \multicolumn{4}{|c|}{$\begin{array}{l}\text { No axillary treatment No axillary treatment } \\
\qquad(\mathrm{n}=345) \\
(\mathrm{n}=141)\end{array}$} & \multicolumn{2}{|c|}{$\begin{array}{l}\text { Entire cohort } \\
\qquad(n=486)\end{array}$} \\
\hline \multicolumn{7}{|c|}{ No. sentinel lymph nodes removed } \\
\hline Median & \multicolumn{2}{|c|}{2} & \multicolumn{2}{|c|}{2} & \multicolumn{2}{|c|}{2} \\
\hline Interquartile range & \multicolumn{2}{|c|}{1,3} & \multicolumn{2}{|c|}{1,3} & \multicolumn{2}{|c|}{1,3} \\
\hline \multicolumn{7}{|l|}{ Age at diagnosis - year } \\
\hline Median & \multicolumn{2}{|c|}{58} & \multicolumn{2}{|c|}{59} & \multicolumn{2}{|c|}{58} \\
\hline Range & \multicolumn{2}{|c|}{$34-93$} & \multicolumn{2}{|c|}{$36-88$} & \multicolumn{2}{|c|}{$34-93$} \\
\hline \multicolumn{7}{|l|}{ Tumor size } \\
\hline$\leq 1 \mathrm{~cm}$ & 91 & $(27)$ & 34 & $(24)$ & 125 & $(26)$ \\
\hline$>1$ to $\leq 2 \mathrm{~cm}$ & 201 & (58) & 80 & $(57)$ & 281 & $(58)$ \\
\hline$>2$ to $\leq 3 \mathrm{~cm}$ & 53 & (15) & 27 & (19) & 80 & $(16)$ \\
\hline \multicolumn{7}{|l|}{ Tumor grade-no. (\%) } \\
\hline 1 & 117 & (35) & 41 & (30) & 158 & (33) \\
\hline 2 & 211 & $(62)$ & 93 & $(67)$ & 304 & $(63)$ \\
\hline 3 & 11 & (3) & 5 & (3) & 16 & (4) \\
\hline \multicolumn{7}{|c|}{ Hormone receptor status-no. (\%) } \\
\hline Negative & 22 & (7) & 11 & (8) & 33 & (7) \\
\hline Positive & 311 & (93) & 130 & $(92)$ & 441 & $(93)$ \\
\hline \multicolumn{7}{|c|}{ Type of breast surgery-no. (\%) } \\
\hline Mastectomy & 109 & $(32)$ & 40 & $(28)$ & 149 & $(31)$ \\
\hline Breast conserving & 236 & (68) & 101 & $(72)$ & 337 & $(69)$ \\
\hline \multicolumn{7}{|c|}{ Radiation of the breast-no. (\%) } \\
\hline No & 118 & (34) & 48 & (34) & 166 & $(34)$ \\
\hline Yes & 227 & (66) & 93 & $(66)$ & 320 & $(66)$ \\
\hline \multicolumn{7}{|c|}{ Adjuvant systemic therapy-no (\%) } \\
\hline No systemic therapy & 260 & (75) & 73 & $(52)$ & 333 & (69) \\
\hline Chemotherapy & 4 & (1) & 3 & $(2)$ & 7 & $(1)$ \\
\hline Hormonal therapy & 67 & (20) & 53 & $(38)$ & 120 & $(25)$ \\
\hline Both & 14 & (4) & 12 & $(8)$ & 26 & $(5)$ \\
\hline
\end{tabular}

Table 4.2 Observed 5-year regional recurrence rates in high and low risk groups according to predicted high and low non-SN metastases risk based on 4 models.

\begin{tabular}{lcccc}
\hline & \multicolumn{2}{c}{$\begin{array}{c}\text { Low predicted non-SN risk } \\
(\leq 10 \%)\end{array}$} & \multicolumn{2}{c}{$\begin{array}{c}\text { High predicted non-SN risk } \\
(>10 \%)\end{array}$} \\
Model & Patients (No.) & $\begin{array}{c}\text { 5-year regional } \\
\text { recurrence rate (\%) }\end{array}$ & Patients (No.) & $\begin{array}{c}\text { 5-year regional } \\
\text { recurrence rate (\%) }\end{array}$ \\
\hline Tenon $^{8}$ & 438 & 2.3 & 48 & 10.1 \\
MSKCC $^{7}$ & 300 & 2.8 & 166 & 3.4 \\
Stanford $^{11}$ & 465 & 3.2 & 21 & 0 \\
Bolster $^{16}$ & 384 & 2.2 & 102 & 6.3 \\
\hline
\end{tabular}

For the MSKCC nomogram, we tested two possible cut-off points. When the cut-off level was set to $10 \%$, then 300 patients had a score of $10 \%$ or less with a $2.8 \%$ (SE +/1.1\%) 5 -year recurrence rate, whereas 166 patients had a score of more than $10 \%$ with $3.4 \%$ (SE +/-1.5\%) 5-year recurrence rate (Figure 4.2 ). If the cut-off level was 
changed into $15 \%$, results improved. The model then identified 426 patients with a low-risk score with an observed regional recurrence rate of $1.9 \%$, and 40 patients with a high-risk score with a 5-year regional recurrence rate of $6.1 \%$. Of note, of 20 patients data required for the MSKCC nomogram were missing, for whom we were not able to calculate non-sentinel node prediction.

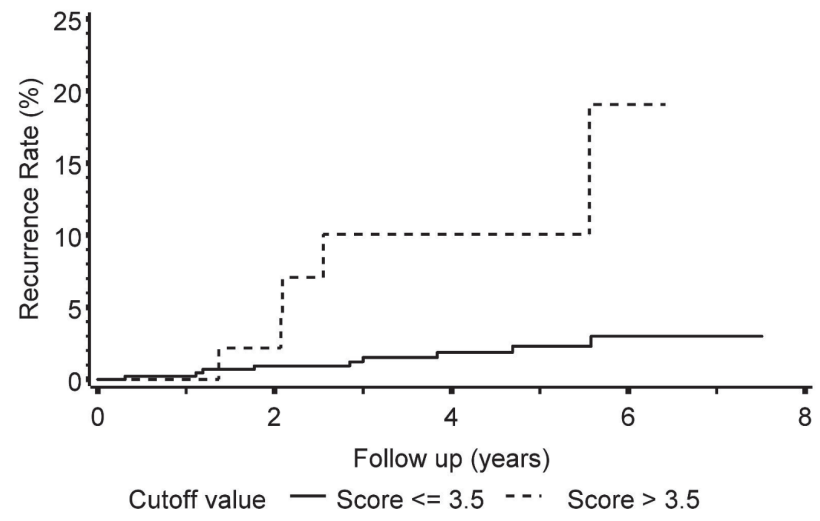

Figure 4.1 Regional recurrence rates in favorable early stage breast cancer patients categorized by the Tenon score ${ }^{8}$.

A higher score predicts an increased risk of non-SN involvement. Recurrence rates for patients with SN isolated tumor cells or micrometastases who did not undergo axillary treatment are shown for a cut-off value of 3.5. Continuous lines represent the patients with a low-risk prediction, and the dotted lines the patients with a high-risk prediction.

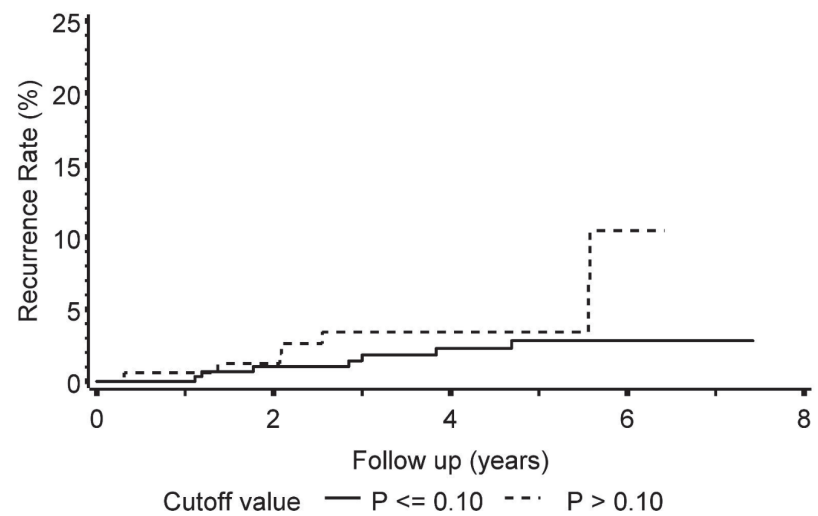

Figure 4.2 Regional recurrence rates in favorable early stage breast cancer patients categorized by the MSKCC nomogram score ${ }^{7}$.

A higher score predicts an increased risk of non-SN involvement. Recurrence rates for patients with $\mathrm{SN}$ isolated tumor cells or micrometastases who did not undergo axillary treatment are shown for a cut-off value of $10 \%$. Continuous lines represent the patients with a low-risk prediction, and the dotted lines the patients with a high-risk prediction. 
Table 4.3 Characteristics of patient populations used to design the 4 models that predict non-SN involvement compared to the current study population, selected not to undergo axillary treatment.

\begin{tabular}{|c|c|c|c|c|c|}
\hline & Tenon $^{8}$ & MSKCC $^{7}$ & Stanford $^{11}$ & Bolster $^{16}$ & Current study \\
\hline Number of patients & 337 & 702 & 285 & 541 & 486 \\
\hline \multicolumn{6}{|l|}{ Tumor status (\%) } \\
\hline pT1 & 87 & 67 & 55 & 54 & 84 \\
\hline рT2 & 12 & 31 & 38 & 43 & 16 \\
\hline pT3 & 1 & 2 & 7 & 3 & 0 \\
\hline \multicolumn{6}{|l|}{ Tumor grade (\%) } \\
\hline 1 & 53 & 3 & 32 & 30 & 33 \\
\hline 2 & 35 & 46 & 42 & 45 & 63 \\
\hline 3 & 12 & 39 & 26 & 25 & 4 \\
\hline \multicolumn{6}{|l|}{ Hormone receptor status (\%) } \\
\hline Negative & 7 & 19 & 13 & 13 & 7 \\
\hline Positive & 93 & 81 & 68 & 87 & 93 \\
\hline \multicolumn{6}{|l|}{ Lymphovascular invasion (\%) } \\
\hline No & 86 & 60 & 41 & 86 & 95 \\
\hline Yes & 14 & 40 & 33 & 14 & 5 \\
\hline \multicolumn{6}{|l|}{ Multifocality (\%) } \\
\hline No & NR & 72 & NR & NR & NR \\
\hline Yes & NR & 28 & NR & NR & NR \\
\hline \multicolumn{6}{|l|}{ Number of SNs } \\
\hline \multicolumn{6}{|l|}{ Number of positive SNs } \\
\hline 1 & 79 & 70 & 73 & NR & 85 \\
\hline 2 & $21^{*}$ & 23 & 21 & NR & 13 \\
\hline$>2$ & NR & 7 & 6 & NR & 2 \\
\hline \multicolumn{6}{|l|}{ Number of negative SNs } \\
\hline 0 & Ratio & 39 & NR & NR & 51 \\
\hline 1 & Ratio & 26 & NR & NR & 28 \\
\hline 2 & Ratio & 15 & NR & NR & 12 \\
\hline$>2$ & Ratio & 20 & NR & NR & 9 \\
\hline \multicolumn{6}{|l|}{ Ratio of positive SNs on total SNs } \\
\hline 1 & 31 & NR & NR & NR & 46 \\
\hline $0,5-1$ & 44 & NR & NR & NR & 28 \\
\hline$<0,5$ & 25 & NR & NR & NR & 26 \\
\hline \multicolumn{6}{|l|}{ Size of SN metastases (\%) } \\
\hline Isolated tumor cells, $\leq 0.2 \mathrm{~mm}$ & 4 & NR & 23 & 10 & 71 \\
\hline Micrometastases, $>0.2-2 \mathrm{~mm}$ & 9 & NR & 70 & 10 & 29 \\
\hline Macrometastases, $>2 \mathrm{~mm}$ & 12 & NR & 7 & 17 & 0 \\
\hline
\end{tabular}

$\mathrm{NR}=$ not reported, $* 2$

Using the Stanford nomogram a cut-off level of $10 \%$ identified 21 patients with a high risk of non-sentinel node involvement but without recurrence, whereas 465 low-risk patients had a 3.2\% (SE +/-0.9\%) recurrence rate (Figure 4.3). Varying the cut-off value did not improve the performance.

Using the Bolster model, a cut-off score of $10 \%$ discriminated between 384 patients with a 5 -year recurrence rate of $2.2 \%$ (SE +/- $0.8 \%$ ) and 102 patients with a recurrence rate of $6.3 \%$ (SE +/- 2.9\%) (Figure 4.4). 


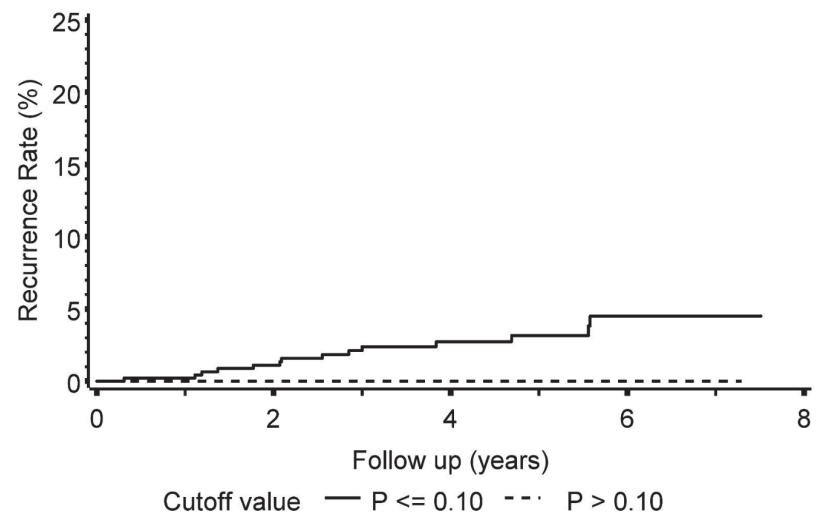

Figure 4.3 Regional recurrence rates in favorable early stage breast cancer patients categorized by the Stanford nomogram ${ }^{11}$.

A higher score predicts an increased risk of non-SN involvement. Recurrence rates for patients with SN isolated tumor cells or micrometastases who did not undergo axillary treatment are shown for a cut-off value of $10 \%$. Continuous lines represent the patients with a low-risk prediction, and the dotted lines the patients with a high-risk prediction.

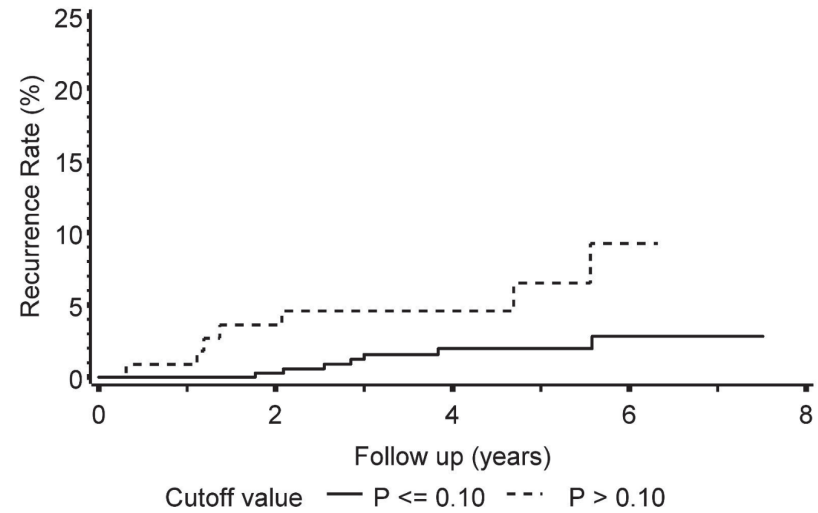

Figure 4.4 Regional recurrence rates in favorable early stage breast cancer patients reported by Bolster et al. ${ }^{16}$ : A higher score predicts an increased risk of non-SN involvement. Recurrence rates for patients with SN isolated tumor cells or micrometastases who did not undergo axillary treatment are shown for a cut-off value of $10 \%$. Continuous lines represent the patients with a low-risk prediction, and the dotted lines the patients with a high-risk prediction. 


\section{Discussion}

Reasons to perform axillary lymph node dissection in breast cancer patients are axillary staging $^{18}$, achieving local control ${ }^{19}$, and improving overall survival ${ }^{15,20}$.

Patients with low-volume disease in the sentinel node may at present not all undergo completion axillary lymph node dissection or axillary irradiation. The 'wait-and-see' policy as an alternative for axillary treatment is based on studies and series showing acceptable regional recurrence rates in the absence of axillary treatment in patients with sentinel node positive disease ${ }^{5,21}$. In a number of studies, however, physicians were noted to have selected patients by size of nodal metastases or by use of nomograms predicting non-sentinel node involvement ${ }^{9,22}$. Although a direct correlation between non-sentinel node involvement and regional recurrence may seem logical, the scientific evidence was missing.

In this present study we investigated, therefore, this relationship, and questioned if it would be possible to identify patients who may or may not need treatment of the axilla. For this purpose, we first determined the predicted risk of non-sentinel node involvement by using four existing nomograms and models in patients who had not undergone axillary treatment in the presence of sentinel node isolated tumor cells or micrometastases. Next, we analyzed the actually observed regional recurrences based on an average 5-year follow-up of these patients. In total we included 486 patients, all diagnosed with favorable primary tumor characteristics during the years $1998-2005$ within the Dutch MIRROR study ${ }^{6,17}$. The main objective of the present study was to assess whether existing nomograms were indeed able to predict regional recurrence rates in these patients. Further, we hoped to identify a cut-off level below which it could be considered safe to withhold axillary treatment. For this purpose we selected nomograms that were reported particularly effective in patients with sentinel node low volume disease ${ }^{14}$. These were the Tenon scoring system, the MSKCC nomogram, the Stanford Online Calculator, and a Dutch logistic regression method by Bolster ${ }^{8,7,11,16}$.

We observed that in three of four models, patients with a higher predicted risk of non-sentinel node involvement had indeed a higher regional recurrence rate if axillary treatment was omitted. The Tenon scoring system outperformed the other models in that it identified the largest subgroup of patients with a low recurrence rate and a small subgroup with a clinical relevant risk of recurrence. Using the Tenon scoring system, we identified 438 patients ( $90 \%$ of patients) with a score of 3.5 or lower with a 5 -year regional recurrence rate of $2.3 \%$ (SE +/- $0.8 \%$ ), compared to a recurrence rate of $10.1 \%$ (SE $+/-0.4 \%$ ) in 48 patients ( $10 \%$ of patients) with a score above 3.5 . For patients with similar tumor and treatment characteristics as in our cohort, we would recommend axillary treatment if they have a Tenon score above 3.5, considering a 5 -year regional recurrence risk of $10.1 \%$ as unacceptably high.

It has been estimated that in the USA and Western Europe approximately $70 \%$ of breast cancer patients will currently undergo an sentinel node procedure ${ }^{23}$. Of 
patients undergoing an sentinel node procedure $10-20 \%$ are reported to have sentinel node isolated tumor cells or sentinel node micrometastases ${ }^{16}$. If the majority of these patients do not need to undergo axillary treatment, this will result in a major improvement in quality of life. In phase III studies, it was shown that long-term sequellae were dramatically lower in sentinel node only patients compared to the patients with axillary lymph node dissection ${ }^{24,25}$. Obviously, such an improvement is only worthwhile if not at the cost of untreatable recurrences. If one would consider a risk of $2.3 \%$ as acceptable and a risk of $10.1 \%$ not, $90 \%$ of patients with sentinel node isolated tumor cells or micrometastases with favorable primary tumor characteristics comparable to the patients included in our cohort would not need axillary treatment, whereas $10 \%$ of these would. For these latter patients, prevention of an axillary recurrence in 1:10 may be worthwhile, but obviously this suggested cut-off value is a subjective one.

It can be argued that it is not correct to analyze patients with sentinel node isolated tumor cells together with patients with sentinel node micrometastases. We believe, however, it is right to do so. The most important argument for this view is that in nomograms size of nodal metastases is just one predictor of non-sentinel node involvement. Of note, three of the four models that were tested included sentinel node metastasis size as one of the predicting features. Hence, this is a major takehome-message: a patient with isolated tumor cells in the sentinel node but with a relatively large primary tumor may have a larger risk of non-sentinel node involvement and regional recurrence if the axilla is left untreated than a patient with micrometastatic sentinel node involvement and a very small primary tumor. Therefore, all parameters that are associated with risk of non-sentinel node involvement should weight together for a correct risk estimation.

Performance of a model is best if patient and tumor characteristics, as far as used in the nomograms, resemble the characteristics of the cohort which is examined. We analyzed the baseline characteristics of the study populations of the tested nomograms and models, and compared these with our cohort characteristics, as presented in Table 4.3. The cohort described to design the Tenon score by Barranger et al. resembled most the subgroup of the current study. Both populations included patients with smaller primary tumor sizes, also noting that tumor size was the most significant factor to predict non-sentinel node metastases in this model. This could explain why this model performed best, besides the fact that the Tenon score consists of only three variables and as such reproducibility of results may easier be obtained. The MSKCC nomogram for patients of which frozen section is not performed consists of six variables ${ }^{7}$. We did not register multifocality. As our cohort consisted of patients with favorable tumor characteristics, we assumed that only a few patients would have multifocal tumors. The Stanford nomogram and the Dutch model are both based on primary tumor size, sentinel node metastasis size, and presence or absence of lymphovascular invasion ${ }^{11,16}$. These models showed not a strong association between the predicted non-sentinel node metastasis risk and regional recurrence rate, actually 
the opposite by the Stanford nomogram with higher recurrence rates in the patients who were estimated to have a lower risk of non-sentinel node involvement, possibly because patient and tumor characteristics differed from our population.

We did not find a 1:1 relation between predicted risk and observed recurrence rate. Various reasons may account for this. First, patients may suffer from non-breast cancer diseases causing mortality, before recurrence may occur. Also, not all tumor cells left behind will have outgrowth potential. Moreover, systemic adjuvant therapy and breast irradiation in case of breast conserving surgery may sterilize axillary nodes. In contrast to the Z0011 study, we found a high regional recurrence rate. Of note, in the Z0011 study, almost all patients underwent adjuvant systemic therapy and all had breast irradiation which includes part of the axilla. At the time of inclusion of our patients, criteria to give adjuvant systemic therapy in The Netherlands were conservative. Unfortunately, our dataset was not large enough to perform separate analyses on patients who did or did not undergo these additional treatments. Obviously, this is a limitation of our study. With more patients receiving aggressive systemic therapies the risk of recurrence in both low- and high-risk categories may decline, and new cut-off levels may be defined. We encourage other researchers to assess this in other population databases.

At recent symposia it was recommended to consider omission of axillary treatment in patients with minimal lymph node involvement who will receive adjuvant systemic therapy and breast irradiation ${ }^{26}$. We conclude that our study stresses the importance of also taking primary tumor characteristics into account. Use of non-sentinel node prediction models may support the identification of patients that still need axillary treatment and those who do not need axillary treatment. For this purpose, the Tenon score outperformed the other models in predicting risk of regional recurrence. We recommend the use of the Tenon scoring system in patients resembling our cohort as it is able to identify a large group of patients (90\%) that had an acceptable 5-year recurrence rate of $2 \%$ without axillary treatment, and a small group of patients that may benefit from additional axillary treatment considering the observed 5-year recurrence rate of $10 \%$. 


\section{References}

1. Lyman GH, Giuliano AE, Somerfield MR, et al. American Society of Clinical Oncology guideline recommendations for sentinel lymph node biopsy in early-stage breast cancer. J Clin Oncol. 2005;23:7703-7720.

2. Pepels MJ, Vestjens $\mathrm{JH}$, de Boer $\mathrm{M}$, et al. Safety of avoiding routine use of axillary dissection in early stage breast cancer: a systematic review. Breast Cancer Res Treat. 2011;125:301-313.

3. Wasif $\mathrm{N}, \mathrm{Ye} X$, Giuliano AE. Survey of ASCO members on management of sentinel node micrometastases in breast cancer: variation in treatment recommendations according to specialty. Ann Surg Oncol. 2009;16:2442-2449.

4. Wasif N, Maggard MA, Ko CY, Giuliano AE. Underuse of axillary dissection for the management of sentinel node micrometastases in breast cancer. Arch Surg. 2010;145:161-166.

5. Giuliano $A E$, Hunt $K K$, Ballman $K V$, et al. Axillary dissection vs no axillary dissection in women with invasive breast cancer and sentinel node metastasis: a randomized clinical trial. JAMA. 2011;9:305:569-575.

6. Pepels $\mathrm{MJ}$, de Boer $\mathrm{M}$, Bult $\mathrm{P}$, et al. Regional recurrence in breast cancer patients with sentinel node micrometastases and isolated tumor cells. Ann Surg. 2012;255:116-121.

7. Van Zee KJ, Manasseh DM, Bevilacqua JL, et al. A nomogram for predicting the likelihood of additional nodal metastases in breast cancer patients with a positive sentinel node biopsy. Ann Surg Oncol. 2003;10:1140-1151.

8. Barranger E, Coutant C, Flahault A, et al. An axilla scoring system to predict non-sentinel lymph node status in breast cancer patients with sentinel lymph node involvement. Breast Cancer Res Treat. 2005;91:113-119.

9. Hwang RF, Krishnamurthy S, Hunt KK, et al. Clinicopathologic factors predicting involvement of nonsentinel axillary nodes in women with breast cancer. Ann Surg Oncol. 2003;10:248-254.

10. Degnim AC, Reynolds C, Pantvaidya G, et al. Nonsentinel node metastasis in breast cancer patients: Assessment of an existing and a new predictive nomogram. Am J Surg. 2005;190:543-550.

11. Kohrt HE, Olshen RA, Bermas HR, et al. New models and online calculator for predicting non-sentinel lymph node status in sentinel lymph node positive breast cancer patients. BMC Cancer. 2008;8:66-80.

12. Pal A, Provenzano E, Duffy SW, et al. A model for predicting non-sentinel lymph node metastatic disease when the sentinel lymph node is positive. Br J Surg. 2008;95:302-309.

13. Saidi RF, Dudrick PS, Remine SG, et al. Nonsentinel lymph node status after positive sentinel lymph node biopsy in early breast cancer. Am Surg. 2004;70:101-105.

14. Coutant C, Olivier C, Lambaudie E, et al. Comparison of models to predict nonsentinel lymph node status in breast cancer patients with metastatic sentinel lymph nodes: a prospective multicenter study. J Clin Oncol. 2009;27:2800-2808.

15. Fisher $\mathrm{B}$, Jeong $\mathrm{JH}$, Anderson $\mathrm{S}$, et al. Twenty-five-year follow-up of a randomized trial comparing radical mastectomy, total mastectomy, and total mastectomy followed by irradiation. $\mathrm{N}$ Engl J Med. 2002;347:567-575.

16. Bolster MJ, Peer PG, Bult $P$, et al. Risk factors for non-sentinel lymph node metastases in patients with breast cancer. The outcome of a multi-institutional study. Ann Surg Oncol. 2007:14:181-189.

17. de Boer $\mathrm{M}$, van Deurzen $\mathrm{CH}$, van Dijck JA, et al. Micrometastases or isolated tumor cells and the outcome of breast cancer. N Engl J Med. 2009;361:653-663.

18. Dees EC, Shulman LN, Souba WW, Smith BL. Does information from axillary dissection change treatment in clinically node-negative patients with breast cancer? An algorithm for assessment of impact of axillary dissection. Ann Surg. 1997;226:279-286.

19. Hayward J, Caleffi M. The significance of local control in the primary treatment of breast cancer. Arch Surg. 1987;122:1244-1247.

20. Orr RK. The impact of prophylactic axillary node dissection on breast cancer survival--a Bayesian meta-analysis. Ann Surg Oncol. 1999;6:109-116.

21. Bilimoria KY, Bentrem DJ, Hansen NM, et al. Comparison of sentinel lymph node biopsy alone and completion axillary lymph node dissection for node-positive breast cancer. J Clin Oncol. 2009;27:2946-2953. 
22. Park J, Fey JV, Naik AM, et al. A declining rate of completion axillary dissection in sentinel lymph node-positive breast cancer patients is associated with the use of a multivariate nomogram. Ann Surg. 2007; 245:462-468.

23. Ho VK, van der Heiden-van der Loo M, Rutgers EJ, et al. Implementation of sentinel node biopsy in breast cancer patients in the Netherlands. Eur J Cancer. 2008;44:683-691.

24. Mansel RE, Fallowfield L, Kissin M, et al. Randomized multicenter trial of sentinel node biopsy versus standard axillary treatment in operable breast cancer: the ALMANAC Trial. J Natl Cancer Inst. 2006;3:98:599-609.

25. Land SR, Kopec JA, Julian TB, et al. Patient-reported outcomes in sentinel-node negative adjuvant breast cancer patients receiving sentinel-node biopsy or axillary dissection: National Surgical Adjuvant Breast and Bowel Project Phase III Protocol B-32. J Clin Oncol. 2010;2825:3929-3936.

26. Giuliano AE. Changes in the management of the axilla in breast cancer. San Antonio Breast Cancer Symposium, 7 December 2012. 


\section{Chapter 5}

\section{Relevant impact of central pathology review on nodal classification in individual breast cancer}

patients

J.H.M.J. Vestjens, M.J.A.E. Pepels, M. de Boer, G.F. Borm, C.H.M. van Deurzen, P.J. Diest, J.A.A.M. van Dijck, E.M.M. Adang, J.W.R. Nortier, E.J.Th. Rutgers, C. Seynaeve, M.B.E. Menke-Pluymers, P. Bult, V.C.G. Tjan-Heijnen 


\section{Abstract}

\section{Background}

In the MIRROR study, $\mathrm{pNO}(\mathrm{i}+)$ and $\mathrm{pN} 1 \mathrm{mi}$ were associated with reduced 5-year disease-free survival compared with pNO. Nodal status was assessed after central pathology review and restaged according to the $6^{\text {th }}$ AJCC classification. We addressed the impact of pathology review.

\section{Patients and methods}

Early favorable primary breast cancer patients, classified pN0, pNO(i+), or pN1(mi) by local pathologists after sentinel node procedure, were included. We assessed the impact of pathology review on nodal status $(n=2842)$, and 5-year disease-free survival for those without adjuvant therapy $(n=1712)$.

\section{Results}

$22 \%$ of the 1082 original pN0 patients was upstaged. Of the 623 original pNO(i+) patients, $1 \%$ was downstaged, $26 \%$ was upstaged. Of 1137 patients staged pN1mi, $15 \%$ was downstaged, $11 \%$ upstaged. Originally, 5 -year disease-free survival was $85 \%$ for $\mathrm{pNO}, 74 \%$ for $\mathrm{pNO}(\mathrm{i}+)$, 73\% for pN1mi; HR 1.70 (95\% Cl 1.27-2.27) and HR 1.57 (95\% $\mathrm{Cl}$ 1.16-2.13) respectively, compared with pNO. By review staging, 5-year disease-free survival was $86 \%$ for $\mathrm{pNO}, 77 \%$ for $\mathrm{pNO}(\mathrm{i}+), 77 \%$ for $\mathrm{pN} 1 \mathrm{mi}$, and $74 \%$ for $\mathrm{pN} 1+$.

\section{Conclusion}

Pathology review changed the nodal-classification in $24 \%$, mainly upstaging, with potentially clinical relevance for individual patients. The association of isolated tumor cells and micrometastases with outcome remained unchanged. Quality control should include nodal breast cancer staging. 


\section{Introduction}

The axillary lymph node status remains one of the most important prognostic factors in breast cancer. With the introduction of the sentinel node procedure, the pathologic work-up is intensified, resulting in an increased detection frequency of small nodal metastases ${ }^{1}$. Until recently the significance of isolated tumor cells (classified as pNO(i+), with deposits $\leq 0.2 \mathrm{~mm}$ ) or micrometastases (classified as pN1mi, with deposits $>0.2$ to $\leq 2.0 \mathrm{~mm}$ ) in relation to clinical outcome was unclear. The MIRROR (Micrometastases and Isolated Tumor Cells: Relevant and Robust or Rubbish?) study was the first large breast cancer cohort study on the relevance of pNO(i+) and pN1mi in the sentinel node era ${ }^{2}$. It was found that patients with favorable early-stage breast cancer and isolated tumor cells or micrometastases in regional lymph nodes, not having received adjuvant systemic therapy, had a reduced disease-free survival at 5 years compared to patients with node-negative disease. $\mathrm{pNO}(\mathrm{i}+)$ as final nodal status was shown to be equally independently associated with disease-free survival as pN1mi. Patients with pNO(i+) or pN1(mi) who received adjuvant systemic therapy, had a better disease-free survival. In the MIRROR study, all available original slides of the sentinel nodes and of positive nodes obtained from patients who underwent an axillary lymph node dissection were centrally reviewed by three pathologists specialized in breast cancer. Restaging according to the sixth AJCC classification took then place $^{2}$. In daily practice, however, treatment decisions are based on the pathology reports assessed by local pathologists. In the present analysis, we investigated the difference in the final lymph node status according to the review pathologists versus the local pathologists, and its association with disease-free survival per subgroup in the patients without adjuvant systemic therapy.

\section{Methods}

\section{Patients}

Women with invasive breast cancer, who had undergone a sentinel node biopsy between 1998 and 2005, were identified from the Netherlands Cancer Registry. Only women with favorable primary tumor characteristics (i.e., tumors of $\leq 1 \mathrm{~cm}$ in diameter, irrespective of grade, or tumors $>1$ to $\leq 3 \mathrm{~cm}$, grade 1 or 2 ) were selected. From these women, only those with a final nodal status of pNO(i+) or pN1mi, detected on microscopic examination of the sentinel node and non-sentinel nodes (in patients who subsequently underwent axillary lymph node dissection) were included. Furthermore, a group of patients with low-risk, node-negative disease, who underwent breast surgery and a sentinel node biopsy with or without an axillary lymph node dissection in the period from 2000 through 2001 was included. For all patients, exclusion criteria were: neoadjuvant chemotherapy, adjuvant systemic 
therapy in node-negative disease ( $\mathrm{pNO}(\mathrm{i}-))$, bilateral breast cancer, or a history of cancer. Detailed information on methods and results was reported by de Boer et al. ${ }^{2}$. All hospitals $(n=113)$ and pathology laboratories $(n=60)$ in the Netherlands participated.

\section{Pathology}

All available original slides from the sentinel nodes and of non-sentinel nodes obtained in the axillary lymph node dissection were reviewed by at least one of three pathologists (C.v.D., P.v.D., P.B.) specialized in breast cancer and experienced in sentinel node pathology. These included slides stained with hematoxylin and eosin, slides stained for immunohistochemical analysis, and frozen sections. The overall agreement between the review pathologists regarding classification as node-negative [pNO/pNO(i+)] or node-positive [pN1mi/pN1a] was 98\% ( $\mathrm{k}=0.96 ; 95 \% \mathrm{Cl} 0.90-1.02)$. Almost all participating pathology laboratories used a protocol in which the sentinel node was serially sectioned at least every $150 \mu \mathrm{m}$ and at a minimum of three levels, with the use of keratin immunohistochemical staining if the hematoxylin and eosin staining was negative. The non-sentinel nodes were macroscopically sectioned every 2-5 $\mathrm{mm}$ and one section per slice was stained with hematoxylin and eosin. Additional sections were not obtained, and immunohistochemical staining was not routinely performed. Classification was done according to the sixth edition of the AJCC Cancer Staging Manual ${ }^{3}$.

\section{Study objectives}

The primary study objective was to assess the difference in the final nodal status as determined by central pathology review compared to the final nodal status as determined by the local pathologists. The secondary study objective was to assess the 5 -year disease-free survival rate according to the original and the revised final nodal status, overall and in patients per subgroup (pNo, pNO(i+), pN1mi, and pN1+). To rule out the influence of adjuvant systemic therapy this analysis was performed in patients not treated with adjuvant systemic therapy.

\section{Statistical analysis}

The chi-square test for trend was used to assess baseline differences between ordinal variables, and analysis of variance was used for continuous variables. To assess the rate of reproducibility between the original and review pathologists the kappa score was assessed. The Kaplan-Meier method was used to estimate the 5-year rate of disease-free survival in patients who did not receive adjuvant systemic therapy. The period of disease-free survival was defined as the interval from the date of diagnosis to locoregional recurrence, distant metastases, contralateral invasive breast cancer or ductal carcinoma in situ, another malignant condition or death from any cause, 
whichever occurred first. For patients who remained alive and disease-free, data were censored at the date of the last contact. A Cox proportional-hazards model was used to compare the cohorts and to adjust for known prognostic clinical and pathological variables. In this analysis, we included age at diagnosis, tumor size, tumor grade, and hormone-receptor status (positive: ER and/or PgR positive). All reported $\mathrm{P}$ values are two-sided, and confidence intervals are at the $95 \%$ level.

\section{Results}

\section{Patients}

At baseline, 2842 breast cancer patients with favorable primary tumor characteristics were selected for this analysis. 135 of these patients were not included in the primary analyses of the MIRROR study because they were classified as having macrometastatic disease (pN1+) after central pathology review ${ }^{2}$. Of the 2842 patients, 1082 had originally been classified as pNO, 623 patients as $\mathrm{pNO}(\mathrm{i}+)$, and 1137 patients as pN1mi. Baseline characteristics are shown for patients classified according to the review pathology (Table 5.1). Overall, there were no major differences in baseline characteristics per nodal category. When patients were classified according to the local pathology also no major differences were seen.

\section{Final nodal status: original versus centrally reviewed}

In Figure 5.1 the final nodal status as assessed by the local pathologist (original) and after central pathology review, respectively, is shown. Of the 1082 patients with originally pNO, 195 patients (18\%) were restaged after central review as pNO(i+), 29 patients $(3 \%)$ as $\mathrm{pN} 1 \mathrm{mi}$ and 5 patients $(0.5 \%)$ as pN1+. Of the 623 patients with originally $\mathrm{pNO}(\mathrm{i}+)$, central review assessed 3 patients $(0.5 \%)$ as pN0, 158 patients (25\%) as pN1mi and 4 patients (0.6\%) as pN1+. And, of the 1137 patients with originally $\mathrm{pN} 1 \mathrm{mi}, 166$ patients (15\%) were considered having $\mathrm{pNO}(\mathrm{i}+)$ and 126 patients (11\%) pN1+ after review. Overall, central pathology review changed the nodalclassification in 686 of the 2842 patients $(24 \%, 95 \% \mathrm{Cl} 23-26 \%)$, consisting of downstaging in $6 \%$ and upstaging in $18 \%$ of the patients. To assess the rate of reproducibility between the local and review pathologists the kappa score was assessed. The kappa score was 0.69 (95\% Cl 0.67-0.71).

To rule out the influence of dedication of the local pathologists we performed a funnel plot. The number of patients included per laboratory ranged between 1 and 155 . Of the 60 involved pathology laboratories, the majority of the laboratories performed comparable with each other, and only a few scored very different showing that the overall discrepancy between the local pathologists and review pathologists was 
comparable in almost all laboratories and not just caused by a few laboratories. (Figure 5.2)

Table 5.1 Baseline characteristics of the patients staged according to the review pathologists.

\begin{tabular}{|c|c|c|c|c|c|c|}
\hline Characteristics & $\begin{array}{c}\text { All } \\
(n=2842)\end{array}$ & $\begin{array}{c}\text { pNO } \\
(n=856)\end{array}$ & $\begin{array}{l}\text { pNO(i+) } \\
(n=819)\end{array}$ & $\begin{array}{c}\text { pN1mi } \\
(n=1032)\end{array}$ & $\begin{array}{c}\mathrm{pN} 1+ \\
(\mathrm{n}=135)\end{array}$ & $p$ value \\
\hline Age at diagnosis (yrs) & & & & & & $<0.0001$ \\
\hline Median & 57 & 59 & 58 & 56 & 54 & \\
\hline Range & $30-93$ & $30-89$ & $31-93$ & $32-89$ & $36-86$ & \\
\hline Tumor size-no. (\%) & & & & & & $<0.0001$ \\
\hline Unknown & $15(1)$ & $5(1)$ & $5(1)$ & $5(1)$ & 0 & \\
\hline$\leq 2 \mathrm{~cm}$ & $2414(85)$ & $789(92)$ & $671(82)$ & $851(82)$ & $103(76)$ & \\
\hline$>2$ to $\leq 3 \mathrm{~cm}$ & 413 (14) & $62(7)$ & $143(17)$ & $176(17)$ & $32(24)$ & \\
\hline Tumor grade-no. (\%) & & & & & & 0.01 \\
\hline 1 & $950(33)$ & 317 (37) & $262(32)$ & 331 (32) & $40(30)$ & \\
\hline 2 & $1707(60)$ & $474(55)$ & $509(62)$ & $635(62)$ & $89(66)$ & \\
\hline 3 & $139(5)$ & $49(6)$ & $34(4)$ & $52(5)$ & $4(3)$ & \\
\hline Unknown & $46(2)$ & $16(2)$ & $14(2)$ & $14(1)$ & $2(1)$ & \\
\hline Tumor type-no. (\%) & & & & & & 0.0004 \\
\hline Ductal & $2164(76)$ & $652(76)$ & $597(73)$ & $819(79)$ & $99(73)$ & \\
\hline Lobular & 315 (11) & 76 (9) & $111(14)$ & $106(10)$ & $22(16)$ & \\
\hline Other & 363 (13) & $128(15)$ & $111(14)$ & $110(11)$ & $14(10)$ & \\
\hline $\begin{array}{l}\text { Expression of estrogen } \\
\text { receptors, progesterone or } \\
\text { both- no. (\%) }\end{array}$ & & & & & & 0.52 \\
\hline Yes & $2593(91)$ & 761 (89) & $739(90)$ & $968(94)$ & $125(93)$ & \\
\hline No & $167(6)$ & $50(6)$ & $58(7)$ & $52(5)$ & $7(5)$ & \\
\hline Unknown & $82(3)$ & $45(5)$ & $22(3)$ & $12(1)$ & $3(2)$ & \\
\hline Type of surgery-no. (\%) & & & & & & 0.04 \\
\hline Breast-conserving & $2018(71)$ & $633(74)$ & $567(69)$ & $722(70)$ & $96(71)$ & \\
\hline Mastectomy & 824 (29) & $223(26)$ & $252(31)$ & $310(30)$ & $39(29)$ & \\
\hline No. of SN removed & & & & & & 0.004 \\
\hline Median & 2 & 1 & 2 & 2 & 2 & \\
\hline Range & $0-14$ & $0-9$ & $0-14$ & $0-10$ & $1-7$ & \\
\hline $\begin{array}{l}\text { Axillary lymph node dissection- } \\
\text { no.(\%) }\end{array}$ & & & & & & $<0.0001$ \\
\hline No & 1394 (49) & $736(86)$ & $408(50)$ & $226(22)$ & $24(18)$ & \\
\hline Yes & $1448(51)$ & $120(14)$ & $411(50)$ & $806(78)$ & $111(82)$ & \\
\hline $\begin{array}{l}\text { Axillary lymph-node dissection, } \\
\text { axillary irradiation or both- } \\
\text { no.(\%) }\end{array}$ & & & & & & $<0.0001$ \\
\hline No & $1231(43)$ & $732(85)$ & $349(43)$ & $137(13)$ & $13(10)$ & \\
\hline Yes & $1611(57)$ & $124(15)$ & $470(57)$ & $895(86)$ & $122(90)$ & \\
\hline
\end{tabular}




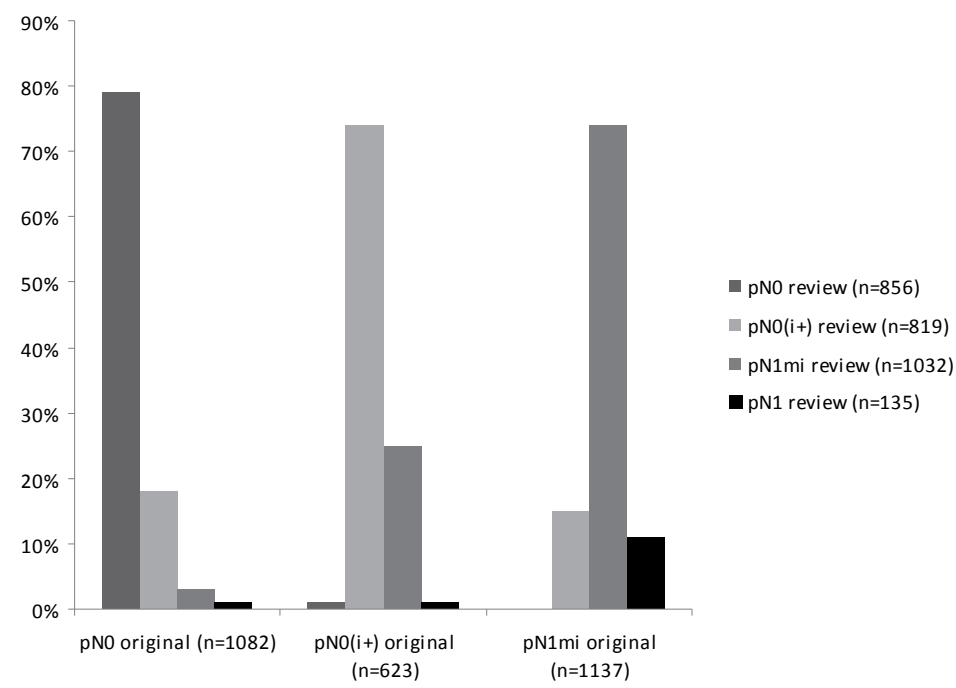

Figure 5.1 Restaging of the originally staged pNO, pNO(i+), and pN1mi patients after central review.

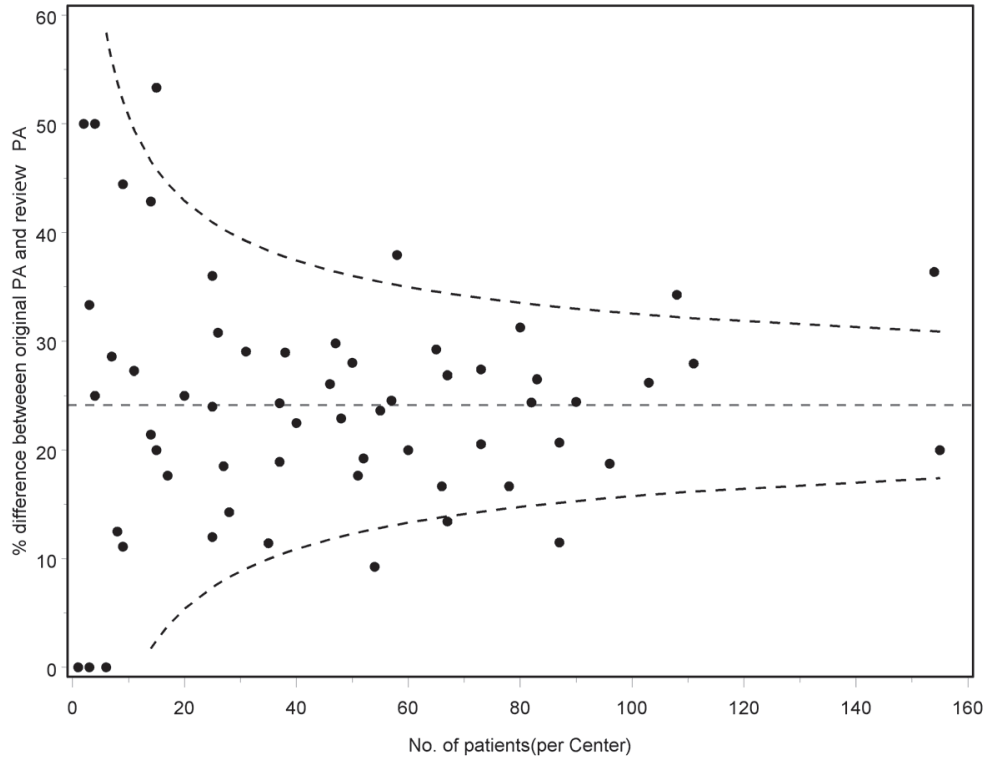

Figure 5.2 Funnel plot of \% difference between original PA and review PA per number of patients. 
As the sixth edition of the AJCC Cancer Staging Manual was introduced in $2002^{3}$, we performed separate analyses for the patients diagnosed before and since 2003. Of the 1786 patients diagnosed before 2003, $438(25 \%, 95 \% \mathrm{Cl} 23-27 \%)$ were restaged after central review, and of the 1056 patients diagnosed since 2003, 248 (23\%, 95\% Cl 21-26\%) were differentially staged after central pathology review. So, before and after the introduction of the sixth edition of the AJCC Cancer Staging Manual, the percentage of restaged patients remained similar.

\section{Disease-free survival rates}

Overall, the 5-year disease-free survival rate in the patients not having been treated with adjuvant systemic therapy $(n=1751)$ was $81.7 \%$.

According to the original final nodal status, the unadjusted 5-year disease-free survival rate was $84.9 \%$ for patients with pNO $(n=1068), 73.6 \%$ for patients with pNO(i+) $(n=364)$, and $73.1 \%$ for those with pN1mi $(n=319)$ (Figure 5.3). The difference in 5-year disease-free survival rate was statistically different between pNO(i+) as compared to pNO $(p=0.0002)$. The difference in 5 -year disease-free survival rate was also statistically different between $\mathrm{pN} 1 \mathrm{mi}$ as compared to $\mathrm{pN0}(\mathrm{p}=0.0008)$. After correction for age at diagnosis, tumor size, tumor differentiation grade, and hormone receptor status an increased risk of disease relapse remained significant for patients with final pNO(i+) with an adjusted hazard ratio of $1.70(95 \% \mathrm{Cl} 1.27-2.27)$ as compared with patients with final pNO status. (Table 5.2) For patients with final pN1mi the adjusted hazard ratio was $1.57(95 \% \mathrm{Cl} 1.16-2.13)$ as compared with final pNO.

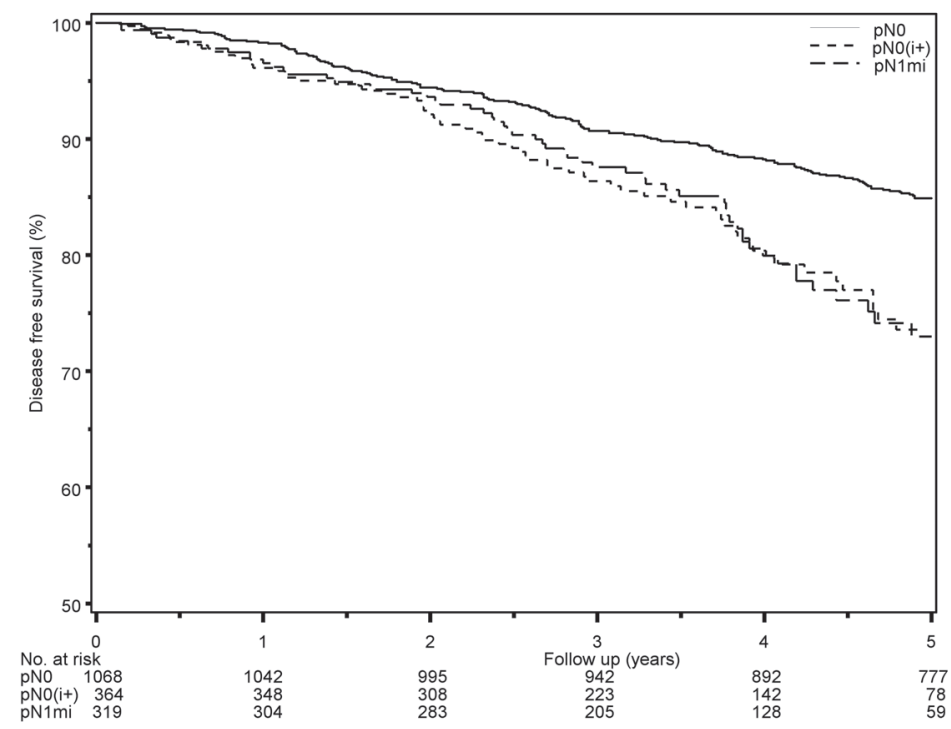

Figure 5.3 Kaplan Meier 5-year disease free survival curves according to the original nodal status. 
Table 5.2 Cox Proportional-Hazards model of the effects of variables on recurrence rate according to the presence or absence of isolated tumor cells or micrometastases, based on original pathology classification.

\begin{tabular}{|c|c|c|c|c|c|c|c|}
\hline \multirow[b]{2}{*}{ Variable } & & \multicolumn{3}{|c|}{$\mathrm{pNO}(\mathrm{i}+)$ versus $\mathrm{pNO}$} & \multicolumn{3}{|c|}{ pN1mi versus pNO } \\
\hline & & HR & $95 \% \mathrm{Cl}$ & $p$-value & $\mathrm{HR}$ & $95 \% \mathrm{Cl}$ & $\mathrm{p}$-value \\
\hline Node-negative ( $p N 0$ ) & & 1.00 & & & 1.00 & & \\
\hline Isolated tumor cells $(\mathrm{pNO}(\mathrm{i}+))$ & & 1.70 & $1.27-2.27$ & $<0.001$ & - & - & - \\
\hline Micrometastases (pN1mi) & & - & - & - & 1.57 & $1.16-2.13$ & $<0.001$ \\
\hline Age (year) ${ }^{1}$ & & 1.02 & $1.00-1.02$ & 0.006 & 1.01 & $1.00-1.02$ & 0.023 \\
\hline Tumor size ${ }^{2}$ & & 1.24 & $1.03-1.50$ & 0.025 & 1.24 & $1.01-1.52$ & 0.036 \\
\hline \multirow[t]{3}{*}{ Tumor grade } & 1 & 1.00 & & & 1.00 & & \\
\hline & 2 & 1.61 & $1.21-2.13$ & 0.001 & 1.64 & $1.22-2.19$ & 0.001 \\
\hline & 3 & 2.65 & $1.52-4.63$ & $<0.001$ & 1.84 & $1.01-3.35$ & 0.047 \\
\hline \multirow[t]{2}{*}{$\mathrm{ER} / \mathrm{PgR}$ status } & $\mathrm{ER}+$ and/or PgR + & 1.00 & & & 1.00 & & \\
\hline & $\mathrm{ER}-$ and PgR - & 1.34 & $0.87-2.08$ & 0.186 & 1.45 & $0.93-2.25$ & 0.102 \\
\hline
\end{tabular}

${ }^{1}$ modelled as continuous variable ${ }^{2}$ hazard ratio when tumor diameter doubles

$\mathrm{HR}$, hazard ratio; $\mathrm{Cl}$, confidence interval; ITC, isolated tumor cells ( $\mathrm{pNO}(\mathrm{i}+))$; $\mathrm{MI}$, micrometastases (pN1mi); $\mathrm{ER}$, estrogen receptor; PgR, progesterone receptor.

Previously, we reported part of the results after central review ${ }^{2}$. After review, the unadjusted 5-year disease-free survival rate was $85.7 \%$ for patients with restaged pN0 ( $n=856), 77.2 \%$ for patients with pNO(i+) ( $n=513)$, and $76.5 \%$ for patients with pN1mi $(n=343)$. After correction for age at diagnosis, tumor size, tumor differentiation grade, and hormone receptor status an increased risk for disease-related events was seen for patients with restaged $\mathrm{pNO}(\mathrm{i}+)$ with a hazard ratio of $1.50(95 \% \mathrm{Cl} 1.15-1.94)$ as compared with patients with restaged pNO status. For patients with restaged pN1mi, versus restaged $\mathrm{pN} 0$, the hazard ratio was 1.56 (95\% $\mathrm{Cl} 1.15-2.13)$. Patients that were excluded from the previous analysis, because of presence of macro-metastases (pN1+), are now - in addition - shown in Figure 5.4 with an unadjusted 5-year diseasefree survival rate of $74.3 \%(n=39)$. The 5 -year disease-free survival rate was lowest in the pN1+ group as expected, however the number of patients in this group was too low for a formal statistical analysis. 


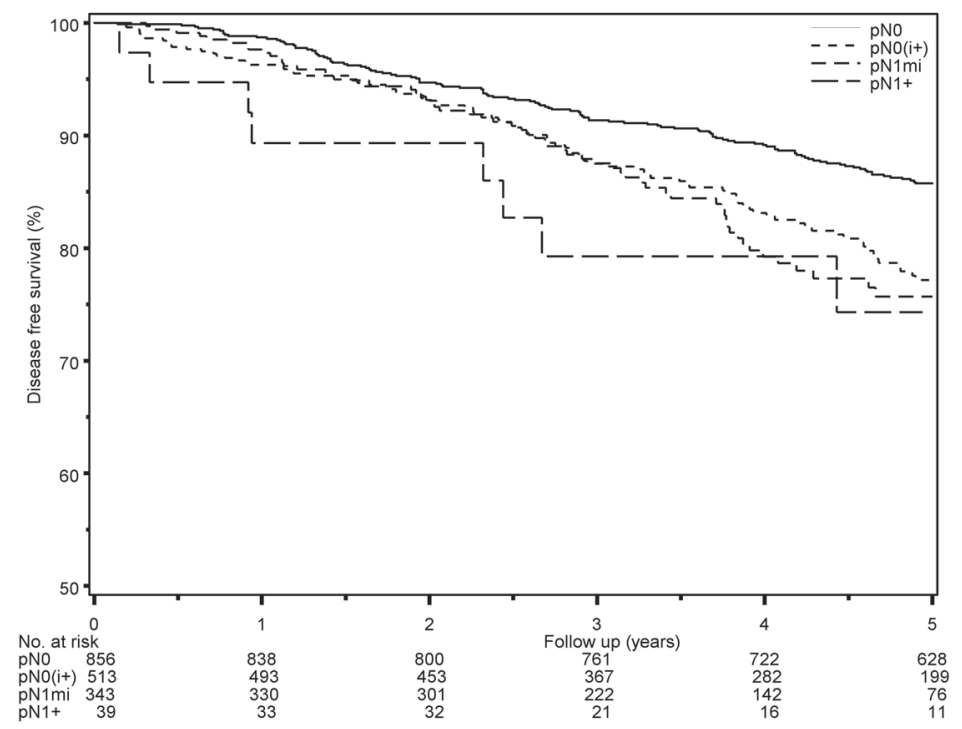

Figure 5.4 Kaplan Meier 5-year disease free survival curves according to the review nodal status.

\section{Discussion}

Previously, we reported that final lymph node status pNO(i+) and pN1mi, assessed after central pathology review, in patients with favorable early-stage breast cancer who did not receive adjuvant systemic therapy were associated with a reduced 5-year disease-free survival ${ }^{2}$. In the current analysis we showed that central pathology review changed the $\mathrm{N}$-classification in $24 \%$ of the patients, mainly consisting of upstaging in $18 \%$ of the patients. Notably, on a population level the association of isolated tumor cells and micrometastases with breast cancer outcome remained unchanged. That is, $\mathrm{pNO}(\mathrm{i}+)$ or $\mathrm{pN} 1 \mathrm{mi}$ were also associated with reduced survival when nodal status was based on local pathology reports. However, restaging may have clinical relevance for an individual patient as restaging may result in a final nodal status making the patient eligible or ineligible for adjuvant systemic therapy with consequences for final outcome.

The discordance among pathologists with respect to breast sentinel node has been shown before in several small studies. Roberts et al. offered 25 slides (containing 1 macrometastatic, 19 micrometastic, and 5 negative slides) to 10 pathologists with vast experience in breast sentinel nodes ${ }^{4}$. Only 3 of the 25 slides (12\%) were interpreted in the same way by all 10 pathologists. These included one negative slide 
and two slides with the most abundant tumor burden. As the number of tumor cells present in a sentinel node gradually decreased, the number of pathologists scoring the case correctly decreased. The European Working Group for Breast Screening Pathology (EWGBSP) assessed the reproducibility of interpreting isolated tumor cells and micrometastases by showing digital images of 50 cases with low-volume sentinel node involvement twice to their members ${ }^{5}$. In the first round the overall kappa score was only 0.39 . The possible causes for this low reproducibility were discussed and methods for improvement were adopted after consultation of experts of the International Committee against Cancer. In the second evaluation round the kappa score improved to a moderate 0.49 . Turner et al. showed an equally low kappa score of 0.49 when the digital images of 56 low-volume involved nodes were reviewed by 6 experienced breast pathologists ${ }^{6}$. However, after a training program that included definitions, guidelines and example-images the kappa score improved to 0.95. The EWGBSP interpretation of AJCC sentinel node staging was however better predictive of non-sentinel node involvement than the Turner et al. interpretation ${ }^{7,8}$. Adherence to category definitions supplemented by explanatory texts in the staging manual of the new edition of the TNM has shown to lead to moderate (kappa score 0.56 in the isolated tumor cells category) and substantial (kappa score 0.62 in the micrometastases category) reproducibility ${ }^{9}$. The difficulty of assessing low-volume involved lymph nodes was also shown in a larger French study ${ }^{10}$. The slides of 337 operable breast cancer patients with one low-volume involved lymph node were examined by three senior pathologists. It showed that the distinction between isolated tumor cells and micrometastases was often difficult, depending on which definition of measuring size was used (size of area with close clusters or size of largest cluster) and depending on whether the AJCC or UICC definitions were used. With the AJCC definition 9\% would have been differently classified. Using the UICC definition the classification was uncertain in $40-45 \%$ of patients. The authors further mentioned that there was no significant difference in metastasis-free survival between pNO(i+) and pN1mi patients whatever method of sizing or classification was used. In the MIRROR study we also showed that the disease-free survival was not significantly different between $\mathrm{pNO}(\mathrm{i}+)$ and $\mathrm{pN} 1 \mathrm{mi}$, but both subgroups had a worse outcome compared to $\mathrm{pNO}(\mathrm{i}-)^{2}$.

In our analysis, the discrepancy between the local pathologists and review pathologists was also high resulting in a change of the final nodal status in $24 \%$ of the patients (kappa score of 0.69). Since our study population comprised patients diagnosed between 1998 and 2005, one might argue that before the introduction of the sixth edition of the AJCC Cancer Staging Manual it was not mandatory to differentiate between micrometastases and isolated tumor cells ${ }^{3}$. However, in subanalyses considering the patients diagnosed before and since 2003 the discordance between the original and review reports was sustained. Another hypothesis could be the dedication of the pathologists. On the other hand, of the 
60 involved pathology laboratories, the majority of the laboratories performed comparable with each other, and only a few scored different (Figure 5.2). The labs with the higher number of patients (ranging between $n=82$ and $n=155$ ) had disagreement rates of $12 \%, 19 \%, 20 \%, 21 \%, 24 \%, 24 \%, 26 \%, 27 \%, 28 \%, 34 \%$ and $36 \%$. Although the $36 \%$ disagreement rate was in the largest group $(n=155)$, exclusion of this group still led to an overall disagreement rate of $23.4 \%$.

The overall agreement between our review pathologists regarding classification as node-negative [pN0/pNO(i+)] or node-positive [pN1mi/pN1a] was $98 \%(\mathrm{k}=0.96 ; 95 \% \mathrm{Cl}$ $0.90-1.02$ ) and overall agreement regarding the sixth AJCC Cancer Staging Manual was $83 \%(\mathrm{k}=0.75 ; 95 \% \mathrm{Cl} 0.65-0.85)$. We believe that this high overall agreement can be explained by dedication and training.

The 5-year disease-free survival was better for all subgroups considering the classification as assessed by the review pathologists. These differences can be explained by stage migration, also called the Will Rogers phenomenon ${ }^{11}$. The improved outcome indicates that the $24 \%$ upstaging as proposed by the review pathologists was indeed correct and of potential clinical relevance.

On a population level, the association of the nodal status with clinical outcome remained unchanged. However, on an individual level the restaging of patients can be of clinical relevance in several ways. When isolated or even no tumor cells in the sentinel node were incorrectly reported, while in fact micro- or macrometastases were present, patients could inappropriately be withheld axillary treatment ${ }^{12}$. Also $15 \%$ of the pN1mi patients were downstaged to pNO(i+), a stage in which it is considered acceptable to withhold axillary treatment, indicating that some of these women have a risk of being overtreated including the increased risk of lymph edema and shoulder dysfunction and without gaining further survival benefit. Probably more important, considering our prior report ${ }^{2}$, less patients may be treated with systemic therapy because of understaging. In our study population, $18 \%(n=517)$ was upstaged. If the criteria to advise systemic therapy start with an nodal status of at least pNO(i+), $8 \%(n=229)$ of the patients would not have received systemic therapy because of understaged nodal status. Recently, the criteria indicative for systemic therapy regarding other patient and tumor characteristics were broadened in the Dutch guidelines. However, still about half of these patients would not have received systemic therapy based on the primary tumor characteristics only (data not shown). The recent publication on the finding of occult metastases in the NSABP B-32 trial also showed a small though statistically significant adverse outcome in patients with occult sentinel lymph node metastases ${ }^{13}$. In this study it was mentioned that adjuvant systemic therapy was more often administered in the group with occult metastases and it was therefore suggested that perhaps other factors known at the start of therapy probably correlate with the presence of occult metastases. It can also be 
hypothesized that without the administration of adjuvant systemic therapy the difference in adverse outcome will be larger.

Because of the observation that pathology review altered the nodal status in $24 \%$ of the patients, we believe that two important recommendations should be made. Firstly, additional studies concerning this issue are eagerly awaited confirming the importance of central review. To interpret forthcoming data reliably, we encourage our colleague investigators to include central pathology review. Our second recommendation regards the quality control of pathology laboratories. We believe that additional training or even specialization of pathologists, in addition to published guidelines, is necessary, as well as inclusion of sentinel node staging in quality control procedures of pathology labs. An example of a training instrument with the publication of new guidelines could be an E-learning course comprising digital examples. 


\section{References}

1. Bolster MJ, Bult P, Wauters CAP, et al. More tumor-affected lymph nodes because of the sentinel node procedure but no stage migration, because the 2002 TNM classifies small tumor deposits as pathologic NO breast cancer. Cancer 2009;115:5589-5595.

2. de Boer M, van Deurzen CHM, van Dijck JAAM, et al. Micrometastases or isolated tumor cells and the outcome of breast cancer. NEJM 2009;361:653-663.

3. Green FL, Page DL, Fleming ID, et al. AJCC cancer staging manual. $6^{\text {th }}$ ed Chicago: American Joint Commission on Cancer 2002.

4. Roberts CA, Beitsch PD, Litz CE, et al. Interpretive disparity among pathologists in breast sentinel lymph node evaluation. Am J Surg 2003;186:324-329.

5. Cserni G, Bianchi S, Boecker W, et al. Improving the reproducibility of diagnosing micrometastases and isolated tumor cells. Cancer 2005;103:358-367.

6. Turner RF, Weaver DL, Cserni G, et al. Nodal stage classification for breast carcinoma: Improving interobserver reproducibility through standardized histologic criteria and image-based training. J Clin Oncol 2008;26:258-263.

7. Van Deurzen $\mathrm{CH}$, Cserni G, Bianchi S, et al. Nodal-stage classification in invasive lobular breast carcinoma: Influence of different interpretations of the pTNM classification. J Clin Oncol 2010; 28:999-1004.

8. Cserni G, Bianchi S, Vezzosi V, et al. Variations in sentinel node isolated tumour cells/micrometastasis and non-sentinel node involvement rates according to different interpretations of the TNM definitions. Eur J Cancer 2008;244:2185-2191.

9. Cserni G, Amendoeira I, Bianchi S, et al. Distinction of isolated tumour cells and micrometastasis in lymph nodes of breast cancer patients according to the new Tumour Node Metastasis (TNM) definitions. Eur J Cancer 2011;47:887-894.

10. De Mascarel I, MacGrogan G, Debeld M, et al. Distinction between isolated tumor cells and micrometastases in breast cancer. Is it reliable and useful? Cancer 2008;112:1672-1678.

11. Feinstein AR, Sosin DM, Wells CK. The Will Rogers phenomenon- Stage migration and new diagnostic techniques as a source of misleading statistics for survival in cancer. N Engl J Med 1985;312:16041608.

12. Pepels MJ, de Boer M, Bult P, et al. Regional Recurrence in Breast Cancer Patients with Sentinel Node Micrometastases and Isolated Tumor Cells. Annals of Surgery 2011 in press.

13. Weaver DL, Ashikaga T, Krag DN, et al. Effect of occult metastases on survival in node-negative breast cancer. N Engl J Med 2011;364:412-421. 


\section{Chapter 6}

\section{Is the sentinel lymph node pathology protocol in breast cancer patients associated with the risk of regional recurrence?}

M.J. Bolster, M.J.A.E. Pepels, C.A.P. Wauters, R.F.M. Schapers, J.W.R. Meijer, L.J.A. Strobbe, C.L.H. van Berlo, J.H.G. Klinkenbijl, T. Wobbes, A.C. Voogd, P. Bult, V.C.G. Tjan-Heijnen Eur J Surg Oncol 2013; Epub ahead 


\section{Abstract}

\section{Background}

Internationally, there is no consensus on the pathology protocol to be used to examine the sentinel lymph node in breast cancer patients. Previously, we reported that ultra-staging led to more axillary lymph node dissections. The question was, whether ultra-staging is effective in reducing the risk of regional relapse.

\section{Methods}

From January 2002 to July 2003, 541 patients from 4 hospitals were prospectively registered when they underwent a sentinel lymph node biopsy. In hospitals A, B, and C, 3 levels of the sentinel nodes were examined pathologically, whereas in hospital $\mathbf{D}$ at least 7 additional levels were examined. Patients with a positive sentinel node, including isolated tumor cells, underwent an axillary lymph node dissection. This analysis focuses on the 341 patients with a negative sentinel node. Primary endpoint was 5-year regional recurrence rate.

\section{Results}

In hospital $\mathbf{D} 34 \%$ of the patients had a negative sentinel node as compared to $71 \%$ in hospitals A, B, and $\mathbf{C}$ combined $(p<0.001)$. At 5 years follow-up, $9(2.6 \%)$ patients had developed a regional lymph node relapse. In hospital $\mathbf{D}$ none of the patients had a regional recurrence, as compared to $9(2.9 \%)$ cases of recurrence in hospitals $\mathbf{A}, \mathbf{B}$, and C.

\section{Conclusion}

The less intensified sentinel node pathology protocol appeared to be associated with a slightly increased risk of regional recurrence. The absolute risk was still less than $3 \%$, and does not seem to justify the intensified sentinel node pathology protocol of hospital D. 


\section{Introduction}

The axillary lymph node status is one of the most important prognostic factors in breast cancer ${ }^{1}$. Nowadays, most patients do not have nodal involvement due to the introduction of population-based breast cancer screening. With the risk of shoulder dysfunction and lymph edema of the arm, an axillary lymph node dissection for axillary staging should be prevented whenever possible ${ }^{2}$.

Therefore, the sentinel lymph node procedure was introduced during the late $1990 \mathrm{~s}^{3}$. Based on figures from the pre-sentinel node era, it was assumed that a completion axillary lymph node dissection could be avoided in approximately $60 \%$ of patients with operable breast cancer by carrying out a sentinel node biopsy.

It is shown that in patients with a negative sentinel node the risk of a positive nonsentinel node varies from only $2 \%$ to $9 \%$. For instance, in the NSABP B-32 study the sentinel lymph node biopsy false-negative rate was $9.8 \%{ }^{5}$. This seems to be an acceptable rate, if missed, especially when one considers that an increasing number of these patients are treated with adjuvant systemic therapy, reducing the risk that these undetected non-sentinel node metastases will ever become clinically apparent. Recently, the results from the ACOSOG Z0011 were reported, randomizing patients with 1 or 2 haematoxylin-eosin-positive sentinel nodes to observation or axillary lymph node dissection ${ }^{3}$. Five-year regional recurrence rate was $0.9 \%$ for sentinel node only compared to $0.5 \%$ for axillary lymph node dissection $(p=0.11)$. Adjuvant systemic therapy was used in the majority of patients (97\%). In the IBCSG Trial 23-01, 931 patients were randomized between axillary lymph node dissection and no axillary lymph node dissection when patients had minimal sentinel node involvement ${ }^{6}$. Minimal involvement was defined as metastases of $\leq 2.0 \mathrm{~mm}$ in size, including presence of isolated tumor cells. After 5 years follow-up less than $1 \%$ of patients had an axillary recurrence with no significant difference between both treated arms. Again of note, $92 \%$ of patients received breast conserving surgery with adjuvant radiotherapy, and $96 \%$ of patients received systemic therapy.

Internationally, it is recommended to examine the sentinel node with haematoxylineosin (H\&E) at, at least, 3 levels of the paraffin block, with immunohistochemistry (IHC) to be used in case of doubt. In the Netherlands, these minimal recommendations actually led to different local protocols. In some hospitals more than the minimally required number of levels is routinely investigated. In the eastern part of the Netherlands, 3 large teaching hospitals and 1 university hospital registered all their sentinel node procedures prospectively during 18 months in the years 2002 and 2003. Based on this registry, we reported earlier that a very intensive pathology protocol in 1 hospital, led to a high detection frequency of isolated tumor cells in the sentinel node. At the time, a completion axillary lymph node dissection was 
recommended for all these patients. As a consequence more than twice as many patients underwent a completion axillary lymph node dissection in the hospital with the intensified pathology protocol as compared with the hospitals who used the standard intensive pathology protocol (66\% versus $29 \% ; p<0.0001)^{7}$.

In this present study we report the follow-up data of patients in these 4 hospitals who had a negative sentinel node, and therefore did not undergo an additional axillary lymph node dissection.

The obvious question was, whether ultra-staging, and thus more patients needing to undergo an additional axillary lymph node dissection, is an effective way of reducing the risk of relapse.

\section{Methods}

During eighteen months in the years 2002 and 2003 (January 2002-June 2003), consecutive patients from 4 hospitals (A, B, C, and D) were prospectively registered when they underwent a sentinel node biopsy because of a cT1/T2NOMx breast tumor. Patients were excluded from a sentinel node biopsy when there was presence of multifocality of the primary breast tumor, when they were treated with radiation therapy of the breast or axilla in the past, when patients had received neo-adjuvant systemic therapy, or when the sentinel node was not detectable. The ethical committee approved the investigational protocol.

The prospectively collected data included the lymph node status with number of nodes examined, number of positive nodes, size of metastases, classification according to the tumor node metastasis (TNM) categories defined in the $6^{\text {th }}$ edition of the TNM Classification of Malignant Tumors ${ }^{8}$, and the detection method (H\&E/IHC). These items were separately registered for sentinel nodes and non-sentinel nodes. Also primary tumor characteristics (localization, tumor size, histology, histological grade, lymph and/or blood vessel invasion, hormone receptor status), patient characteristics (age), information on the surgical procedure (sentinel node biopsy with or without axillary lymph node dissection, lumpectomy or mastectomy, and various combinations), and information on adjuvant therapy (systemic and/or radiotherapy) were collected.

The surgical procedure was, in all 4 hospitals, in accordance to the Dutch guideline for treatment of breast cancer ${ }^{9}$. That is, sentinel node localization was performed using the combined technique of blue dye and radioisotope in all patients. In the presence of isolated tumor cells, micro-, or macro-metastases in the sentinel node, a completion axillary lymph node dissection was recommended. 
The Dutch guideline for treatment of breast cancer describes only the minimal criteria concerning the sentinel node pathology protocol. It is advised to examine the sentinel node with haematoxylin-eosin at, at least, 3 levels of the paraffin block with immunohistochemistry to be used in case of doubt. As a result, in hospitals A, B, and C, 3 levels of the sentinel node were pathologically examined, whereas in hospital $\mathbf{D}$, at least 7 additional levels were examined (at least 10 levels in total). In the absence of apparent metastases with haematoxylin-eosin examination, immunohistochemistry examination was performed in all 4 hospitals.

According to the international TNM-classification 2002, isolated tumor cells, micrometastases, and macro-metastases were classified as follows: isolated tumor cells [pNO(i+)] are defined as solitary tumor cells or tumor cell clusters with a size of $0.2 \mathrm{~mm}$ or less. Micro-metastases [pN1mi] are more than $0.2 \mathrm{~mm}$ and maximally $2.0 \mathrm{~mm}$ in size. Macro-metastases are $>2.0 \mathrm{~mm}$ in size. For the sentinel node findings, 'sentinel node' was added between brackets [pN(sn)].

This present analysis focuses on the sentinel node negative patients in hospitals A, B, $\mathbf{C}$, and $\mathbf{D}$. These sentinel node negative patients did not undergo a completion axillary lymph node dissection.

For all patients still alive, follow-up data were collected up to July $1^{\text {st }} 2008$, guaranteeing a follow-up period of at least 5 years.

Follow-up of patients was done in line with the national guidelines ${ }^{9}$. In short: in the first year 3-monthly visit with physical examinations, in the second year 6-monthly, and thereafter yearly. All patients with remaining breast tissue underwent a yearly mammography and if indicated also an MRI scan. An ultrasound of the axilla was not routinely recommended. Axillary and infra- and supraclavicular lymph node recurrence was considered regional recurrence.

\section{Statistical analysis}

The primary endpoint was the 5-year rate of regional recurrence, involving axillary and infra- and supraclavicular sites. The period to regional recurrence was defined as the interval from the date of diagnosis to regional recurrence. All regional recurrences were recorded, irrespective of presence of distant metastases. Patients who died before the end of follow-up were censored. Follow-up was censored at July $1^{\text {st }} 2008$. To determine whether an association exists between the sentinel node pathology protocol and regional recurrence rate, we compared the outcome for hospital D versus hospital A, B, and $\mathbf{C}$.

The baseline characteristics of the 4 hospitals were compared with chi-square tests. The hazard rate for regional recurrence for 5 years follow-up was determined using life-table analysis, reported with 95\% confidence interval $(\mathrm{Cl})$. Differences between hospitals $\mathbf{D}$ versus $\mathbf{A}, \mathbf{B}$, and $\mathbf{C}$ were analyzed by using the logrank-test.

A $p$-value $<0.05$ was considered statistically significant. 


\section{Results}

\section{Patient characteristics}

We registered 198 eligible patients in hospital A, of which 134 (67.6\%) patients had a negative sentinel node. In hospital B 120 out of $153(78.4 \%)$ patients had a negative sentinel node, 59 out of 104 (56.7\%) patients in hospital C, and 28 out of 86 (32.6\%) patients in hospital $\mathbf{D}$.

Patients in hospital D were more often diagnosed with isolated tumor cells $134.9 \%$ versus $5.3 \%$ in $\mathbf{A}, \mathbf{B}$, and $\mathbf{C}, p<0.001$ ), which resulted in more completion axillary lymph node dissections. Sixty-nine percent of patients in hospitals $\mathbf{A}, \mathbf{B}$, and $\mathbf{C}$, as compared to $33 \%$ of patients in hospital $\mathbf{D}$ did not undergo a completion axillary lymph node dissection, because of a negative sentinel node $(p<0.0001)$.

In total, 341 patients (63\% of all registered patients) were sentinel node negative, and did not undergo an additional axillary lymph node dissection. Patient and primary tumor characteristics for the sentinel node negative patients are shown in Table 6.1. There were overall no differences between hospital $\mathbf{D}$ versus hospitals $\mathbf{A}, \mathbf{B}$, and $\mathbf{C}$.

Table 6.1 Patient and primary tumor characteristics of sentinel node negative patients per hospital.

\begin{tabular}{|c|c|c|c|c|c|}
\hline Baseline characteristics & $\begin{array}{l}\text { Hospital A } \\
\text { Number of } \\
\text { patients } \\
n=131(\%)\end{array}$ & $\begin{array}{c}\text { Hospital B } \\
\text { Number of } \\
\text { patients } \\
\mathrm{n}=113(\%)\end{array}$ & $\begin{array}{c}\text { Hospital C } \\
\text { Number of } \\
\text { patients } \\
n=59(\%)\end{array}$ & $\begin{array}{l}\text { Hospital D } \\
\text { Number of } \\
\text { patients } \\
n=28(\%)\end{array}$ & $\begin{array}{c}p \text {-value } \\
\text { Hospital D } \\
\text { versus } \\
A, B \text {, and C }\end{array}$ \\
\hline Age: & & & & & 0.799 \\
\hline$<50$ & $30(22.9)$ & $26(23.0)$ & $15(25.4)$ & $6(21.4)$ & \\
\hline $50-<60$ & 47 (35.9) & $28(24.8)$ & $17(28.8)$ & $10(35.7)$ & \\
\hline $60-<70$ & $29(22.1)$ & $31(27.4)$ & $16(27.1)$ & 5 (17.9) & \\
\hline$\geq 70$ & $25(19.1)$ & $28(24.8)$ & $11(18.7)$ & $7(25.0)$ & \\
\hline Tumor size $(\mathrm{cm})^{\mathrm{a}}$ : & & & & & 0.158 \\
\hline$<1.0$ & $22(16.8)$ & $42(37.8)$ & $16(27.6)$ & 12 (42.9) & \\
\hline $1.1-2.0$ & $61(46.6)$ & $51(46.0)$ & $30(51.7)$ & 9 (32.1) & \\
\hline $2.1-3.0$ & $38(29.0)$ & $13(11.7)$ & $8(13.8)$ & $4(14.3)$ & \\
\hline$>3.0$ & $10(7.6)$ & $5(4.5)$ & $4(6.9)$ & $3(10.7)$ & \\
\hline Histological grade ${ }^{\mathrm{b}}$ : & & & & & 0.979 \\
\hline 1 & $30(23.1)$ & $49(44.1)$ & $20(33.9)$ & 9 (34.6) & \\
\hline II & $61(46.9)$ & $47(42.3)$ & $25(42.4)$ & $11(42.3)$ & \\
\hline III & $39(30.0)$ & $15(13.6)$ & $14(23.7)$ & $6(23.1)$ & \\
\hline Hormone-receptor status': & & & & & 0.339 \\
\hline ER and/or PgR + & $120(91.6)$ & 88 (77.9) & 47 (79.7) & 20 (76.9) & \\
\hline ER and PgR - & $11(8.4)$ & $25(22.1)$ & $12(20.3)$ & $6(23.1)$ & \\
\hline Lymph and/or blood vessel invasion: & & & & & 0.129 \\
\hline No & $124(94.7)$ & $109(96.5)$ & $57(96.6)$ & $25(89.3)$ & \\
\hline Yes & $7(5.3)$ & $4(3.5)$ & $2(3.4)$ & $3(10.7)$ & \\
\hline
\end{tabular}




\section{Risk of regional lymph node recurrence}

At a follow-up of at least 5 years, 9 patients showed a regional lymph node relapse. Of these patients 5 patients underwent a mastectomy, and 4 patients underwent breast conserving surgery followed by radiotherapy. Only 4 out of 9 patients who had a recurrence received adjuvant systemic therapy (Table 6.2). Five (1.5\%) patients had an axillary lymph node recurrence and $4(1.2 \%)$ patients a supraclavicular recurrence (Table 6.3). There were no patients with combined relapse.

Based on actuarial cumulative risk analysis for regional recurrence, the 5-year regional recurrence rate was $2.4 \%$ ( $95 \% \mathrm{Cl} 0.8-4.0)$.

At this moment, none of the patients with a regional relapse had a distant relapse, and all patients with axillary lymph node recurrence underwent a delayed axillary lymph node dissection.

Table 6.2 Patient characteristics of patients with regional lymph node recurrence.

\begin{tabular}{llcccccc}
\hline Patient Age-group & $\begin{array}{c}\text { Tumor size } \\
(\mathrm{cm})\end{array}$ & $\begin{array}{c}\text { Histological } \\
\text { grade }\end{array}$ & $\begin{array}{c}\text { Hormone- } \\
\text { receptor } \\
\text { status }\end{array}$ & $\begin{array}{c}\text { Systemic } \\
\text { therapy }\end{array}$ & $\begin{array}{c}\text { Radiation } \\
\text { therapy }\end{array}$ & $\begin{array}{c}\text { Time to } \\
\text { lymph node } \\
\text { recurrence } \\
\text { (months) }\end{array}$ \\
\hline 1 & $\geq 70$ & 1.4 & I & ER and PgR + & - & + & 23 \\
2 & $50-59$ & 1.5 & II & PgR + & + & - & 31 \\
3 & $\geq 70$ & 3.5 & I & ER + & + & - & 4 \\
4 & $60-69$ & 1.5 & I & ER + & - & + & 27 \\
5 & $60-69$ & 3.5 & II & ER + & + & - & 47 \\
6 & $50-59$ & 2.2 & III & ER and PgR + & + & - & 60 \\
7 & $\geq 70$ & 0.8 & I & ER + & - & - & 26 \\
8 & $\geq 70$ & 1.5 & II & ER and PgR + & - & + & 11 \\
9 & $60-69$ & 0.9 & I & ER + & - & + & 66 \\
\hline
\end{tabular}

Table 6.3 Recurrence pattern for sentinel node negative patients per hospital and the total group.

\begin{tabular}{lcccc|c}
\hline & $\begin{array}{c}\text { Hospital A } \\
\text { Number of } \\
\text { patients } \\
\mathrm{N} \mathrm{( \% )}\end{array}$ & $\begin{array}{c}\text { Hospital B } \\
\text { Number of } \\
\text { patients } \\
\mathrm{N}(\%)\end{array}$ & $\begin{array}{c}\text { Hospital C } \\
\text { Number of } \\
\text { patients } \\
\mathrm{N} \mathrm{( \% )}\end{array}$ & $\begin{array}{c}\text { Hospital D } \\
\text { Number of } \\
\text { patients } \\
\mathrm{N}(\%)\end{array}$ & $\begin{array}{c}\text { Total } \\
\text { Number of } \\
\text { patients } \\
\mathrm{N}(\%)\end{array}$ \\
\hline $\begin{array}{l}\text { Total number sentinel node } \\
\text { procedures/patients }\end{array}$ & 198 & 153 & 104 & 86 & 541 \\
$\begin{array}{l}\text { Sentinel node negative } \\
\text { patients }\end{array}$ & $134(67.6)$ & $120(78.4)$ & $59(56.7)$ & $28(32.6)$ & $341(63.0)$ \\
\hline $\begin{array}{l}\text { Axillary recurrence } \\
\begin{array}{l}\text { Supraclavicular recurrence } \\
\text { Local recurrence }\end{array}\end{array}$ & $3(2.2)$ & 0 & $2(3.4)$ & 0 & $5(1.5)$ \\
\hline
\end{tabular}

Based on actuarial analysis, the 5-year regional recurrence rate for hospital A was 3.0\% (95\% Cl 0.0-6.0), for hospital B 1.7\% (95\% Cl 0.0-4.1), and 3.4\% (95\% Cl 0.0-8.2) for hospital C. There were no regional recurrences in hospital D (Figure 6.1). When 
taken hospitals A, B, and $\mathbf{C}$ together, the 5-year regional recurrence rate was $2.6 \%$ (95\% $\mathrm{Cl} 0.8-4.4)$, as compared to $0.0 \%$ in hospital $\mathbf{D}(p=0.37)$.

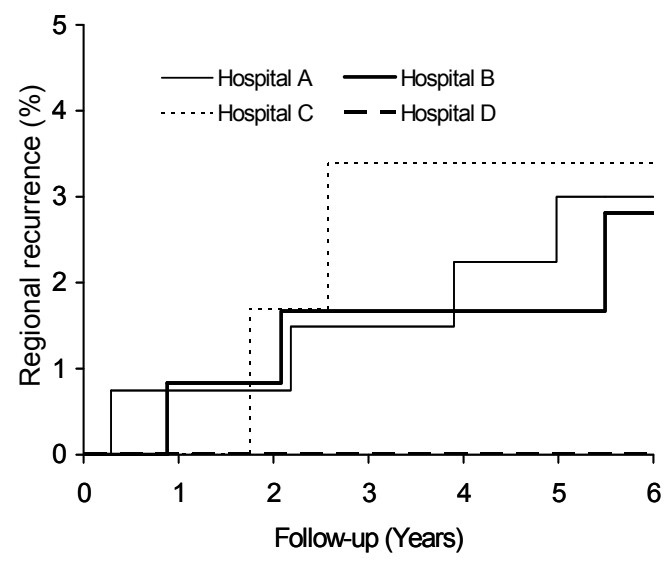

Figure 6.1 Cumulative risk for regional lymph node recurrence per hospital.

Table 6.2 shows patient and primary tumor characteristics, as well as the timeframe to nodal recurrence, of the 9 cases with regional lymph node recurrence.

All patients were 50 years of age or older and had an ER or PgR positive tumor. Five of 9 patients had not received adjuvant systemic therapy.

At a follow-up of 60 to 78 months, median time to recurrence was 27 months with a range of 4 to 66 months.

\section{Discussion}

We reported before that further intensification of the sentinel node pathology protocol, beyond the minimal recommendations, resulted in $37 \%$ more axillary lymph node dissections because of higher detection frequency of sentinel node isolated tumor cells ${ }^{7}$. Whether such a policy would reduce the number of recurrences, was the subject of this present study. In hospital $\mathbf{D}$, using ultra-staging of the sentinel node, no lymph node recurrences occurred during a follow-up of more than 5 years. In contrast, in the 3 hospitals (A, B, and C) using the 'standard intensified' pathology protocol, the 5 -years regional recurrence risk was $2.6 \%$.

Assuming that there is an absolute difference in the risk of regional recurrence of $3 \%$ between the hospitals with a 'standard intensified' pathology protocol and those which perform ultra-staging of the sentinel node, the question raises whether 37 
extra axillary lymph node dissections per 100 patients are worthwhile in order to prevent 3 regional recurrences. It gives a ratio for number needed to treat of approximately $1: 13$. In terms of morbidity of the surgical procedure and in terms of costs, a more than 'standard intensified' pathology protocol may thus not be of value. Of note, during inclusion the national breast cancer guidelines of the Netherlands were quite conservative with respect to the recommendations for adjuvant systemic therapy. Only 4 out of 9 patients who had a recurrence had received adjuvant systemic therapy (Table 6.2). Nowadays, more patients with sentinel node micrometastases are treated with more effective systemic therapy, such as anthracycline/taxane-containing regimens, which are considered the most effective chemotherapy in early breast cancer. If more patients would have had adjuvant systemic therapy, the risk of relapse might have been lower ${ }^{10}$. Further of note, 5 of 9 patients were treated with mastectomy without radiotherapy. The excellent results of the Z0011 study are thought to be related to the use of tangential radiotherapy to the axilla as part of the for inclusion requested breast conserving surgery, and the use of systemic therapy in nearly all patients.

In the years 2002 and 2003, it was within the Netherlands common practice that patients with isolated tumor cells in the sentinel node underwent a completion axillary lymph node dissection ${ }^{9}$, but during later years this policy changed, in agreement with ASCO guidelines. ASCO guidelines do not recommend a routine axillary lymph node dissection if just isolated tumor cells are detected in the sentinel node $^{11}$.

In literature, many single center series and 4 randomized trials have been reported on axillary recurrence rates in patients with a negative sentinel node $\mathrm{s}^{5,12-14}$. The reported recurrence rates in these studies regarding sentinel node negative patients seem to be lower compared to our study. In most series the pathology protocol was not or only briefly mentioned as if this would not impact recurrence rate. In the first randomized trial on this topic, by Veronesi et al, it was reported that a very intensive sentinel node pathology protocol was used ${ }^{15}$. In that particular study, approximately 15 pairs of sections were cut at 50 micrometer intervals of each half of the sentinel node, with approximately 60 sections per sentinel node being examined. It is important to realize that the excellent follow-up results from this center cannot simply be translated to other hospitals if another pathology protocol is followed.

Also of note, in the aforementioned randomized Milan study only patients with a tumor of $2 \mathrm{~cm}$ or less were included, whereas currently in most centers the sentinel node procedure is implemented for patients having a tumor size of $5 \mathrm{~cm}$ or less. This is of relevance, because, irrespective of sentinel node findings, the primary tumor characteristics are also strongly associated with risk of non-sentinel node metastases ${ }^{16}$. 
In fact, breast cancer-specific survival is the most relevant endpoint to judge the clinical impact of the different sentinel node pathology protocols. To this end, still too few deaths have occurred to draw conclusions with regard to differences in outcome between hospitals. We will continue to collect follow-up information from this cohort on disease-specific events, including breast cancer-related death.

In conclusion, we showed that hospital D performed 37\% more completion axillary lymph node dissections for no improvement in regional recurrence rate as compared to hospitals $\mathbf{A}, \mathbf{B}$, and $\mathbf{C}$ at 5 years follow-up. Whether the intensified sentinel node pathology protocol of hospital $D$ proves to be of value in 10 years, remains to be awaited. To this end, a sentinel node pathology protocol as is used in most centers nowadays, with on average 3 levels per paraffin block, seems to be adequate. 


\section{References}

1. Fisher B, Bauer M, Wickerham DL, et al. Relation of number of positive axillary nodes to the prognosis of patients with primary breast cancer. An NSABP update. Cancer 1983;52:1551-1557.

2. Mansel RE, Fallowfield L, Kissin M, et al. Randomized multicenter trial of sentinel node biopsy versus standard axillary treatment in operable breast cancer: the ALMANAC Trial. J Natl Cancer Inst 2006;98:599-609.

3. Giuliano $A E$, Haigh $\mathrm{PI}$, Brennan $\mathrm{MB}$, et al. Prospective observational study of sentinel lymphadenectomy without further axillary dissection in patients with sentinel node-negative breast cancer. J Clin Oncol 2000;18:2553-2559.

4. Van Dijck JA, Coebergh JW, Siesling S, et al. Breast cancer in women. In: Trends of cancer in the Netherlands 1989-1998 (ed). Utrecht, the Netherlands: Association of comprehensive cancer centers/Netherlands Cancer Registry, 2002: 31-32.

5. Krag DN, Anderson SJ, Julian TB et al. Sentinel lymph node resection compared with conventional axillary lymph node dissection in clinically node-negative patients with breast cancer: overall survival findings from the NSABP B-32 randomized phase 3 trial. Lancet Oncol 2010;11:927-933.

6. Galimberti V, Cole BF, Zurrida S, et al. Update of International Breast Cancer Study Group Trial 23-01 to compare axillary dissection versus no axillary dissection in patients with clinically node negative breast cancer and micrometastases in the sentinel node. Cancer Res 2011;71(24 Suppl):\#S3-1.

7. Bolster MJ, Bult P, Schapers RF, et al. Differences in sentinel lymph node pathology protocols lead to differences in surgical strategy in breast cancer patients. Ann Surg Oncol 2006;13:1466-1473.

8. Sobin LH, Wittekind C. International union against cancer. TNM classification of malignant tumors, Sixth Edition. New York: Wiley-Liss, 2002.

9. National Breast Cancer Organization Netherlands (2004). Guideline treatment of patients with breast cancer. Available: http://www.oncoline.nl.

10. de Boer $\mathrm{M}$, van Deurzen $\mathrm{CH}$, van Dijck JA, et al. Micrometastases or isolated tumor cells and the outcome of breast cancer. N Engl J Med 2009;361:653-663.

11. Lyman GH, Giuliano AE, Somerfield MR, et al. American Society of Clinical Oncology guideline recommendations for sentinel lymph node biopsy in early-stage breast cancer. J Clin Oncol 2005;23:7703-7720.

12. Canavese G, Catturich A, Vecchio C, et al. Sentinel node biopsy compared with complete axillary dissection for staging early breast cancer with clinically negative lymph nodes: results of randomized trial. Ann Oncol 2009;20:1001-1007.

13. Zavagno G, De Salvo GL, Scalco G, et al. A randomized clinical trial on sentinel lymph node biopsy versus axillary lymph node dissection in breast cancer: results of the Sentinella/GIVOM trial. Ann Surg 2008;247:207-213.

14. Veronesi U, Paganelli G, Viale G, et al. Sentinel-lymph-node biopsy as a staging procedure in breast cancer: update of a randomized controlled study. Lancet Oncol 2006;7:983-990.

15. Veronesi U, Paganelli G, Viale G, et al. A randomized comparison of sentinel-node biopsy with routine axillary dissection in breast cancer. N Engl J Med 2003;349:546-553.

16. Bolster MJ, Peer PG, Bult $P$, et al. Risk factors for non-sentinel lymph node metastases in patients with breast cancer. The outcome of a multi-institutional study. Ann Surg Oncol 2007;14:181-189. 


\section{Chapter 7}

General conclusions and future perspectives 
94 Chapter 7 


\section{General conclusions and future perspectives}

This thesis addresses several major topics with regard to the sentinel node procedure, based on the data of two studies, the MIRROR and the VAZ-01122 studies. First, whether patients can be identified that do not need completion axillary lymph node dissection in the presence of minimal sentinel node involvement. Secondly, whether models predicting non-sentinel node involvement can also be used to select patients for axillary lymph node dissection. Thirdly, the influence of the pathology protocol on decision making and quality of delivered axillary treatment.

In the MIRROR study cohort, we showed that not performing axillary treatment in patients with sentinel node micrometastases is associated with an increased 5-year regional recurrence rate, and that doubling of tumor size, grade 3 and negative hormone receptor status were also significantly associated with recurrence ${ }^{1}$. The ACOSOG Z0011 trial, published in 2011, demonstrated no benefit of axillary lymph node dissection for patients with one to two metastatic sentinel lymph nodes. This study included women with clinical T1-2N1M0 breast cancer, treated with lumpectomy and breast irradiation. Patients with one or two positive sentinel nodes detected by haematoxylin-eosin were randomized to axillary lymph node dissection or no further axillary treatment. No statistically significant differences existed in overall survival and disease-free survival between the two groups. Equally important, regional recurrence rate in the sentinel node only group was less than $1 \%$ despite the fact that an estimated $27 \%$ of patients had additional metastases in the undissected axillary nodes ${ }^{2}$. The low regional recurrence rate of 20011 against the much higher regional recurrence rate of the MIRROR study can be explained by several factors. These can be divided in factors concerning patient and tumor characteristics and factors concerning differences in treatment. With regard to patient and tumor characteristics, both studies included patients with small tumors and limited lymph node metastases. Policies on systemic therapy, surgery and irradiation were, however, different between the two studies. In the Netherlands indications for systemic therapy were conservative for the inclusion period (1997-2006) of the MIRROR study, with only $31 \%$ having received systemic therapy. Nowadays, more patients with nodal micrometastases are treated with more effective systemic therapy ${ }^{3}$. In contrast, in Z0011 almost all patients were treated with systemic therapy, and chemotherapy consisted mainly of anthracycline/taxane-containing chemotherapy which is now considered being the most effective chemotherapy in early breast cancer. Moreover, in Z0011 almost all patients were treated with breast irradiation as part of breast conserving therapy which covers part of levels I and II of the axilla, possibly sterilizing nodal metastases. In the MIRROR study only $65 \%$ of the patients underwent breast irradiation.

The Z0011 trial demonstrates that in patients with favorable small primary tumors and low axillary tumor burden, axillary lymph node dissection can safely be withheld. 
However, the results of Z0011 cannot be generalized to all sentinel node positive patients, such as patients treated with neo-adjuvant systemic therapy, patients not treated with adjuvant systemic therapy, patients treated with mastectomy without irradiation, patients with larger primary tumor size and/or other unfavorable characteristics, patients with more than two positive sentinel nodes, and patients treated with modern breast irradiation techniques no longer including axillary lymph node levels. Also longer follow up than the median of 6.5 years is needed, as in women with ER positive disease who take 5 years of adjuvant endocrine therapy, more than half of all recurrences arise after year $5^{4}$. NCCN changed the guideline in 2012 to consider withholding patients additional axillary lymph node dissection if they meet all inclusion criteria of Z0011. If not, then axillary lymph node dissection is still recommended ${ }^{5}$. In the Netherlands the updated guideline allows omission of routine axillary lymph node dissection in micrometastatic and limited macrometastatic disease provided patients have undergone breast-conserving therapy with whole breast irradiation followed by adjuvant systemic therapy ${ }^{3}$. In this respect it is important to consider the type of breast irradiation. If modern techniques with $3 D$ confirmation is used, than irradiation on level 1 of the axilla should be considered, in agreement with conventional breast irradiation techniques as were used in Z0011.

The differences in initial treatments and breast cancer outcome as seen in the MIRROR study as opposed to the Z0011 study have shown the importance of daily practice assessments. A foreign clinical study, even a randomized one, cannot be implemented here, if that study didn't use the same baseline treatments as the current practice in the Netherlands. The updated NABON guidelines have, therefore, explicitly mentioned use of systemic therapy and use of axillary irradiaton as criteria for omission of axillary dissection.

Whether axillary irradiation can replace axillary lymph node dissection is the subject of the AMAROS (After Mapping of the Axilla: Radiotherapy Or Surgery?) study, in which patients with sentinel node metastases are randomized between axillary irradiation or lymph node dissection ${ }^{6}$. Results of the AMAROS study are expected in a few years.

As the risk of non-sentinel node metastases not only depends on the number and size of sentinel node metastases, but also on primary tumor characteristics ${ }^{7}$, nomograms that incorporate these items provide an improved estimate of additional non-sentinel lymph node involvement ${ }^{8}$. However, non-sentinel node involvement is not 1:1 associated with risk of axillary recurrence when axillary treatment is omitted, as systemic therapy and breast irradiation techniques will influence this risk of recurrence ${ }^{9}$.

Therefore, we evaluated in the MIRROR cohort whether four nomograms that were validated in macro- and micrometastatic sentinel node disease to predict non-sentinel node involvement could also predict regional recurrence rates ${ }^{10}$. These four 
nomograms all incorporated primary tumor characteristics besides presence and size of sentinel node metastases. In our cohort, the Tenon score ${ }^{11}$ identified a small group with a high risk score (being at risk of non-sentinel involvement), which showed to be associated with a high regional recurrence rate when not treated with further axillary treatment. In the (large) patient group with a low risk of non-sentinel node involvement, a low regional recurrence rate was observed when axillary treatment was omitted. The other three models performed worse as compared to the Tenon model.

Hence, the Tenon scoring system might be useful in future decision-making with regard to use of additional axillary treatment. However, we also appreciate that all models, including the Tenon score model, were not $100 \%$ perfect. These uncertainties should be mentioned when discussing the proposed breast cancer treatments with the patient. Further research is needed to improve selection of patients with regard to axillary treatment, and to reduce the risk of overtreatment.

In the neoadjuvant setting, patients with cytology proven axillary metastases at primary diagnosis, who have complete pathological response in the sentinel node biopsy after neoadjuvant treatment, might not need further axillary surgery. As such this could be a way to further reduce the numbers of completion lymph node dissection. But, as current evidence from non-randomized trials still shows a relative large false-negative rate in the sentinel node after chemotherapy, further research in this setting is still needed. On the other hand, patients who do not have a complete pathological response after neo-adjuvant systemic therapy and/or patients who have a false-negative sentinel node after neo-adjuvant systemic therapy may not all experience a regional recurrence, if no axillary treatment is given, as not all metastatic cells in the axillary nodes have outgrowth potential and moreover, part of these patients may receive further HER2-targeted and endocrine adjuvant therapy. Tissue microarray analysis may help to identify the patients that may respond to these additional therapies ${ }^{12}$.

Actually, the sentinel node procedure was introduced as a way to reduce the need of further axillary surgery, in those with a negative sentinel node. Concerns regarding the false negative rate of the sentinel node procedure and risk of axillary recurrences led, however, to an intensified sentinel node pathology protocol ${ }^{13}$. Beside the traditional haematoxylin-eosin section, multiple slides of the sentinel node were made, i.e. stepsectioning, when the first section appeared to be tumor negative. Also immunohistochemistry is a technique that has proven to be useful for detection of tumor cells, especially micrometastases and isolated tumor cells ${ }^{14}$. It is clear that the goal of the sentinel node procedure is not to find all metastases, but to find clinically relevant metastases, because not all metastases have outgrowth potential.

In the MIRROR study, nodal status was assessed after central pathology review and restaged according to the 6 th $A J C C$ classification ${ }^{15}$. Central pathology review changed 
the nodal-classification in $24 \%$ of the patients, mainly upstaging, with potentially clinical relevance for individual patients. Most of the upstaging concerned patients in whom sentinel node involvement was identified by immunohistochemistry ${ }^{16}$.

But, the routine use of immunohistochemistry in order to look for low volume disease was declined by a majority of panel members of the 2011 St. Gallen Consensus Conference and is also not a required part of sentinel node evaluation according to $\mathrm{ASCO}^{17,13}$. NCCN recommends immunohistochemistry in equivoqual cases on haematoxylin-eosin ${ }^{5}$.

Although in studies the presence of isolated tumor cells was shown to be related to prognosis $^{18,19}$, the magnitude of the difference in disease-free survival and overall survival at 5 years is small ${ }^{18}$. Secondly, the number of patients in whom adjuvant systemic therapy is given because of sentinel node isolated tumor cells instead of characteristics of the primary tumor is low. Therefore we also think that with current available evidence with regard to systemic therapy the effort of immunohistochemical nodal assessment may not outweigh the benefit. Also because the presence of isolated tumor cells is not taken into account for axillary treatment decision-making, as the risk of non-sentinel node involvement is $l o w^{20}$. Sentinel node micrometastases are still considered relevant for axillary treatment. So, the pathology protocol should be directed to find sentinel node micrometastases.

In conclusion, axillary treatment is no longer recommended in all sentinel node positive patients. Careful selection of patients in whom additional axillary treatment can be omitted is warranted. Nomograms can be used in clinical decision making to inform patients about the risks and benefits to treat or not to treat potential axillary metastases, but these are not perfect instruments. The risk of regional recurrences must be weighed against the risk of overtreatment.

Hence, the results as obtained from studies as presented in this thesis must be seen in the light of current diagnostic tools. In view of the rise of targeted therapies directed against tumor and micro-environment factors, and the developments in gene profiling of the primary tumor and metastases, patients who are at increased risk for breast cancer recurrence will be defined increasingly more precisely ${ }^{21}$. Therefore, policies on axillary treatment are expected to change further in the next decade. 


\section{References}

1. Pepels MJ, Vestjens JH, de Boer M, Smidt M, van Diest PJ, Borm GF, Tjan-Heijnen VC. Safety of avoiding routine use of axillary dissection in early stage breast cancer: a systematic review. Breast Cancer Res Treat 2011;125:301-313.

2. Giuliano $\mathrm{AE}$, Hunt $\mathrm{KK}$, Ballman $\mathrm{KV}$, et al. Axillary dissection vs no axillary dissection in women with invasive breast cancer and sentinel node metastasis: a randomized clinical trial. JAMA 2011;305: 569-575.

3. Mammacarcinoom. Landelijke richtlijn, versie 2.0. Nationaal Borstkanker Overleg Nederland (NABON). Available at: www.oncoline.nl .

4. Saphner T, Tormey DC, Gray R. Annual hazard rates of recurrence for breast cancer after primary therapy. J Clin Oncol 1996;14:2738-2746.

5. NCCN Guidelines Version 3.2012 Invasive Breast Cancer. Available at: www.nccn.org.

6. Straver ME, Meijnen P, van Tienhoven $G$, et al. Role of axillary clearance after a tumor-positive sentinel node in the administration of adjuvant therapy in early breast cancer. J Clin Oncol 2010;28:731-737.

7. Bolster MJ, Peer PG, Bult P, Thunnissen FB, Schapers RF, Meijer JW, Strobbe LJ, van Berlo CL, Klinkenbijl JH, Beex LV, Wobbes T, Tjan-Heijnen VC. Risk factors for non-sentinel lymph node metastases in patients with breast cancer. The outcome of a multi-institutional study. Ann Surg Oncol 2007;14:181-189.

8. Coutant C, Olivier C, Lambaudie E, et al. Comparison of models to predict nonsentinel lymph node status in breast cancer patients with metastatic sentinel lymph nodes: a prospective multicenter study. J Clin Oncol 2009;27:2800-2808.

9. Fisher $\mathrm{B}$, Jeong $\mathrm{JH}$, Anderson $\mathrm{S}$, et al. Twenty-five-year follow up of a randomized trial comparing radical mastectomy, total mastectomy, and total mastectomy followed by irradiation. $\mathrm{N}$ Engl J Med 2002;347:567-575.

10. Pepels MJ, Vestjens JH, de Boer M, Bult P, van Dijck JA, Menke-Pluijmers M, van Diest PJ, Borm G, Tjan-Heijnen VC. Submitted. Presented in part at San Antonio Breast Cancer Congress December 2011. Models predicting non-sentinel node involvement also predict for regional recurrence in breast cancer patients without axillary treatment. Presented in part at San Antonio Breast Cancer Congress December 2011. Abstract PD02-07.

11. Barranger E, Coutant C, Flahault A, et al. An axilla scoring system to predict non-sentinel lymph node status in breast cancer patients with sentinel lymph node involvement. Breast Cancer Res Treat 2005;113-119.

12. Colombo P, Milanezi F, Weigelt B, Reis-Filho JS. Microarrays in the 2010s: the contribution of microarray-based gene expression profiling to breast cancer classification, prognostication and prediction. Breast Cancer Res 2011;13:212.

13. Lyman $G H$, Giuliano $A E$, Somerfield $M R$ et al. American Society of Clinical Oncology guideline recommendations for sentinel lymph node biopsy in early-stage breast cancer. J Clin Oncol 2005;23:7703-7720.

14. Cserni G, Amendoeira I, Apostolikas $\mathrm{N}$ et al. Pathological work-up of sentinel lymph nodes in breast cancer. Review of current data to be considered for the formulation of guidelines. Eur J Cancer 2003;39:1654-1667.

15. Green FL, Page DL, Fleming ID. American Joint Committee on Cancer Staging Manual. 6th ed. Philadelphia: Springer; 2002.

16. Vestjens JH, Pepels MJ, de Boer M, Borm GF, van Deurzen CH, van Diest PJ, van Dijck JA, Adang EM, Nortier JW, Rutgers EJ, Seynaeve C, Menke-Pluymers MB, Bult P, Tjan-Heijnen VC. Relevant impact of central pathology review on nodal classification in individual breast cancer patients. Ann Oncol 2012;23:2561-2566.

17. Kaufmann M, Morrow M, von Minckwitz G, Harris JR, Biedenkopf Expert Panel Members. Locoregional treatment of primary breast cancer: consensus recommendations from an International Expert Panel. Cancer 2010;116:1184-1191. 
18. Weaver DL, Ashikaga T, Krag DN, Skelly JM, Anderson SJ, Harlow SP, Julian TB, Mamounas EP, Wolmark N. Effect of occult metastases on survival in node-negative breast cancer. N Engl J Med 2011;364:412-421.

19. de Boer $\mathrm{M}$, van Deurzen $\mathrm{CH}$, van Dijck JA, et al. Micrometastases or isolated tumor cells and the outcome of breast cancer. N Engl J Med 2009;361:653-663.

20. van Deurzen $\mathrm{CH}$, de Boer $\mathrm{M}$, Monninkhof $\mathrm{EM}$, et al. Non-sentinel lymph node metastases associated with isolated breast cancer cells in the sentinel node. J Natl Cancer Inst 2008;22:1574-1580.

21. Gökmen-Polar Y, Badve S. Molecular profiling assays in breast cancer: are we ready for prime time? Oncology 2012;26:350-357, 361. 
Summary 


\section{Summary}

Axillary lymph node status is the most important prognostic factor in breast cancer, that is, prognosis declines with increasing number of tumor positive lymph nodes ${ }^{1}$. Information on lymph node involvement is considered crucial to decide on the most optimal breast cancer treatment in an individual patient. For patients with clinically node-negative disease, the sentinel lymph node procedure nowadays identifies patients with a negative sentinel node who are considered not requiring further axillary treatment, even though we know that a small proportion of patients with a negative sentinel node actually do have a false negative sentinel node ${ }^{2}$. The risk of a false negative sentinel node could be reduced by intensifying the pathology workup of the sentinel node with serial sectioning and use of immunohistochemistry. An intensified pathology protocol leads, however, to an increased detection frequency of small nodal metastases, such as isolated tumor cells or micrometastases ${ }^{3}$. Since 2002, isolated tumor cells ( $\mathrm{pNO}(\mathrm{i}+)$, deposits $\leq 0.2 \mathrm{~mm}$ ) and micrometastases (pN1mi, deposits $>0.2-\leq 2.0 \mathrm{~mm}$ ) are defined as separate categories in the sixth American Joint Committee on Cancer (AJCC) Cancer Staging Manual ${ }^{4}$. One pivotal question, to justify the intensified work-up of the sentinel node, is whether these small nodal metastases are of prognostic relevance. A second relevant question is whether the detection of sentinel node isolated tumor cells or micrometastases warrants further (axillary) treatment. These questions correspond to the major topics of this thesis.

In Chapter 1, a general introduction and outline of the thesis is presented. First, we assessed the impact of sentinel node metastasis size on regional recurrence rate if axillary treatment was withheld. Further, we examined the role of existing nonsentinel node prediction models in identifying the patients who might or might not need axillary treatment. Finally, we describe the role of pathology protocols in decision-making related to axillary treatment and regional recurrence rates.

In Chapter 2, we present a systematic review of the results of all published studies on axillary recurrence rates in patients with clinically node-negative breast cancer, who did or did not undergo axillary lymph node dissection ${ }^{5}$. PubMed and Cochrane library were searched for. Sixty-eight studies were included: studies of clinically nodenegative patients in the pre-sentinel node era (pre-sentinel node studies); observational studies of sentinel node-negative patients, without axillary lymph node dissection; comparative studies of sentinel node-negative patients, with a non-axillary lymph node dissection and an axillary lymph node dissection group; sentinel nodepositive studies, of patients without axillary lymph node dissection. Primary endpoint was the pooled axillary recurrence rate (ARR) of each category; secondary endpoint was the overall survival (OS) rate.

In pre-sentinel node studies, with larger tumors and less systemic therapy, axillary recurrence rate without axillary lymph node dissection after 5-10 years follow-up was 
$12-18 \%$, and the overall survival was reduced by $5 \%$, equivalent to a relative reduction in deaths ranging from $7-46 \%$. In the observational sentinel node-negative studies, with median follow-up of 36 months, the pooled axillary recurrence rate was $0.6 \%(95 \% \mathrm{Cl} 0.6-0.8)$. In the comparative sentinel node-negative studies, pooled axillary recurrence rate was $0.4 \%(95 \% \mathrm{Cl} 0.2-0.6)$ without axillary lymph node dissection versus $0.3 \%(95 \% \mathrm{Cl} 0.1-0.6)$ with axillary lymph node dissection at 31 and 47 months, respectively, and no survival disadvantage. In sentinel node-positive studies, axillary recurrence rate was up to $1.7 \%(95 \% \mathrm{Cl} 1.0-2.7)$ at 30 months. For patients with a haematoxylin-eosin positive sentinel node the axillary recurrence rate without axillary lymph node dissection was $5 \%$ after 23 months, which may imply rates as high as 13 and $18 \%$ after 5 and 8 years.

In conclusion, this systematic review confirms the safety of omitting axillary lymph node dissection in sentinel node-negative patients. There is a potential role for avoiding axillary lymph node dissection in selected sentinel node-positive patients, but eligibility criteria and the role of systemic therapy need further to be elucidated.

We further explored the previous conclusion that there is a potential role for avoiding axillary lymph node dissection in selected sentinel node-positive patients. In Chapter 3 we investigated the impact of axillary treatment, axillary lymph node dissection (axillary lymph node dissection) or irradiation, on 5-year regional recurrence rate in Dutch breast cancer patients with invasive cancer and favorable primary tumor characteristics, and isolated tumor cells or micrometastases in the sentinel node, who were included in the MIRROR study ${ }^{6}$.

In total, 857 patients with node-negative disease, 795 patients with isolated tumor cells, and 1028 patients with micrometastases in the sentinel node were included. Without axillary treatment, the 5-year regional recurrence rates were $2.3 \%, 2.0 \%$, and $5.6 \%$, respectively. Compared with patients who underwent axillary treatment, the adjusted hazard ratio for regional recurrence in patients who underwent a sentinel node procedure only was $1.08(95 \% \mathrm{Cl}, 0.23-4.98)$ for node-negative disease, 2.39 (95\% Cl, 0.67-8.48) for isolated tumor cells, and $4.39(95 \% \mathrm{Cl}, 1.46-13.24)$ for micrometastases. Doubling of tumor size, grade 3 and negative hormone receptor status were also significantly associated with recurrence. Important to note, in our study only $48 \%$ of patients with sentinel node micrometastases and none of the patients with node-negative disease, who did not undergo axillary treatment, had received adjuvant systemic therapy.

We conclude that not performing axillary treatment in patients with sentinel node micrometastases is associated with an increased 5-year regional recurrence rate. Axillary treatment is recommended in patients with sentinel node micrometastases and unfavorable tumor characteristics who will not receive adjuvant systemic therapy. 
Next, we investigated whether it would be possible to identify subgroups of patients for whom axillary treatment would not add to breast cancer outcome and thus could be considered overtreatment.

In Chapter 4 we investigated the association between predicted risk of non-sentinel node involvement by four models and the actual observed regional recurrence rate in patients with favorable early breast cancer and sentinel node isolated tumor cells or micrometastases who did not undergo axillary lymph node dissection, based on data from patients in the MIRROR study ${ }^{7}$. These models include both clinical and pathologic features, such as the size and/or number of the sentinel node metastases, and the size and/or presence of lymphovascular invasion in the primary tumor. Then according to the four models predictions of non-sentinel node metastases were calculated and set against the actual observed regional recurrence rates. The threshold allowing separation into low versus high-risk patients was set at $10 \%$ risk estimation of nonsentinel node involvement. The primary aim was to determine whether the risk estimation of non-sentinel node involvement (low versus high risk) according to one of these four models was associated with the actually observed regional recurrence rate (low versus high). We aimed to assess the predictive quality of the four models. That is, being able to identify a large subgroup of patients with a low recurrence rate in the absence of axillary surgery and a small subgroup of patients with an increased recurrence rate. Overall 5-year regional recurrence rate was 3.0\% (Cl 2.8-3.2). Using the Tenon scoring system ${ }^{8}, 438$ low-risk patients had a 5 -year regional recurrence rate of $2.3 \%$ (CI 1.1-4.6), and 48 high-risk patients a recurrence rate of $10.1 \%$ (Cl 9.3-10.9). The MSKCC nomogram ${ }^{9}$ identified 300 low-risk patients with a recurrence rate of $2.8 \%$ (Cl 1.3-6.1), versus 166 high-risk patients with a rate of $3.4 \%(\mathrm{Cl} 2.5-4.6)$ (20 patients not assessable). The Stanford nomogram ${ }^{10}$ identified 21 high-risk patients without recurrence, and 465 low-risk patients with a $3.2 \%(\mathrm{Cl} 1.8-5.6)$ recurrence rate. A Dutch model $^{11}$ discriminated between 384 low-risk patients with a recurrence rate of $2.2 \%$ (Cl 1.1-4.6) and 102 high-risk patients with a rate of 6.3\% (Cl 2.5-15.8). We conclude that the Tenon scoring system outperformed the other models as it it identified the largest subgroup of patients with a low recurrence rate. In patients resembling our cohort we would recommend axillary treatment if they had a Tenon score above 3.5.

Then we examined the influence of the pathology protocol on decision making and quality of delivered axillary treatment. In the MIRROR study, nodal status was assessed after central pathology review and restaged according to the 6th AJCC classification. In Chapter $\mathbf{5}$ we assessed the impact of pathology review on nodal status $(n=2842)$, and the impact of the review on 5-year disease-free survival related to nodal status for those without adjuvant therapy $(n=1712)^{12} .22 \%$ of the 1082 original pNO patients was upstaged. Of the 623 original pNO(i+) patients, $1 \%$ was downstaged, 26\% was upstaged. Of 1137 patients staged pN1mi, 15\% was downstaged, $11 \%$ upstaged. Originally, 5-year disease-free survival was $85 \%$ for pN0, $74 \%$ for $\mathrm{pNO}(\mathrm{i}+)$, 73\% for pN1mi; HR $1.70(95 \% \mathrm{Cl} 1.27-2.27)$ and $\mathrm{HR} 1.57$ (95\% Cl 1.16-2.13) 
respectively, compared with pN0. By review staging, 5-year disease-free survival was $86 \%$ for $\mathrm{pNO}, 77 \%$ for $\mathrm{pNO}(\mathrm{i}+$ ), $77 \%$ for $\mathrm{pN} 1 \mathrm{mi}$, and $74 \%$ for $\mathrm{pN} 1+$.

We conclude that pathology review changed the nodal classification in $24 \%$, mainly by upstaging, with potentially clinical relevance for individual patients. The association of isolated tumor cells and micrometastases with outcome remained unchanged. Quality control should include nodal breast cancer staging.

Finally we looked at the pathology protocol which is used to examine the sentinel node. In Chapter 6 we examined in 4 hospitals in the Netherlands (A, B, C and D) whether ultra-staging led to a higher frequency of axillary lymph node dissection ${ }^{13}$. The question was, whether ultra-staging and more patients undergoing an additional axillary lymph node dissection, resulted in reducing the risk of relapse. Of 541 patients who underwent a sentinel node procedure, 341 (63\%) patients had a negative sentinel node, and did not undergo an axillary lymph node dissection. In hospital $D$ fewer patients had a negative sentinel node when compared to patients in hospitals $A, B$, and $C(34 \%$ versus $71 \%, p<0.001)$. At 5 years follow-up, $9(2.6 \%)$ patients showed a regional lymph node relapse. Five $(1.5 \%)$ patients had an axillary lymph node recurrence and 4 (1.2\%) patients a supraclavicular recurrence. In hospital D none of the patients had a regional recurrence, as compared to $9(2.9 \%)$ cases of recurrence in hospitals A, B, and C.

In conclusion, we show that patients who had undergone a less intensified sentinel node pathology protocol, with a reduced detection rate of sentinel node isolated tumor cells, had a slightly increased risk of regional recurrence. However, the absolute risk of less than $3 \%$ does not seem to justify the performance of 37 additional axillary lymph node dissections per every 100 patients. Therefore, a sentinel node pathology protocol as is used in most centers nowadays, with on average 3 levels per paraffin block, seems to be adequate. 


\section{References}

1. Fisher B, Bauer M, Wickerham DL, et al. Relation of number of positive axillary nodes to the prognosis of patients with primary breast cancer. An NSABP update. Cancer 1983;52:1551-1557.

2. Lyman $G H$, Giuliano $A E$, Somerfield $M R$ et al. American Society of Clinical Oncology guideline recommendations for sentinel lymph node biopsy in early-stage breast cancer. J Clin Oncol 2005; 23:7703-7720.

3. Bolster MJ, Peer PG, Bult P, Thunnissen FB, Schapers RF, Meijer JW, Strobbe LJ, van Berlo CL, Klinkenbijl JH, Beex LV, Wobbes T, Tjan-Heijnen VC. Risk factors for non-sentinel lymph node metastases in patients with breast cancer. The outcome of a multi-institutional study. Ann Surg Oncol 2007;14:181-189.

4. Green FL, Page DL, Fleming ID. American Joint Committee on Cancer Staging Manual. 6th ed. Philadelphia: Springer; 2002.

5. Pepels MJ, Vestjens JH, de Boer M, Smidt M, van Diest PJ, Borm GF, Tjan-Heijnen VC. Safety of avoiding routine use of axillary dissection in early stage breast cancer: a systematic review. Breast Cancer Res Treat 2011;125:301-313.

6. Pepels MJ, de Boer M, Bult P, van Dijck JA, van Deurzen CH, Menke-Pluymers MB, van Diest PJ, Borm GF, Tjan-Heijnen VC. Regional recurrence in breast cancer patients with sentinel node micrometastases and isolated tumor cells. Ann Surg 2012;255:116-121.

7. Pepels MJ, Vestjens JH, de Boer M, Bult P, van Dijck JA, Menke-Pluijmers M, van Diest PJ, Borm G, Tjan-Heijnen VC. Submitted. Presented in part at San Antonio Breast Cancer Congress December 2011. Models predicting non-sentinel node involvement also predict for regional recurrence in breast cancer patients without axillary treatment. Presented in part at San Antonio Breast Cancer Congress December 2011. Abstract PD02-07.

8. Barranger E, Coutant C, Flahault A, et al. An axilla scoring system to predict non-sentinel lymph node status in breast cancer patients with sentinel lymph node involvement. Breast Cancer Res Treat 2005;113-119.

9. Van Zee KJ, Manasseh DM, Bevilacqua JL, et al. A nomogram for predicting the likelihood of additional nodal metastases in breast cancer patients with a positive sentinel node biopsy. Ann Surg Oncol 2003;1140-1151.

10. Kohrt HE, Olshen RA, Bermas HR, et al. New models and online calculator for predicting non-sentinel lymph node status in sentinel lymph node positive breast cancer patients. BMC Cancer 8:66-80.

11. Bolster MJ, Peer PG, Bult P, Thunnissen FB, Schapers RF, Meijer JW, Strobbe LJ, van Berlo CL, Klinkenbijl JH, Beex LV, Wobbes T, Tjan-Heijnen VC. Risk factors for non-sentinel lymph node metastases in patients with breast cancer. The outcome of a multi-institutional study. Ann Surg Oncol.2007;14:181-189.

12. Vestjens JH, Pepels MJ, de Boer M, Borm GF, van Deurzen CH, van Diest PJ, van Dijck JA, Adang EM, Nortier JW, Rutgers EJ, Seynaeve C, Menke-Pluymers MB, Bult P, Tjan-Heijnen VC. Relevant impact of central pathology review on nodal classification in individual breast cancer patients. Ann Oncol. 2012 Apr 11. [Epub ahead of print].

13. Bolster MJ, Bult P, Schapers RF, Meijer JW, Strobbe LJ, van Berlo CL, Klinkenbij JH, Peer PG, Wobbes T, Tjan-Heijnen VC. Differences in sentinel lymph node pathology protocols lead to differences in surgical strategy in breast cancer patients. Ann Surg Oncol 2006;13:1466-1473. 
Samenvatting 


\section{Samenvatting}

Bij borstkankerpatiënten wordt de prognose slechter bij een toenemend aantal lymfeklieren met uitzaaiingen in de oksel. Redenen om lymfeklieren in de oksel door middel van een okselklieroperatie (dissectie) te verwijderen zijn het voorkomen van terugkeer van uitzaaiingen in de okselklieren en het verbeteren van de ziektevrije en totale overleving. Vanaf 1990 is de schildwachtklierprocedure geïntroduceerd bij borstkankerpatiënten die bij lichamelijk of röntgenonderzoek geen aanwijzingen hadden voor lymfekliermetastasen in de oksel (klinisch lymfeklier-negatieve patiënten) met het doel minder vaak okselklierdissecties te hoeven verrichten. Onderzoeken bevestigden sindsdien dat bij patiënten bij wie door middel van de schildwachtklierprocedure geen uitzaaiingen aangetoond werden (schildwachtkliernegatieve ziekte) het weglaten van de okselklieroperatie geen negatief effect had op terugkeer van uitzaaiingen en op de overleving. Daarnaast leidt de schildwachtklierbiopsie tot minder bijwerkingen in vergelijking met de okselklierdissectie, zoals lymfoedeem van de arm, pijn en bewegingsbeperking van de arm en schouder.

In Nederland wordt sinds 1996 de schildwachtklierprocedure geleidelijk toegepast in klinisch klier-negatieve borstkankerpatiënten. In 2003 werd echter nog steeds 42\% van de vrouwen met klinisch negatieve okselklieren behandeld met de okselklierdissectie. In 2006, 10 jaar na de introductie van de schildwachtklierprocedure in Nederland, was dit aantal verminderd tot $22 \%$.

De schildwachtklierprocedure is gebaseerd op de vooronderstelling dat als de lymfeklier die direct lymfeafvloed ontvangt van het gebied in de borst waar de tumor zich bevindt (de schildwachtklier) geen kankercellen bevat, er ook geen uitzaaiingen zitten in de resterende oksellymfeklieren achter de schildwachtklier (de nietschildwachtklieren), zodat deze niet verwijderd hoeven te worden. Schildwachtklieren bevinden zich meestal in de oksel, maar soms ook onder het sleutelbeen of naast het borstbeen (tezamen 'regionale klieren' genoemd). Om schildwachtklieren te identificeren wordt preoperatief een blauwe en radioactieve vloeistof ingespoten in de borst rond de tumor. De lymfe vanuit de tumor kleurt hierdoor blauw en wordt radioactief en verspreidt zich naar één of meerdere lymfeklieren in de oksel. De lymfeklieren die radioactief en blauw zijn worden geïdentificeerd als schildwachtklieren en vervolgens verwijderd. Schildwachtklieren worden postoperatief beoordeeld door pathologen op aanwezigheid van uitzaaiingen. Dit gebeurd door middel van het in plakken snijden van de schildwachtklieren in coupes van ten hoogste $2 \mathrm{~mm}$. Hierbij wordt een kleuring (immunohistochemie) aangebracht op de coupes waardoor kleine uitzaaiingen eenvoudiger herkend kunnen worden.

Internationaal gezien is er geen consensus over de optimale manier van bewerking van de schildwachtklieren. Wanneer meer coupes van de schildwachtklier worden gemaakt, worden daarin meer uitzaaiingen gevonden, en daalt de kans op een vals 
negatieve schildwachtklier. Dit heeft er toe geleid dat steeds vaker micrometastasen (uitzaaiingen tussen 0,2 en 2,0 millimeter) en geïsoleerde tumorcellen (individuele cellen of tumorcelgroepjes die kleiner zijn dan 0,2 millimeter) werden aangetroffen. Tot enkele jaren geleden werd bij patiënten met geïsoleerde tumorcellen of micrometastasen in de schildwachtklier altijd een okselklieroperatie uitgevoerd. Geleidelijk aan is echter de houding veranderd ten opzichte van het gebruik van de okselklieroperatie bij patiënten met slechts een klein risico op uitzaaiingen in lymfeklieren achter de schildwachtklier (de niet-schildwachtklieren), bijvoorbeeld bij patiënten met een kleine tumor in de borst en geïsoleerde tumorcellen of micrometastasen in de schildwachtklier.

Dit proefschrift bespreekt een aantal belangrijke thema's met betrekking tot de schildwachtklier procedure, gebaseerd op de gegevens van twee studies, de MIRRORen de VAZ-01122-studies. Ten eerste, of patiënten kunnen worden geïdentificeerd die geen okselklieroperatie nodig hebben bij de aanwezigheid van minimale uitzaaiingen in de schildwachtklier. Ten tweede, of rekenmodellen die de kans op uitzaaiingen in okselklieren achter de schildwachtklier berekenen ook gebruikt kunnen worden om patiënten die wel of niet een okselklierdissectie moeten ondergaan te selecteren. Ten derde, wat de invloed van het pathologie protocol is op de besluitvorming rondom de behandeling van okselklier uitzaaiingen en op de kwaliteit van de geleverde behandeling.

De MIRROR-studie, acroniem voor "Micrometastases and Isolated tumor cells: Relevant and Robust Or Rubbish?" werd in eerste instantie opgezet om de relatie tussen geïsoleerde tumorcellen of micrometastasen in regionale lymfeklieren en de klinische uitkomst te beoordelen bij patiënten die een schildwachtklierprocedure hadden ondergaan en die wel of geen systemische adjuvante chemo- of hormoontherapie hadden gekregen. Alle Nederlandse ziekenhuizen en pathologie laboratoria hebben aan deze studie deelgenomen. In de MIRROR-studie werden patiënten met een vroeg stadium borstkanker die een schildwachtklierbiopsie ondergingen tussen 1997 en 2006 geïncludeerd, op voorwaarde dat zij gunstige kenmerken hadden van het gezwel in de borst volgens de Nederlandse richtlijn versie 2002, dat wil zeggen, tumorgrootte van $1 \mathrm{~cm}$ of kleiner, ongeacht gradering (dit is een maat voor de groeisnelheid, waarbij graad 3 de meest kwaadaardige variant is), of grootte van de tumor $1-3 \mathrm{~cm}$ en graad 1 of 2 . Hierbij werden patiënten inbegrepen met geïsoleerde tumorcellen of micrometastasen als definitieve klierstatus na de schildwachtklierbiopsie die wel of geen axillaire behandeling hadden gekregen. Verder werd een controlegroep van patiënten met klier-negatieve ziekte die een schildwachtklierprocedure ondergingen in het jaar 2000 of 2001 willekeurig geselecteerd. Klierstatus (nodale status) werd beoordeeld na centrale herbeoordeling van de pathologie coupes en gerestadieerd volgens de 6e AJCC (American Joint Committee on Cancer) classificatie. De MIRROR-studie toonde aan dat geïsoleerde 
tumorcellen en micrometastasen in de schildwachtklier geassocieerd waren met een verminderde 5 -jaars ziektevrije overleving in vergelijking met kliernegatieve patiënten die geen adjuvante systemische therapie bestaande uit hormoon- of chemotherapie hadden gehad, en dat de prognose beter was bij patiënten die wel deze adjuvante systemische therapie kregen.

De VAZ-01122 studie was een regionale studie in 4 ziekenhuizen in het oostelijke deel van Nederland. In deze studie werden 566 borstkankerpatiënten die een schildwachtklierbiopsie kregen prospectief geïncludeerd. Patiënten met een klinische tumorgrootte van $5 \mathrm{~cm}$ of minder kwamen in aanmerking voor een schildwachtklierprocedure als er geen klinische tekenen waren van multifocaliteit (meer dan één gezwel in de borst) of uitzaaiingen in de oksellymfeklieren. Alleen patiënten die identificeerbare schildwachtklieren hadden werden opgenomen in deze studie. Patiënten die eerder met radiotherapie op de borst of oksel behandeld waren of patiënten die chemotherapie hadden gekregen voorafgaand aan de schildwachtklieroperatie kwamen niet in aanmerking. Het primaire doel van de studie was om het risico van niet-schildwachtklier betrokkenheid te beoordelen. Er werd aangetoond dat patiënten met kleine schildwachtklier uitzaaiingen een lager risico op niet-schildwachtklier uitzaaiingen hadden dan die met grotere schildwachtklier metastasen: een risico op $14 \%$ niet-schildwachtklier betrokkenheid bij geïsoleerde tumorcellen, $28 \%$ bij micrometastasen en $38 \%$ bij macrometastases (uitzaaiingen groter dan 2,0 mm) in de schildwachtklier. Afgezien van de grootte van de uitzaaiingen in de schildwachtklier, hadden ook de primaire tumorgrootte en de aanwezigheid van vaatinvasie invloed op het risico op uitzaaiingen in niet-schildwachtklieren.

In hoofdstuk 1 wordt een algemene inleiding en overzicht van het proefschrift gepresenteerd. Ten eerste hebben we de invloed van de grootte van de uitzaaiingen in de schildwachtklier op regionaal recidief geanalyseerd wanneer geen behandeling van de niet-schildwachtklieren werd verricht. Verder onderzochten we de toepasbaarheid van rekenmodellen die de kans op niet-schildwachtklier uitzaaiingen voorspellen bij het identificeren van de patiënten die wel of geen okselbehandeling nodig hebben. Tot slot beschrijven we de rol van de pathologie protocollen in de besluitvorming met betrekking tot okselbehandeling en de rol in het voorkomen van een regionaal recidief.

In hoofdstuk 2 geven we een systematisch overzicht van de resultaten van gepubliceerde studies over het optreden van lymfeklieruitzaaiingen in de oksel bij borstkankerpatiënten die aanvankelijk bij klinisch onderzoek geen aanwijzingen hadden voor lymfeklieruitzaaiingen, en daarna wel of niet een okselklieroperatie ondergingen. In de periode voordat de schildwachtklierbiopsie werd uitgevoerd, waarbij in de gepubliceerde onderzoeken patiënten met grotere tumoren voorkwamen en waarbij minder systemische therapie werd gegeven, waren recidief- 
percentages zonder okselklierdissectie na 5 tot 10 jaar follow-up 12 tot $18 \%$. De totale overleving werd verminderd met $5 \%$. In studies van schildwachtklier-negatieve patiënten, die geen verdere okselklierdissectie ondergingen, was het oksel recidiefpercentage 0,6\% (95\% $\mathrm{BI} 0.6-0.8)$, na een mediane follow-up van 36 maanden. In de studies van schildwachtklier-negatieve patiënten, met een groep die wel en een groep die geen okselklieroperatie onderging, was het oksel recidiefpercentage zonder okselklierdissectie $0,4 \% \quad(95 \%$ BI $0,2-0,6)$ versus $0,3 \% \quad(95 \% \quad \mathrm{BI} \quad 0,1-0,6)$ met okselklierdissectie na respectievelijk 31 en 47 maanden, en er was geen overlevingsnadeel. In studies waarbij patiënten geen okselklierdissectie ondergingen bij aanwezigheid van uitzaaiingen in de schildwachtklier was het recidiefpercentage 1,7\% (95\% BI 1,0-2.7) na 30 maanden. Voor patiënten met een positieve schildwachtklier bevestigd met hematoxyline en eosine kleuring was het recidiefpercentage zonder okselklierdissectie $5 \%$ na 23 maanden. Deze systematische review bevestigde de veiligheid van het weglaten van de okselklierdissectie in schildwachtklier-negatieve patiënten, en toonde aan dat er een rol was voor het vermijden van de okselklierdissectie in geselecteerde schildwachtklier-positieve patiënten, waarbij de criteria en de rol van systemische therapie verder opgehelderd moeten worden.

Vervolgens hebben we onderzoek gedaan naar de mogelijke rol voor het niet uitvoeren van de okselklieroperatie in geselecteerde schildwachtklier-positieve patiënten. In hoofdstuk 3 onderzochten we de invloed van de okselbehandeling, bestaande uit lymfeklieroperatie of bestraling van de oksel, op het 5 -jaars regionale recidief-percentage in Nederlandse borstkankerpatiënten met invasieve kanker, gunstige primaire tumorkenmerken, en geïsoleerde tumorcellen of micrometastasen in de schildwachtklier, die werden geïncludeerd in de MIRROR-studie. In totaal werden 857 patiënten zonder uitzaaiingen, 795 patiënten met geïsoleerde tumorcellen, en 1028 patiënten met micrometastasen in de schildwachtklier geïncludeerd. Zonder okselbehandeling waren de 5 -jaars regionale recidiefpercentages respectievelijk $2,3 \%, 2,0 \%$ en $5,6 \%$. In vergelijking met patiënten die wel behandeling kregen van de oksel, was het relatieve risico voor het ontwikkelen van een regionaal recidief $4,39(95 \% \mathrm{BI}, 1,46-13,24)$ voor micrometastasen. Verdubbeling van de tumorgrootte, graad 3 en negatieve hormoon receptor status waren significant geassocieerd met recidief. Belangrijk om op te merken was dat in ons onderzoek adjuvante systemische therapie werd gegeven bij slechts $48 \%$ van de patiënten met schildwachtklier micrometastasen en geen van de patiënten met klier-negatieve ziekte, die geen verdere oksel-behandeling ondergingen.

We concluderen dat het niet uitvoeren van okselbehandeling bij patiënten met schildwachtklier micrometastasen in verband wordt gebracht met verhoogde 5-jaars regionale recidieven. Okselbehandeling wordt aanbevolen bij patiënten met schildwachtklier micrometastasen en ongunstige kenmerken van de tumor, die geen adjuvante systemische therapie krijgen. 
In hoofdstuk 4 onderzoeken we het verband tussen het voorspelde risico op uitzaaiingen in niet-schildwachtklieren en het werkelijk geobserveerde regionale recidiefpercentage bij patiënten met borstkanker met gunstige kenmerken van de primaire tumor en geïsoleerde tumorcellen of micrometastasen in de schildwachtklier die geen okselklierdissectie ondergingen. Het doel was een model te vinden waarmee een groep patiënten te identificeren was die geen voordeel zouden hebben van een okselklierdissectie. Vier bestaande modellen die het risico op uitzaaiingen in nietschildwachtklieren voorspellen werden getest. De vier modellen omvatten zowel klinische als pathologische kenmerken, zoals de grootte en/of het aantal van de schildwachtklier uitzaaiingen, de grootte en/of de aanwezigheid van lymfevat invasie in de primaire tumor. Met deze modellen zijn risicoberekeningen gemaakt voor het voorspellen van uitzaaiingen in niet-schildwachtklieren gebaseerd op gegevens van patiënten in de MIRROR-studie. Deze risicoberekeningen werden vergeleken met de werkelijk geobserveerde regionale recidiefpercentages in het MIRROR cohort. Het algemene 5 -jaars regionale recidiefpercentage was 3,0\%. Met behulp van de Tenon score, hadden 438 patiënten met een laag voorspeld risico een 5-jaars regionaal recidiefpercentage van $2,3 \%$, en 48 hoogrisico patiënten een recidiefpercentage van $10,1 \%$. We concluderen dat de Tenon score het beste onderscheid maakt door de identificatie van de grootste subgroep van patiënten met een laag recidiefpercentage, bij wie de okselklierdissectie weggelaten zou kunnen worden.

Daarna hebben we onderzocht wat de invloed was van het pathologie protocol op de besluitvorming rondom de behandeling van okselklier uitzaaiingen en op de kwaliteit van de geleverde behandeling. In de MIRROR-studie werd de lymfeklier status (nodale status) geëvalueerd na centrale pathologie herbeoordeling en vervolgens opnieuw gestadieerd volgens de 6e AJCC classificatie. In hoofdstuk 5 onderzochten we de invloed van centrale herbeoordeling van de lymfeklier-status door drie pathologen, en de invloed van deze herziening op de 5-jaars ziektevrije overleving voor patiënten die geen adjuvante therapie kregen. Tweeëntwintig procent (22\%) van de 1.082 patiënten die oorspronkelijk geen uitzaaiingen in de lymfeklieren hadden (pNO) kwam in een hoger stadium terecht. Van de 623 patiënten die oorspronkelijk geïsoleerde tumorcellen hadden ( $\mathrm{pNO}(\mathrm{i}+))$ kwam $1 \%$ in een lager stadium terecht, maar kwam $26 \%$ in een hoger stadium terecht. Van 1.137 patiënten met oorspronkelijk micrometastasen (pN1mi), kwam 15\% in een lager stadium, en $11 \%$ in een hoger stadium. Voorafgaand aan de herbeoordeling van de lymfeklierstatus was de 5-jaars ziektevrije overleving $85 \%$ voor pN0, $74 \%$ voor pNO(i +), 73\% voor pN1mi respectievelijk. $\mathrm{Na}$ herbeoordeling was de 5 -jaars ziektevrije overleving $86 \%$ voor pN0, $77 \%$ voor pNO(i+), $77 \%$ voor pN1mi en $74 \%$ voor pN1 + (macrometastasen $>2,0 \mathrm{~mm}$ ).

We concluderen dat door centrale pathologie herbeoordeling van de lymfeklierstatus het lymfeklierstadium veranderde in $24 \%$, voornamelijk doordat patiënten in een hoger stadium terecht kwamen, met potentieel klinische relevantie voor individuele 
patiënten. Nascholing in het beoordelen van de nodale status wordt daarom aanbevolen als middel tot kwaliteitsverbetering bij de diagnostiek van borstkanker.

Tot slot hebben we gekeken naar het pathologie protocol dat wordt gebruikt om de schildwachtklier te onderzoeken. In hoofdstuk 6 hebben we in vier ziekenhuizen in Nederland (A, B, C en D) onderzocht of een geïntensiveerde pathologische bewerking en onderzoek van de schild-wachtklier geleid heeft tot een hogere frequentie van het verrichten van okselklierdissecties. De vraag was of er bij een intensiever schildwachtklier protocol meer patiënten een okselklierdissectie kregen en of dit leidde tot een vermindering in het optreden van een regionaal recidief. Van 541 patiënten die een schildwachtklierprocedure ondergingen, hadden 341 (63\%) patiënten een negatieve schildwachtklier, en deze kregen geen okselklierdissectie. In ziekenhuis $D$ hadden minder patiënten een negatieve schildwachtklier in vergelijking met patiënten in ziekenhuizen A, B en C ( $34 \%$ versus $71 \%, p<0,001)$. Na 5 jaar followup trad bij $9(2,6 \%)$ patiënten een regionaal lymfeklierrecidief op. Vijf $(1,5 \%)$ patiënten hadden een lymfeklierrecidief in de oksel en vier $(1,2 \%)$ patiënten hadden een recidief boven het sleutelbeen. In ziekenhuis $D$ had geen van de patiënten een regionaal recidief, vergeleken met negen $(2,9 \%)$ recidieven in ziekenhuizen $A, B$ en $C$. We concluderen dat patiënten die een minder geïntensiveerd schildwachtklier pathologie protocol hadden ondergaan, met als gevolg een verminderde detectie van geïsoleerde tumorcellen in de schildwachtklier, een licht verhoogd risico hadden op een regionaal recidief. Echter, het absolute recidief risico van minder dan $3 \%$ lijkt niet de 37 aanvullende okselklieroperaties per elke 100 patiënten te rechtvaardigen. Daarom lijkt het schildwachtklier pathologie protocol dat tegenwoordig in de meeste centra wordt gebruikt, met gemiddeld 3 niveaus per paraffineblok, voldoende te zijn.

In hoofdstuk 7 geven we een beschouwing op de gevonden resultaten, worden conclusies getrokken en wordt vooruitgekeken naar de toekomst. In de MIRRORstudie toonden we aan dat het niet uitvoeren van okselbehandeling bij patiënten met schildwachtklier micrometastasen in verband wordt gebracht met een verhoogd 5 -jaars regionaal recidiefpercentage, en dat verdubbeling van de grootte van de tumor, graad 3 en negatieve hormoonreceptor status ook significant geassocieerd zijn met het optreden van een regionaal recidief. De Z0011 ACOSOG studie, gepubliceerd in 2011 , toonde geen voordeel van okselklierdissectie ten opzichte van het verrichten van alleen een schildwachtklieroperatie voor patiënten met één tot twee metastatische schildwachtklieren. Er werden geen statistisch significante verschillen gevonden in de totale overleving en ziektevrije overleving tussen de twee groepen. Even belangrijk was dat het regionaal recidief percentage in de groep die alleen een schildwachtklierprocedure onderging minder dan $1 \%$ was, ondanks het feit dat naar schatting $27 \%$ van de patiënten extra metastasen hadden in de niet verwijderde okselklieren. Het lage regionale recidiefpercentage van de Z0011 studie versus het veel hogere regionale recidiefpercentage van de MIRROR-studie kan worden verklaard 
door een aantal factoren. Deze kunnen worden onderverdeeld in factoren met betrekking tot de patiënt, tumorkenmerken en verschillen in behandeling. Met betrekking tot de patiënt- en tumorkenmerken, includeerden beide studies patiënten met kleine tumoren en beperkte lymfklieruitzaaiingen. Beleid inzake systemische therapie, chirurgie en bestraling waren echter verschillend tussen de twee studies. In Nederland waren de indicaties voor het geven van systemische therapie conservatief in de inclusieperiode (1997-2006) van de MIRROR-studie met slechts $31 \%$ van de patiënten die systemische therapie kregen. Tegenwoordig worden meer patiënten met schildwachtklier micrometastasen behandeld met meer effectieve systemische therapie. Daarentegen werden in de Z0011 studie bijna alle patiënten behandeld met systemische therapie waarbij de chemotherapie voornamelijk bestond uit anthracycline / taxaan bevattende middelen die nu worden beschouwd als de meest effectieve chemotherapie in vroeg stadium borstkanker. Bovendien werden bijna alle patiënten behandeld met bestraling van de borst als onderdeel van borstsparende therapie waarbij gedeelten van de oksel mee bestraald werden, hetgeen klieruitzaaiingen kan steriliseren. In de MIRROR-studie kreeg slechts $65 \%$ van de patiënten bestraling van de borst en borstsparende behandeling.

De Z0011 studie toont aan dat bij patiënten met een gunstige kleine primaire tumor en kleine uitzaaiingen in de oksel, okselklierdissectie veilig kan worden weggelaten. Echter, de resultaten van Z0011 mogen niet gegeneraliseerd worden naar alle schildwachtklier-positieve patiënten, zoals patiënten die worden behandeld met neoadjuvante systemische therapie, patiënten die niet behandeld worden met adjuvante systemische therapie, patiënten behandeld met amputatie van de borst zonder bestraling, patiënten met grotere primaire tumorgrootte en/of andere ongunstige eigenschappen, patiënten met meer dan twee positieve schildwachtklieren en patiënten die behandeld worden met moderne technieken van borstbestraling waarbij de okselklierniveaus niet meegenomen worden. Ook is langere follow-up dan 6,5 jaar nodig, omdat bij vrouwen met oestrogeenreceptor positieve ziekte die 5 jaar adjuvante hormoontherapie krijgen, meer dan de helft van alle recidieven zich voordoen na deze 5 jaar.

De resultaten van een buitenlandse klinische studie, zelfs een gerandomiseerde zoals de Z0011, kunnen niet gegeneraliseerd worden naar de situatie in Nederland, indien die studie niet gebruik maakte van dezelfde behandelingen zoals in de praktijk in Nederland zijn toegepast. In de Nederlandse richtlijn staat dan ook expliciet vermeld dat gebruik van systemische therapie en het toepassen van okselbestraling vereist zijn bij het weglaten van de okselklierdissectie.

Of okselklierbestraling okselklierdissectie kan vervangen is het onderwerp van de AMAROS (After Mapping of the Axilla: Radiotherapy Or Surgery) studie, waarbij patiënten met schildwachtklieruitzaaiingen zijn gerandomiseerd tussen okselklierbestraling of okselklierdissectie. Resultaten van de AMAROS studie worden binnen enkele jaren verwacht. 
Hoewel in studies de aanwezigheid van geïsoleerde tumorcellen gerelateerd was aan de prognose, was het verschil in ziektevrije overleving na 5 jaar klein. Het aantal patiënten bij wie adjuvante therapie wordt gegeven vanwege geïsoleerde tumorcellen in de schildwachtklier met een tumor in de borst waarvoor het niet geïndiceerd is, is klein. Daarom zijn we van mening dat met het huidige beschikbare bewijs gedetailleerde immunohistochemische beoordeling van de schildwachtklier om geïsoleerde tumorcellen te vinden niet het voordeel van een betere (ziektevrije) overleving compenseert. Daarnaast wordt de aanwezigheid van geïsoleerde tumorcellen niet in aanmerking genomen in de besluitvorming om wel of geen okselklierdissectie te verrichten, omdat het risico op niet-schildwachtklier uitzaaiingen laag is. Schildwachtklier micrometastasen worden nog steeds beschouwd als relevant voor het toepassen van okselbehandeling. Daarom moet het pathologie protocol gericht zijn op het vinden van schildwachtklier micrometastasen.

Concluderend wordt behandeling van alle okselklieren niet meer aanbevolen bij álle schildwachtklierpositieve patiënten. Zorgvuldige selectie van patiënten bij wie aanvullende okselbehandeling kan worden weggelaten is noodzakelijk. Nomogrammen kunnen gebruikt worden in de klinische besluitvorming om patiënten te informeren over de risico's en voordelen om potentiële okselklier uitzaaiingen wel of niet te behandelen, maar deze nomogrammen zijn geen perfecte instrumenten. Het risico op een regionaal recidief moet worden afgewogen tegen het risico van overbehandeling. Het schildwachtklier pathologie protocol dat tegenwoordig in de meeste centra wordt gebruikt, met gemiddeld 3 niveaus per paraffineblok, lijkt toereikend te zijn voor het vinden van klinisch relevante kliermetastasen. Nascholing van pathologen in het beoordelen van de lymfeklierstatus wordt aanbevolen als middel tot kwaliteitsverbetering bij de diagnostiek van borstkanker. 
List of publications 


\section{List of publications}

M.J.A.E. Pepels, F.P. Peters, J.J. Mebis, T.L. Ceelen, A.G. Hoofwijk, F.L. Erdkamp. Sclerosing peritonitis: an unusual cause of ascites in a patient with systemic lupus erythematosus. Neth J Med 2006;64:346-349.

H.W. Hundscheid, M.J.A.E. Pepels, L.G. Engels, R.J. Loffeld. Treatment of irritable bowel syndrome with osteopathy: results of a randomized controlled pilot study. J Gastroenterol Hepatol 2007;22:1394-1398.

V.C.G. Tjan-Heijnen, M.J.A.E. Pepels, M. de Boer. Prognostic impact of isolated tumor cells and micrometastases in axillary lymph nodes of breast cancer patients. Breast Dis 2010;31:107-113.

M.J.A.E. Pepels, J.H.M.J. Vestjens, M. de Boer, M. Smidt, P.J. van Diest, G.F. Borm, V.C.G. Tjan-Heijnen. Safety of avoiding routine use of axillary dissection in early stage breast cancer: a systematic review. Breast Cancer Res Treat 2011;125:301-313.

M.J.A.E. Pepels, M. de Boer M, P. Bult, J.A.A.M. van Dijck, C.H.M. van Deurzen, M.B.E. Menke-Pluymers, P.J. van Diest, G.F. Borm, V.C.G. Tjan-Heijnen. Regional recurrence in breast cancer patients with sentinel node micrometastases and isolated tumor cells. Ann Surg 2012;255:116-121.

J.H.M.J. Vestjens, M.J.A.E. Pepels, M. de Boer, G.F. Borm, C.H.M. van Deurzen, P.J. van Diest, J.A.A.M. van Dijck, E.M.M. Adang, J.W.R. Nortier, E.J.Th. Rutgers, C. Seynaeve, M.B.E. Menke-Pluymers, P. Bult, V.C.G. Tjan-Heijnen. Relevant impact of central pathology review on nodal classification in individual breast cancer patients. Ann Oncol 2012;23:2561-2566.

M.J. Bolster, M.J.A.E. Pepels, C.A.P. Wauters, R.F.M. Schapers, J.W.R. Meijer, L.J.A. Strobbe, C.L.H. van Berlo, J.H.G. Klinkenbijl, T. Wobbes, A.C. Voogd, P. Bult, V.C.G. Tjan-Heijnen. Is the sentinel lymph node pathology protocol in breast cancer patients associated with the risk of regional recurrence? Eur J Surg Oncol 2013; Epub ahead.

M.J.A.E. Pepels, J.H.M.J. Vestjens, M. de Boer, P. Bult, J.A.A.M. van Dijck, M.B.E. Menke-Pluymers, P.J. van Diest, G.F. Borm, V.C.G. Tjan-Heijnen. Models predicting non-sentinel node involvement also predict for regional recurrence in breast cancer patients without axillary treatment. Eur J Surg Oncol 2013; in press. 
Gegevens wetenschappelijke stage gepubliceerd in:

A. Ferrera, W.J. Melchers, J.P. Velema, M. Figueroa. Association of infections with human immunodeficiency virus and human papillomavirus in Honduras. Am J Trop Med Hyg 1997;57:138-141. 
Dankwoord 


\section{Dankwoord}

In Maastricht bestond er tijdens mijn opleiding tot medisch oncoloog nog geen 'onderzoekslijn'. Toen ik aan Vivianne Tjan aangaf dat ik graag promotieonderzoek wilde doen was ik blij met haar antwoord dat er in het kader van de MIRROR-studie nog een onontgonnen gebied aan onderzoeksvragen lag. Gaandeweg bleek dat het onderwerp okselklierbehandeling bij borstkanker in de picture kwam, en dat maakte het onderzoek doen alleen maar leuker. De MIRROR-studie is mede mogelijk gemaakt door ondersteuning van de Borstkanker Onderzoek Groep (BOOG) en door participatie van alle integrale kankercentra, alle Nederlandse ziekenhuizen en laboratoria voor pathologie.

Ik ben de vele mensen die me hebben geholpen en gesteund dankbaar. Zonder hen had dit proefschrift niet tot volle bloei kunnen komen.

Hoera est!

Prof. dr. V.C.G. Tjan-Heijnen, beste Vivianne, je positieve instelling en enthousiasme maakten dat ik het vertrouwen bleef houden in de afronding van de promotie. Ik heb veel geleerd van je systematische plan van aanpak. De discussies over het onderwerp waren meestal kort en bondig, en altijd nuttig en plezierig. Je hebt inmiddels een heel team om je heen gevormd en samen hebben jullie de afdeling medische oncologie tot volle bloei gebracht, daar zijn jij en je afdeling terecht trots op.

Prof. dr. G.F. Borm, beste George, je kritische instelling maakt dat ik niet teveel in mijn eigen stramien bleef steken. Ongetwijfeld heeft je degelijke statistische onderbouwing ervoor gezorgd dat onze artikelen goed ontvangen en gepubliceerd werden. Je hield altijd oog voor de hoofdlijnen en logische opbouw van onze artikelen en daar ben ik je zeer erkentelijk voor.

Dr. M. de Boer, beste Maaike, je hebt ongelofelijk veel werk verzet met de dataverzameling voor de MIRROR-studie en het fundament gelegd voor interessante en relevante artikelen over borstkankerbehandeling. Ik kon altijd bij je terecht met vragen en je keek altijd kritisch mee met onze artikelen. Je input kon ik goed gebruiken! Ik ben blij voor je dat je in Maastricht je plek hebt gevonden.

Alle mede-auteurs, zonder jullie geen promotie! Hanneke, Marieke, Jos, Peter, Paul, Carolien, Marian, Marjolein en Adri. Het samen werken aan een project buiten mijn baan als medicus practicus heb ik als een verrijking ervaren. Wim Lemmens, bedankt voor al je ondersteuning in de statistiek bij het schrijven van de artikelen. 
De beoordelingscommissie. Graag wil ik Prof. dr. H.C. Schouten, Prof. dr. M.F. von Meyenfeldt en dr. P.S.J.G. Hupperets bedanken voor het positieve commentaar en de goedkeuring van het manuscript. Beste Harrie en Pierre, jullie hebben mij enthousiast gemaakt voor de medische oncologie en nu zijn jullie ook betrokken bij de afronding van mijn promotie. Heel erg bedankt daarvoor.

De werkgroep medische oncologie in het MUMC, met name Pierre, Rob, Roy en Patricia, waar de belangstelling voor het vak en het doen van onderzoek verder tot bloei is gekomen. Daarnaast uiteraard het personeel op de dagbehandeling en afdeling oncologie met wie ik plezierig heb samengewerkt.

Mijn collega's in het Elkerliek ziekenhuis die me de vrijheid hebben gegeven om het onderzoek af te ronden. Het was vaak schipperen met de tijd als practicus en promovendus.

De internisten en arts-assistenten tijdens mijn opleiding tot internist in het MUMC, met wie ik goed heb samengewerkt.

De internisten, MDL-artsen en arts-assistenten van het Maasland ziekenhuis Sittard, die voor een gedegen en prettige interne opleiding hebben gezorgd, en met wie ik prachtige 'congressen in de sneeuw' heb meegemaakt.

Tiny Wouters, na je pensionering zal je nog steeds 'boekjes blijven maken' denk je, en dat is maar goed ook. Zonder jou geen boekje. Het heeft mij veel ergernis gescheeld.

Lilian, bedankt voor je snelle reacties op mijn verzoeken. Je hebt prima werk verzet op het secretariaat.

Bas, bedankt voor het mooie ontwerp van de omslag dat je in zo'n korte tijd klaar had! Een foto van het beeld "I'âme sentinelle" volstond om je de richting te wijzen.

Kim, je liep steeds een stukje op me vooruit met de promotie, zodat ik er mijn voordeel mee kon doen. Je hebt me vaak goede tips gegeven, en we konden onze frustraties delen. Nu weer tijd voor andere dingen!

Mijn vriendenkring en familie, voor het bieden van de broodnodige afleiding van werk en beslommeringen. Eindelijk hoef ik wat minder te schipperen tussen het werken achter de laptop en gezamenlijke afspraken.

Mijn paranimfen. Johanneke. Het begon ermee dat we in Leiden in dezelfde roeiboot stapten. Daarna diverse vakanties samen gevierd, we hebben veel lol gehad. Je bent me al geruime tijd voorgegaan in het promoveren en ik weet dat je het erg leuk vindt 
om het van een andere kant mee te maken. Als de kinderen ouder zijn kunnen we weer wat vaker samen op stap gaan.

Henriëtte. Het doen van onderzoek zou jou zeker goed afgaan met je precieze instelling, maar je hebt gekozen voor een artsenbaan in een 'perifere kliniek'. We hebben beiden voor een heel verschillende richting gekozen. Desondanks vinden we nog regelmatig raakvlakken in ons vak. Jij weet als geen ander dat het moeilijk is om keuzes te maken als je veel verschillende interesses hebt.

Pap, Elise, Wil en Henriëtte die me altijd hebben bijgestaan, geleerd hebben door te zetten, maar ook te relativeren. We hebben samen vele mijlpalen bereikt, en dit is er weer een. Nu zien jullie wat ik die jaren achter de schermen heb gedaan. Mam en Muriël, die trots over mijn schouder meekijken vandaag.

Paula en John, mijn lieve schoonouders. Jullie staan altijd voor ons klaar, en maken de reis naar het zuiden als we hulp nodig hebben. Bedankt voor jullie liefde en steun.

Rodney, op wie ik altijd terug kan vallen. Je hebt ervoor gezorgd dat thuis de dingen op rolletjes bleven lopen. Je onafhankelijke kijk op dingen, je gevoel voor humor en zorgzame instelling hebben hiertoe volop bijgedragen. Je hebt me geholpen om de beperkte tijd die ik had efficiënt te gebruiken voor het schrijven van artikelen en daarnaast de gelegenheid geboden ontspanning te zoeken. Als ik weer eens vastliep achter de computer had jij het geduld me weer op gang te helpen. Anne-Lyse, lieve meid, je bent lekker nieuwsgierig. Voortaan gaan we vaker samen leuke dingen doen. 
Curriculum Vitae 


\section{Curriculum Vitae}

Manon Pepels werd op 15 februari 1971 geboren in Stein. In 1989 behaalde ze haar Gymnasium B diploma aan de Scholengemeenschap Sint Michiel te Geleen. In datzelfde jaar startte zij met de studie Bestuurskunde aan de Rijksuniversiteit Leiden, waar ze in 1990 cum laude haar propedeuse behaalde. Hierna stapte ze over op de studie Geneeskunde aan de Katholieke Universiteit Nijmegen (thans: Radboud Universiteit Nijmegen), waar ze in 1991 de propedeuse haalde. In 1994 verbleef ze 6 maanden voor haar wetenschapsstage op de afdeling medische microbiologie aan Universidad Nacional Autónoma in Honduras. Na het behalen van haar artsexamen in september 1997 was ze vanaf 1998 werkzaam als arts-assistent niet in opleiding op de afdelingen Longziekten en Interne Geneeskunde van het Canisius Wilhelmina Ziekenhuis te Nijmegen en later in het Maartensgasthuis te Venlo (thans: VieCuri Medisch Centrum). In 2001 startte ze met de opleiding tot internist in het Maasland Ziekenhuis te Sittard (thans: Orbis Medisch Centrum) (opleider: dr. B.J. Looij) waarna ze deze in het academisch ziekenhuis Maastricht (thans: Maastricht Universitair Medisch Centrum) (opleiders: prof. dr. H.F.P. Hillen, later prof. dr. C.D.A. Stehouwer) voortzette vanaf 2005. In hetzelfde jaar ving ook de opleiding tot oncoloog aan (opleiders: prof. dr. H.C. Schouten, later prof. dr. V.C.G. Tjan-Heijnen). In april 2007 volgde haar registratie als internist en in oktober 2007 de registratie als oncoloog. Hierna werkte ze als chef de clinique oncologie in Hasselt en Tongeren. Vanaf 2008 begon zij aan de promotie over okselklierbehandeling en regionale recidieven bij mammacarcinoom. Sinds 2009 werkt ze als internist-oncoloog in het Elkerliek ziekenhuis te Helmond. Manon is getrouwd met Rodney Kranenburg en samen hebben ze een dochter, Anne-Lyse (2011). 
132 